\title{
Dušan Kostić
}

\section{Biomarcadores para diagnóstico precoce de injúria renal em uropatias obstrutivas congênitas}

\author{
Tese apresentada à Faculdade de Medicina da \\ Universidade de São Paulo para obtenção do título de \\ Doutor em Ciências
}

Programa de Pediatria

Orientadora: Profa. Dra. Vera Hermina Kalika Koch

(Versão corrigida. Resolução CoPGr 5890, de 20 de dezembro de 2010.

A versão original está disponível na Biblioteca FMUSP)

\section{São Paulo}


Dados Internacionais de Catalogação na Publicação (CIP)

Preparada pela Biblioteca da

Faculdade de Medicina da Universidade de São Paulo

Creprodução autorizada pelo autor

Kostic, Dusan

Biomarcadores para diagnóstico precoce de injúria renal em uropatias obstrutivas congênitas / Dusan Kostic. -- São Paulo, 2018.

Tese(doutorado)--Faculdade de Medicina da

Universidade de São Paulo.

Programa de Pediatria.

Orientadora: Vera Hermina Kalika Koch.

Descritores: 1.Nefropatias 2.Hidronefrose

3. Biomarcadores 4.Proteómica 5. Lactente

6. Insuficiência renal

USP / FM/DBD-180/18

Responsável: Kátia Maria Bruno Ferreira - CRB-8/6008 
DEDICATÓRIA 
Aos meus pais Sonja e Stanko, por sua coragem, determinação, amor, confiança e apoio, guiando-me pela vida. 
AGRADECIMENTOS 
À minha esposa Isabel e minha filha Ana, pela paciência, compreensão, amor e participação nesse período de estudo, que nos permitiu aprendizados e lições de convivência. Além disso, agradeço a Isabel pela ajuda na elaboração do manuscrito, suas opiniões críticas e sugestões construtivas.

À minha orientadora Dr. ${ }^{a}$ Vera Koch, eterna gratidão pela amizade e pelas oportunidades que criou, uma década atrás, quando eu passava por um momento difícil, reconhecendo os meus potenciais e me incentivando na vida profissional e pessoal.

A todas as crianças dessa pesquisa que, junto com os seus pais e familiares, dedicaram o seu tempo e doaram o seu corpo, tão preciosos, colocando a sua confiança e esperança no avanço da ciência.

Às colegas médicas assistentes do Berçário Anexo a Maternidade - BAM, do departamento de Pediatria do Instituto da Criança do HCFMUSP, Dr. ${ }^{a}$ Glenda Priscilla Neves dos Santos Beozzo, Dr. ${ }^{a}$ Nicole Lee Udsen e Dr. ${ }^{a}$ Tamara Strauss pela sua dedicação, colaboração e amizade, assim como pela sua participação ativa e direta nesse estudo, na seleção dos pacientes do grupo-controle, coleta de exames, atendimento e seguimento de todos os participantes, junto com os nossos colegas residentes do mesmo departamento.

Aos colegas médicos e meus caros amigos, Saulo Brasil do Couto e André Henrique Teruaki Kato pela sua colaboração ativa na seleção dos pacientes, coleta e análise de dados, seguimento dos participantes, opiniões e sugestões construtivas.

Às colegas do Laboratório de Investigações Médicas 36 (LIM-36), Dr. ${ }^{a}$ Patrícia Palmeira, Laila Lima e Fernanda Fonseca, pelo seu tempo, dedicação e participação direta na analise do material coletado, orientações e sugestões valiosas no armazenamento e preparo das amostras, além do suporte logístico.

Às colegas médicas assistentes da Unidade de Nefrologia Pediátrica do Instituto da Criança do HCFMUSP, Dr. ${ }^{a}$ Andreia Watanabe, Dr. ${ }^{a}$ Erika Arai Furusawa e Dr. ${ }^{a}$ Simone 
Vieira pela amizade, colaboração e participação direta no seguimento dos pacientes, orientações críticas e sugestões construtivas no desenvolvimento desse projeto.

Ao Prof. Dr. Victor Bunduki da Unidade da Medicina Fetal do Departamento da Ginecologia e Obstetrícia do HCFMUSP, pela participação na seleção e acompanhamento dos pacientes e suas mães, coleta de exames, além das sugestões e opiniões críticas e construtivas.

À Dr. a Lisa Suzuki do setor do Diagnóstico por Imagem do Instituto da Criança HCFMUSP, junto com a sua equipe da ultrassonografia, pela colaboração na realização dos exames de ultrassonografia renal nos participantes deste estudo.

|À secretária da Comissão de Pós-Graduação do Departamento da Pediatria da FMUSP, Mônica A. Souza e à secretária da Biblioteca do Instituto da Criança - HCFMUSP, Mariza Yoshikawa, pelas orientações administrativas e ajuda na busca de literatura em várias etapas do desenvolvimento desse estudo.

Às equipes da administração, recepção e coleta de exames do Laboratório do Instituto da Criança - HCFMUSP pela sua colaboração, paciência, eficiência, atitude, humanismo e profissionalismo.

Agradeço ainda aos meus sogros, Avelina Maria Fernandes Brandão e Ronaldo Correia de Brito, pela ajuda na elaboração do texto do manuscrito, sugestões e orientações construtivas e, junto com a minha irmã Nevena Kostić, tia Slobodanka Simić e outros familiares, pela sua paciência e compreensão.

Por fim, agradeço aos meus amigos: Dušan Dželebdžić, Stanko Pavlović, Roberto Nery Dantas Junior, André Maurício Souza Fernandes, Ricardo Alexandre Coutinho, Fernando de Sá Camargo Barros e Roberto Tozze pela sua amizade, presença, interesse e participação de forma direta ou indireta nesse trabalho. 
“Дуготрајно робовање и рђава управа могу толико збунити и унаказити схватање једног народа да здрав разум и прав суд у њему отанчају и ослабе, да се потпуно извитопере. Такав поремећен народ не може више да разликује не само добро од зла, него ни своју сопствену корист од очигледне штете."

$* * *$

"A longa escravidão e a má governabilidade podem confundir e devastar tanto a compreensão de uma nação, que o seu bom senso e raciocínio lógico enfraquecem, desaparecem ou se tornam deformados. Uma nação assim perturbada não consegue mais diferenciar o bem do mal, nem também o seu próprio benefício do óbvio malefício."

Ivo Andrić 


\section{Normalização adotada}

Esta tese está de acordo com as seguintes normas, em vigor no momento desta publicação:

Referências: adaptado de International Committee of Medical Journals Editors (Vancouver).

Universidade de São Paulo. Faculdade de Medicina. Divisão de Biblioteca e Documentação. Guia de apresentação de dissertações, teses e monografias. Elaborado por Anneliese Carneiro da Cunha, Maria Julia de A. L. Freddi, Maria F. Crestana, Marinalva de Souza Aragão, Suely Campos Cardoso, Valéria Vilhena. 3a ed. São Paulo: Divisão de Biblioteca e Documentação; 2011.

Abreviaturas dos títulos dos periódicos de acordo com List of Journals Indexed in Index Medicus. 
SUMÁRIO 


\section{Sumário}

Lista de abreviaturas

Lista de símbolos

Lista de siglas

Lista de figuras

Lista de tabelas

Resumo

Abstract

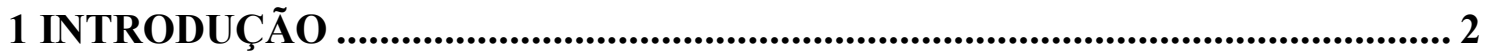

1.1. Uropatia obstrutiva congênita .............................................................................................2

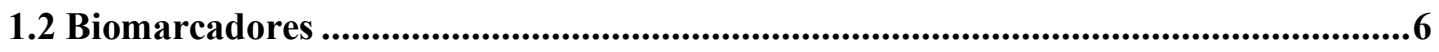

1.2.1 Lipocalina Associada a Gelatinase de Neutrófilo (NGAL) .......................................6

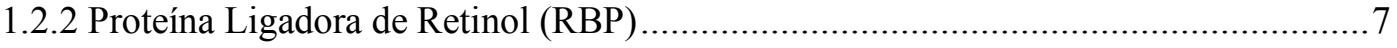

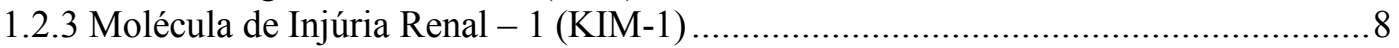

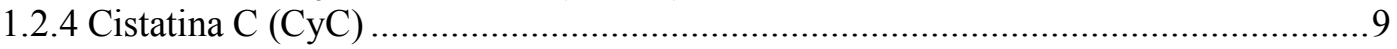

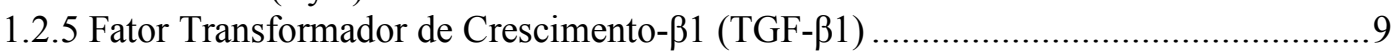

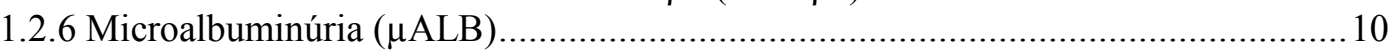

1.3 Combinação de biomarcadores ........................................................................................11

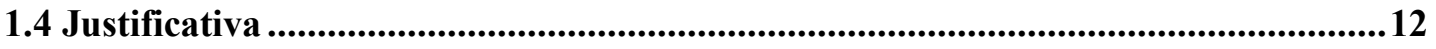

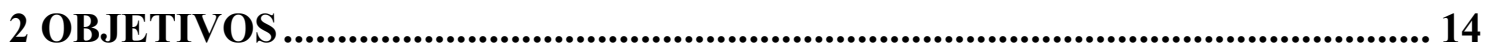

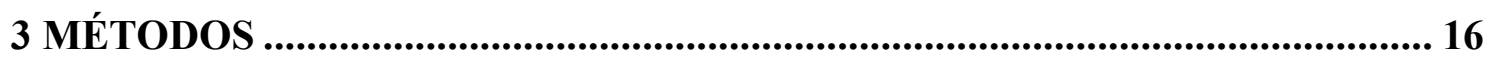

3.1 Desenho do estudo e seleção amostral ...............................................................................16

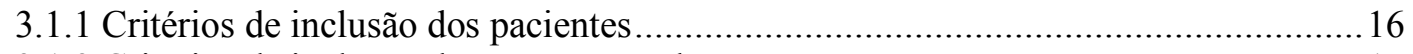

3.1.2 Critérios de inclusão do grupo-controle ..................................................................17

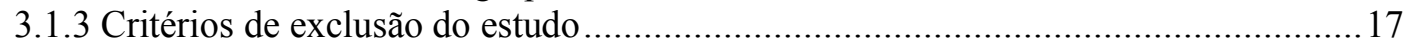

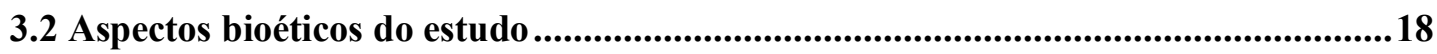

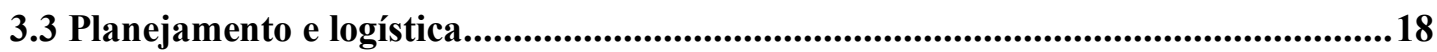

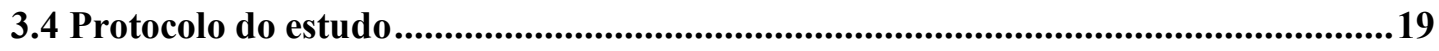


3.5 Decisão cirúrgica e definição da injúria renal..................................................................20

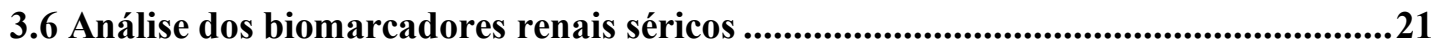

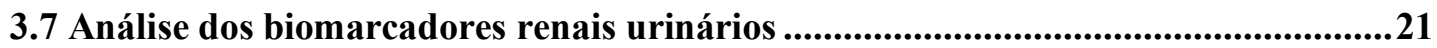

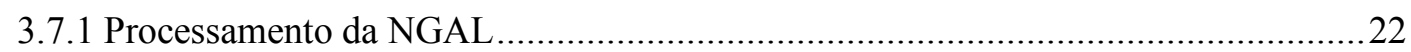

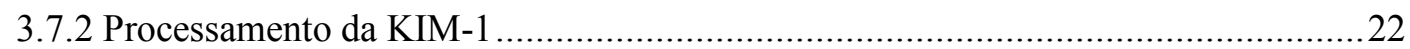

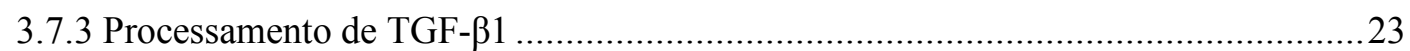

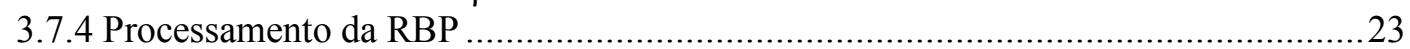

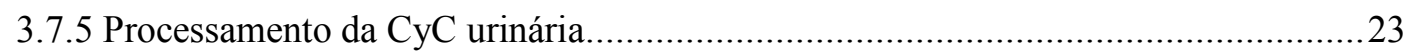

3.7.6 Processamento de $\mu$ ALB, creatinina urinária e normalização dos biomarcadores....24

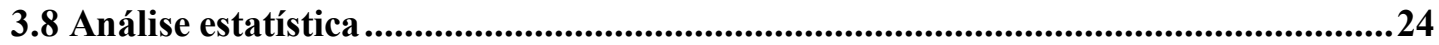

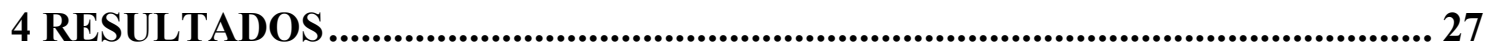

4.1 Dados demográficos e características dos participantes do estudo.............................27

4.2 Grupo-controle: o perfil dos biomarcadores renais .........................................................30

4.3 Grupo-pacientes: lesão renal e perfil dos biomarcadores renais..............................32

4.3.1 Desempenho dos biomarcadores em relação a lesão renal........................................33

4.4 Indicação cirúrgica e os biomarcadores em UOC..................................................42

4.4.1 Desempenho dos biomarcadores em relação a indicação cirúrgica ..........................42

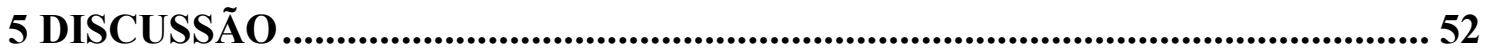

5.1 Perfil dos biomarcadores para deteç̧ão precoce de injúria renal em lactentes e recém-nascidos saudáveis............................................................................................52

5.2 Perfil dos biomarcadores para deteç̧ão precoce de injúria renal em UOC durante o primeiro ano de vida ...........................................................................57

5.3 Papel dos biomarcadores renais como discriminadores da necessidade de intervenção cirúrgica em lactentes com UOC......................................................................60

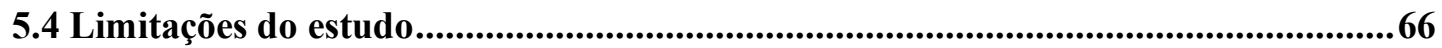

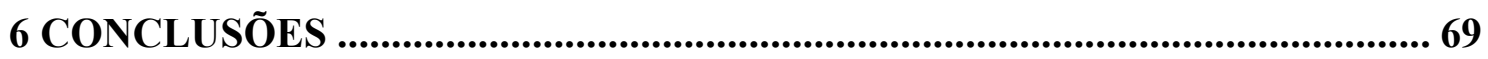

7 ANEXOS ...................................................................................................................... 71

Anexo A - Termo de consentimento livre e esclarecido do grupo pacientes.....................71

Anexo B - Termo de consentimento livre e esclarecido do grupo-controle.......................75

Anexo C - Características demográficas e clínicas dos pacientes com UOC em relação a indicação cirúrgica

Anexo D - Características clínicas e cirúrgicas da UOC em grupos e subgrupos

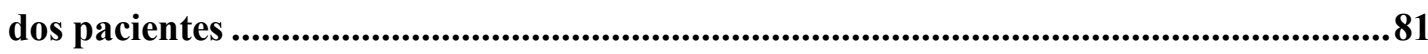


Anexo E - Potencial benefício dos biomarcadores na tomada das decisões sobre a indicação cirúrgica a tempo, comparado com os métodos diagnósticos tradicionais.

Anexo F - Potencial benefício dos biomarcadores na tomada das decisões sobre a indicação cirúrgica a tempo, comparado com os métodos diagnósticos

tradicionais e analisado para cada biomarcador, individualmente.................................85

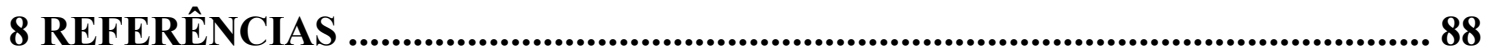


LISTAS 


\section{Abreviaturas}

acu.

acurácia

e.g.

"exempli grata", por exemplo

etc.

"et caetera", e os restantes

espec.

especificidade

sem.

semanas

sens.

sensibilidade 


\section{Símbolos}

$\begin{array}{ll}\mathrm{Cl} & \text { cloro } \\ \mathrm{dL} & \text { decilitro } \\ \mathrm{Hg} & \text { mercúrio } \\ \mathrm{kDa} & \text { quilodalton } \\ \mathrm{L} & \text { litro } \\ \mathrm{m} & \text { metro } \\ \mathrm{m}^{2} & \text { metro quadrado } \\ \mathrm{min} & \text { minuto } \\ \mu \mathrm{L} & \text { microlitro } \\ \mathrm{mL} & \text { mililitro } \\ \mathrm{mm} & \text { milimetro } \\ \mathrm{mOsm} & \text { miliosmol } \\ \mathrm{Na} & \text { sódio } \\ \mathrm{rpm} & \text { rotações por minuto } \\ { }^{\circ} \mathrm{C} & \text { grau Celsius } \\ > & \text { maior que } \\ < & \text { menor que } \\ \geq & \text { maior ou igual que } \\ \leq & \text { menor ou igual que } \\ = & \text { igual a }\end{array}$




\section{Siglas}

\begin{tabular}{|c|c|}
\hline AUC & "area under curve", área sob a curva \\
\hline $\mathrm{AIG}$ & adequado para idade gestacional \\
\hline ATR & acidose tubular renal \\
\hline BAM & berçário anexo a maternidade \\
\hline BMs & biomarcadores \\
\hline CAPPesq & Comissão de Ética para Análise de Projetos de Pesquisa \\
\hline $\mathrm{Cl}$ & cloro \\
\hline $\mathrm{Cr}$ & creatinina \\
\hline $\mathrm{CrS}$ & creatinina sérica \\
\hline $\mathrm{CrU}$ & creatinina na urina \\
\hline $\mathrm{CyC}$ & cistatina $\mathrm{C}$ \\
\hline $\mathrm{CyCs}$ & cistatina $\mathrm{C}$ sérica \\
\hline $\mathrm{CyCu}$ & cistatina $\mathrm{C}$ urinária \\
\hline DAP & diámetro anteroposterior da pelve renal \\
\hline DRC & doença renal crônica \\
\hline ELISA & imunoensaio enzimático quantitativo \\
\hline FRD & função renal diferencial \\
\hline GIG & grande para idade gestacional \\
\hline GNO & grupo não operado \\
\hline GOI & grupo operado intermediário \\
\hline GOP & grupo operado precoce \\
\hline GOT & grupo operado tardio \\
\hline HB & hidronefrose bilateral \\
\hline $\mathrm{HN}$ & hidronefrose \\
\hline HCFMUSP & $\begin{array}{l}\text { Hospital das Clínicas da Faculdade de Medicina da Universidade } \\
\text { de São Paulo }\end{array}$ \\
\hline $\mathrm{HU}$ & hidronefrose unilateral \\
\hline HUN & hidroureteronefrose \\
\hline IC & intervalo de confiança \\
\hline
\end{tabular}




\begin{tabular}{|c|c|}
\hline $\operatorname{IgA}$ & imunoglobulina A \\
\hline IG & idade gestacional \\
\hline IRA & injúria renal aguda \\
\hline ITU & infecção do trato urinário \\
\hline JUP & junção ureteropiélica \\
\hline JUV & junção ureterovesical \\
\hline KIM-1 & molécula de injúria renal-1 \\
\hline LID & limite inferior de detecção \\
\hline LIM & laboratório de investigações médicas \\
\hline$\mu \mathrm{ALB}$ & microalbuminúria \\
\hline mRNA & ácido ribonucleico mensageiro \\
\hline NGAL & lipocalina associada à gelatinase neutrofílica \\
\hline NP & nefropatia parenquimatosa \\
\hline OTUB & obstrução de vias urinárias baixas \\
\hline OTUS & obstrução de vias urinárias superiores \\
\hline RBP & proteína ligadora de retinol \\
\hline RD-DTPA- ${ }^{99 m} \mathrm{Tc}$ & $\begin{array}{l}\text { renograma dinâmico com ácido dietilenotriamino pentacético } \\
\text { marcado com tecnécio } 99 \text { metaestável }\end{array}$ \\
\hline RE-DMSA & renograma estático com ácido dimercaptosuccínico \\
\hline RFGe & ritmo de filtração glomerular estimado \\
\hline $\mathrm{RN}$ & recém-nascido \\
\hline ROC & "receiver operating characteristics curve" \\
\hline RVU & refluxo vesico-ureteral \\
\hline TGF- $ß 1$ & fator transformador de crescimento-beta 1 \\
\hline UCM & uretrocistografia miccional \\
\hline UOC & uropatias obstrutivas congênitas \\
\hline USG & ultrassonografia \\
\hline VPN & valor preditivo negativo \\
\hline VPP & valor preditivo positivo \\
\hline VUP & válvula de uretra posterior \\
\hline
\end{tabular}




\section{Figuras}

Figura 1 - Dinâmica de recrutamento dos controles saudáveis e dos pacientes, no período de junho 2012 a junho 2016.

Figura 2 - Peso e estatura do grupo controle e subgrupos com HU, HB e OTUB, durante o primeiro ano de vida, apresentados como média com desvio padrão

Figura 3 - Análise comparativa do perfil dos valores séricos de $\mathrm{CrS}$ e CyCs e dos RFGe correspondentes, apresentados como média e desvio padrão, nos primeiros 12 meses de vida, no grupo controle

Figura 4 - Análise comparativa do perfil de valores dos biomarcadores renais urinários ( $\mu \mathrm{ALB}$, RBP, TGF- $\beta 1$, KIM-1, NGAL e CyCu), descritos como mediana ( $\mathrm{p} 5 ; \mathrm{p} 95$ ), durante o primeiro ano de vida no grupo controle

Figura 5 - Análise comparativa dos biomarcadores séricos ( $\mathrm{CrS}$ e $\mathrm{CyCs})$, descritos como mediana ( $55 ; \mathrm{p} 95)$, no primeiro ano de vida entre os grupos controle e pacientes

Figura 6 - Análise comparativa dos biomarcadores séricos $(\mathrm{CrS}$ e CyCs), descritos como mediana (p5; p95), no $1^{\circ}$ ano de vida, entre os grupo controle e subgrupos $\mathrm{HU}, \mathrm{HB}$ e OTUB

Figura 7 - Análise comparativa do RFGe dos biomarcadores séricos (CrS e $\mathrm{CyCs}$ ), descritos como mediana ( 55 ; p95), no primeiro ano de vida entre o grupo-controle, grupo dos pacientes e subgrupos $\mathrm{HU}, \mathrm{HB}$ e OTUB

Figura 8 - Análise do perfil dos biomarcadores renais urinários: RBP, NGAL, $\mathrm{CyCu}$, KIM-1, TGF- $\beta 1$ e $\mu \mathrm{ALB}$ ao longo do primeiro ano de vida, nos grupos controle e pacientes 
Figura 9 - Análise do perfil dos biomarcadores renais urinários: RBP, NGAL, CyCu, KIM-1, TGF-ß1 e $\mu$ ALB ao longo do $1^{\circ}$ ano de vida, nos grupos controle e nos subgrupos $\mathrm{HU}, \mathrm{BH}$ e OTUB

Figura 10 - Análise do poder discriminativo dos biomarcadores renais para identificação da lesão renal ou da sua progressão em UOC no primeiro ano de vida através de curvas ROC.

Figura 11 - Comparação dos valores de biomarcadores séricos (CrS e CyCs), descritos como mediana e $(5 ; 95)$ percentis, entre os valores do grupo-controle, dosagens pré e pos-operatórias nos pacientes do grupo operado precocemente (GOP) e em tempo intermediário (GOI) com os valores obtidos em pacientes do grupo não operado (GNO) e grupo operado tardio (GOT) aos 12 meses de idade

Figura 12 - Comparação dos valores de biomarcadores séricos ( $\mathrm{CrS}$ e $\mathrm{CyCs})$, descritos como mediana e $(5 ; 95)$ percentis, entre o grupo controle, dosagens pré e pós-operatórias nos pacientes operados precocemente (GOP) e em tempo intermediário (GOI) com valores obtidos em pacientes não operados (GNO) e operados tardiamente (GOT) aos 12 meses de idade, de acordo com subgrupos HU, HB, OTUB 44

Figura 13 - Comparação dos valores de biomarcadores urinários, descritos como mediana e $(5 ; 95)$ percentis, entre o grupo controle, dosagens pré e pós-operatórias nos pacientes do GOP e GOI com valores obtidos em pacientes do GNO e GOT aos 12 meses de idade

Figura 14 - Comparação dos valores individuais dos biomarcadores urinários entre o grupo controle, dosagens pré e pós-operatórias nos pacientes do GOP e GOI com valores obtidos em pacientes do GNO e GOT aos 12 meses de idade 46 
Figura 15 - Análise do poder discriminativo dos biomarcadores renais como preditores da indicação de abordagem cirúrgica em UOC no primeiro ano através de curvas ROC. 


\section{Tabelas}

Tabela 1 - Área de aplicação dos biomarcadores para deteç̧ão precoce da injúria renal obstrutiva: diferenciação, diagnóstico precoce e estimativa da gravidade da lesão renal .....

Tabela 2 - Características demográficas, medidas antropométricas e valores da pressão arterial durante o seguimento no primeiro ano de vida dos pacientes com UOC e do grupo-controle

Tabela 3 - Diagnóstico pré e pós-natal, complicações e procedimentos no grupo e nos subgrupos de pacientes com HU, HB e OTUB

Tabela 4 - Ritmo de filtração glomerular estimado de creatinina sérica e cistatina $\mathrm{C}$ sérica no primeiro ano de vida nos subgrupos dos pacientes com UOC e controles saudáveis, apresentados como média com desvio padrão 36

Tabela 5 - Desempenho individual dos biomarcadores renais séricos e urinários em relação à identificação da lesão renal ou a sua progressão em UOC durante o primeiro ano de vida

Tabela 6 - Desempenho da combinação dos biomarcadores renais em relação à identificação da lesão renal ou a sua progressão em UOC durante o primeiro ano de vida

Tabela 9 - Desempenho individual dos biomarcadores renais séricos e urinários em relação à identificação da obstrução do trato urinário com indicação de abordagem cirúrgica em UOC durante o primeiro ano de vida 48

Tabela 10 - Desempenho da combinação dos biomarcadores renais em relação à identificação da obstrução do trato urinário com indicação de abordagem cirúrgica em UOC durante o primeiro ano de vida 
Tabela 13 - Apresentação geral dos estudos disponíveis na literatura sobre o desempenho dos biomarcadores renais em relação a identificação precoce da obstrução das vias urinarias que necessita da intervenção cirúrgica

Tabela 7 - Características demográficas e clínicas dos pacientes operados, não operados e do grupo-controle em relação a indicação cirúrgica nos portadores de UOC 80

Tabela 8 - Características clínicas e cirúrgicas da UOC em grupos e subgrupos dos pacientes

Tabela 11 - Características dos biomarcadores de acordo com o seu desempenho em relação à tomada das decisões cirúrgicas convencional 84

Tabela 12 - Concordância e discordância entre o método tradicional e de acordo com o desempenho dos biomarcadores renais séricos e urinários em relação à tomada das decisões sobre a indicação cirúrgica a tempo 
RESUMO 
Kostic D. Biomarcadores para diagnóstico precoce de injúria renal em uropatias obstrutivas congênitas [tese]. São Paulo: Faculdade de Medicina, Universidade de São Paulo; 2018.

Introdução: Os estudos com proteômica especificamente relacionada à nefrologia e urologia pediátrica são limitados. $\mathrm{O}$ diagnóstico do comprometimento da função renal e da sua deterioração na presença de uropatias obstrutivas congênitas (UOC) representa o desafio na rotina da nefro-urologia pediátrica. Novos biomarcadores com o potencial para detecção precoce da lesão renal surgiram recentemente, permitindo a escolha da melhor opção terapêutica no tempo hábil, e assim minimizando ou prevenindo o dano renal definitivo. Objetivos: Avaliar o perfil de dois biomarcadores renais séricos: creatinina $(\mathrm{CrS})$ e cistatina $\mathrm{C}(\mathrm{CyCs})$; e seis biomaracadores renais urinários: lipocalina associada à gelatinase neutrofílica (NGAL), proteína ligadora de retinol (RBP), molécula de injúria renal $1(\mathrm{KIM}-1)$, cistatina $\mathrm{C}$ na urina $(\mathrm{CyCu})$, fator transformador de crescimento-beta 1 (TGF-ß1) e microalbuminúria ( $\mu \mathrm{ALB}$ ) durante o primeiro ano de vida em lactentes saudáveis; em relação à detecção precoce da lesão renal em lactentes com UOC; em relação à sua capacidade de prever a necessidade de intervenção cirúrgica em lactentes com UOC. Metodologia: 37 lactentes com UOC foram divididos em três subgrupos: 14/37 casos com hidroureteronefrose unilateral (HU), 13/37 com hidroureteronefrose bilateral (HB) e 10/37 com obstrução de vias urinárias baixas (OTUB); e comparados com 24 lactentes saudáveis. No grupo dos pacientes, as amostras de sangue e urina foram obtidas ao nascer e entre o $3^{\circ}$ e $7^{\circ}$ dia, $1^{\circ}, 2^{\circ}, 3^{\circ}, 6^{\circ}, 9^{\circ}$ e $12^{\circ}$ mês de vida. Grupo de controle seguia o mesmo cronograma, com exceção da coleta de sangue que ocorria ao nascer, entre o $3^{\circ}$ e $7^{\circ}$ dia, no $6^{\circ}$ e $12^{\circ}$ mês de vida. Todas as amostras foram armazenadas sob $70{ }^{\circ} \mathrm{C}$, e analisadas posteriormente através de imunoensaio enzimático quantitativo (ELISA). Resultados: No grupo-controle, $\mathrm{CrS}, \mathrm{CyCs}, \mathrm{CyCu}$ e RBP refletiram a maturação glomerular e tubular. O ritmo de filtração glomerular pela CyCs atingiu os níveis estáveis no $6^{\circ}$ mês de vida $\left(93 \pm 22 \mathrm{~mL} / \mathrm{min} / 1,73 \mathrm{~m}^{2}\right)$. KIM-1 e TGF- $\beta 1$ mantiveram os níveis absolutos próximos ao limite de detecção pelo método. Os valores do NGAL no sexo feminino foram significativamente maiores $(\mathrm{p}=0,005)$ ao longo do $1^{\mathrm{o}}$ ano, quando comparados aos do sexo masculino. Em comparação aos controles, a coorte dos pacientes apresentou valores mais elevados para todos os biomarcadores urinários no $1^{\circ}$ mês de vida $(\mathrm{p} \leq 0,009)$, sendo que NGAL $(\mathrm{p}=0,005)$, TGF- $\beta 1 \quad(\mathrm{p}<0,001)$ e $\mu$ ALB $(p<0,001)$ mostraram-se elevados desde o nascimento, em comparação aos controles. $O$ RBP apresentou o melhor desempenho no subgrupo com HB e OTUB (AUC $=0,844$, sensibilidade $\geq 83,3 \%$, especificidade $94,3 \%$ ), assim como o KIM-1 no HU (AUC $=0,768$, sensibilidade 70,7\%, especificidade 82,7\%). RBP em combinação com TGF-ß1 ou KIM1 e NGAL com CyCs e $\mathrm{CyCu}$, atingiram os melhores resultados para detecção da lesão renal (AUC $=0,934$, sensibilidade 89,4\%, especificidade 92,8\%; $\mathrm{AUC}=0,896$, sensibilidade $86,8 \%$, especificidade $81,1 \%$; $A U C=0,867$, sensibilidade $92,4 \%$, especificidade $79,5 \%$, respectivamente). Nos pacientes operados, os níveis elevados de RBP $(p \leq 0,043)$, NGAL $(p \leq 0,043)$, KIM-1 $(p \leq 0,03)$ e TGF- $\beta 1 \quad(p \leq 0,034)$ baixaram significativamente após a cirurgia, no subgrupo com HU e OTUB. NGAL, isolado ou em combinação, com CyCs e $\mathrm{CyCu}$ demonstrou o melhor desempenho para determinar a necessidade cirúrgica (AUC $=0,801$, sensibilidade 63,6\%, especificidade 96,7\%; $\mathrm{AUC}=0,881$, sensibilidade $87,7 \%$, especificidade $82,2 \%$, respectivamente). A analise do perfil dos biomarcadores indicou a necessidade da intervenção cirúrgica em 55,4\% (7/13) dos casos não-operados e antecipou a decisão cirúrgica no mínimo 3 meses, em 58\% $(14 / 24)$ de todos os pacientes operados, baseada nas diretrizes atuais. Conclusão: A 
evolução dos valores normais dos biomarcadores no primeiro ano de vida, pode servir como a base para os próximos estudos de detecção precoce de afecções uro-nefrologicas. RBP, NGAL, KIM-1, TGF-ß1 e CyC, individualmente ou em combinação, demonstraram um forte potencial para identificar a lesão renal e servir como uma ferramenta de diagnóstico não-invasivo para diferenciar pacientes que necessitam de intervenção cirúrgica precoce daqueles que se beneficiariam de uma conduta conservadora.

Descritores: nefropatias; hidronefrose; biomarcadores; proteómica; lactente; insuficiência renal. 
ABSTRACT 
Kostic D. Biomarkers for early detection of renal injury in congenital obstructive uropathies [thesis]. São Paulo: "Faculdade de Medicina, Universidade de São Paulo"; 2018.

Introduction: The proteomics studies specifically related to pediatric nephrology and urology are limited. The diagnosis of renal function impairment and deterioration in congenital obstructive uropathies (COU) represents challenge in pediatric nephrourology routine. New renal biomarkers applied in this setting have potential for early renal injury detection, allowing reliable choice of optimal therapeutic options and thus preventing or minimizing definitive renal damage. Objectives: To analyze the first-year profiles of two serum renal biomarkers: Creatinine $(\mathrm{CrS})$ and Cystatin $\mathrm{C}(\mathrm{CyCs})$; and six urinary renal biomarkers: Neutrophil Gelatinase-Associated Lipocalin (NGAL), RetinolBinding Protein (RBP), Kidney Injury Molecule-1 (KIM-1), urine Cystatin $C(\mathrm{CyCu})$, Transforming Growth Factor Beta 1 (TGF- $\beta 1$ ), and microalbuminuria ( $\mu$ ALB) in a cohort of healthy infants; in relation to early detection of renal injury capability in a group of infants with COU; in relation to capability of predicting the need for surgery in a group of infants with COU. Methods: 37 infants with COU were divided in 3 subgroups: 14/37 cases with unilateral hydro(uretero)nephrosis (UH), 13/37 with bilateral hydro(uretero)nephrosis $(\mathrm{BH})$ and $10 / 37$ patients with lower urinary tract obstruction (LUTO), compared with 24 healthy infants matched by gestational age and birth weight. In the patient group, blood and urine samples were collected at birth, between $3^{\text {rd }} 7^{\text {th }}$ day, at $1^{\text {st }}, 2^{\text {nd }}, 3^{\text {rd }}, 6^{\text {th }}, 9^{\text {th }}$ and $12^{\text {th }}$ month of age. In the control group urine sampling followed the same routine with exception that blood sampling was obtained between $3^{\text {rd }}-7^{\text {th }}$ day, at $6^{\text {th }}$ and $12^{\text {th }}$ month of age. The samples were stored at $-70^{\circ} \mathrm{C}$, and thereafter analyzed by quantitative enzymatic immunoassay (ELISA). Results: In the group of healthy controls, the values of $\mathrm{CrS}, \mathrm{CyCs}, \mathrm{CyCu}$ and $\mathrm{RBP}$ reflected glomerular and tubular maturation. The glomerular filtration rate by CyCs reached steady-state levels at $6^{\text {th }}$ month of life (93 $\pm 22 \mathrm{~mL} / \mathrm{min} / 1,73 \mathrm{~m}^{2}$ ). KIM-1 and TGF- 31 maintained very low absolute levels, near to the limit of detection by the method. NGAL levels in females were significantly higher $(p=0,005)$ throughout the first year of life, when compared to male gender. In the cohort of patients, all the urinary biomarkers showed significantly higher values at the first month of life $(p \leq 0,009)$, while NGAL $(p=0,005)$, TGF- $\beta 1(p<0,001)$ e $\mu$ ALB $(p<0,001)$ were high since birth, compared to control group. The best single biomarker performance was achieved by RBP in BH and LUTO subgroups ( $A U C=0,844$, sensitivity $\geq 83,3 \%$, specificity 94,3\%), and by KIM-1 in UH subgroup (AUC $=0,768$, sensitivity 70,7\%, specificity $82,7 \%$ ). The best biomarker combination results for all subgroups were obtained by matching RBP with TGF- 31 or KIM- 1 and NGAL with $\mathrm{CyC}$ (AUC $=0,934$, sensitivity $89,4 \%$, specificity $92,8 \%$; AUC $=0,896$, sensitivity $86,8 \%$, specificity $81,1 \%$; AUC $=0,867$, sensitivity $92,4 \%$, specificity $79,5 \%$, respectively). In the operated group of patients, the levels of RBP ( $\mathrm{p} \leq 0,043)$, NGAL $(\mathrm{p} \leq 0,043), \mathrm{KIM}-1(\mathrm{p} \leq 0,03)$ e TGF- $\beta 1$ $(p \leq 0,034)$ dropped significantly after surgery, in UH and LUTO subgroups. NGAL alone or in combination with $\mathrm{CyCs}$ and $\mathrm{CyCu}$, demonstrated the best performance to determine the need for surgery (AUC=0,801, sensitivity 63,6\%, specificity 96,7\%; AUC $=0,881$, sensitivity $87,7 \%$, specificity $82,2 \%$, respectively). Biomarkers' profile analysis indicated the need for surgical intervention in 55,4\% (7/13) of non-operated cases and anticipated clinically based surgical decision for at least 3 months, in 58\% (14/24) of all operated patients. Conclusions: The presented biomarkers' normal values evolution during the first year of life can be of use as a base for future studies that will involve early detection of uronephrological disorders in infants. RBP, NGAL, KIM-1, TGF-ß1 and CyC, alone 
or in combination, demonstrated strong capability to identify renal injury and serve as a noninvasive diagnostic tool for differentiating between infants that require early surgical intervention from those who would benefit from conservative approach.

Descriptors: kidney disease; hydronephrosis; biomarkers; proteomics; infant; renal insufficiency. 
INTRODUÇÃO 


\section{INTRODUÇÃO}

\subsection{Uropatia obstrutiva congênita}

Uropatia obstrutiva congênita (UOC) representa qualquer condição de prejuízo da drenagem de urina podendo levar, se não corrigida, à limitação do potencial funcional final do rim em desenvolvimento, inclusive a reserva funcional e a resposta ao estresse ${ }^{1,2}$. A incidência de UOC nas gestações rastreadas varia de 1-5\%, e representa a maior causa identificável de injúria renal nas crianças ${ }^{3}$. A incidência da obstrução do trato urinário superior (OTUS) varia de 1:1000-1500 nascidos vivos; obstrução da junção ureteropiélica (JUP) ocorre em 39-64\% dos casos, enquanto a da junção ureterovesical (JUV) está presente em $9-14 \%$ dos pacientes ${ }^{4-6}$. Em todas essas situações ocorre dilatação do sistema coletor renal, conhecida como hidronefrose $(\mathrm{HN})$ ou hidroureteronefrose $(\mathrm{HUN})$, quando inclui a dilatação dos ureteres ${ }^{7}$. HN fetal e neonatal representa a característica principal da OTUS, geralmente considerada como funcional e transitória, resultante de anormalidades da musculatura lisa da pelve renal e dos ureteres ${ }^{4}$. A obstrução do trato urinário baixo (OTUB), associada à alta morbimortalidade, apresenta incidência geral de 2,2 a cada 10000 nascidos vivos, sendo válvula de uretra posterior (VUP) com 63,7\%, atresia uretral com $29,2 \%$ e síndrome de Prune Belly com 3,5\%, as formas mais frequentes $^{4,5}$. A gravidade da OTUB não se correlaciona com o grau de dilatação do trato urinário superior $^{8}$, sendo que até $1,5 \%$ da população rastreada necessita de seguimento a longo prazo ou uma intervenção cirúrgica, devido ao risco de progressão para doença renal crônica (DRC) avançada ${ }^{9,10}$. Nas últimas três décadas, diversos modelos experimentais em animais e poucos estudos que incluíram investigações clínicas e histopatologia humana, mostraram que quando OTUS e OTUB se instalam precocemente durante a gestação, têm como consequência a injúria renal irrecuperável caracterizada pela displasia renal e, em último caso, o desfecho desfavorável ${ }^{4,6,11-16}$. A obstrução que ocorre mais tardiamente, a partir de 22 semanas de gestação, pode levar a nefropatia intersticial crônica cuja gravidade depende do grau e da duração da obstrução ${ }^{4,11,17-19}$. 
Constituem desafios atuais, a identificação dos pacientes com provável comprometimento de crescimento e desenvolvimento renal e a escolha da intervenção cirúrgica realizada a tempo de prevenir a progressão da lesão renal definitiva ${ }^{9,}{ }^{17}$. A intervenção precoce na obstrução reduz o processo patológico que leva a injúria túbulointersticial, enquanto a demora em resolver esse problema é seguida pela lesão renal progressiva devido à fibrose túbulo-intersticial. Com a introdução da ultrassonografia fetal como rotina no seguimento pré-natal, o diagnóstico precoce de HN/HUN se tornou possível, o que para alguns pacientes foi benéfico, resultando em uma intervenção cirúrgica a tempo, enquanto a maioria dos casos continuou apresentando achados de significado clínico duvidoso ao longo tempo ${ }^{20}$.

$\mathrm{Na}$ prática clínica atual o manejo da HN congênita geralmente é baseado em dados clínicos e instrumentais. Para a maioria dos pacientes isso significa um período prolongado de seguimento clínico que envolve avaliações frequentes através de analises laboratoriais, ultrassonografia seriada, cintilografia dinâmica, uretrocistografia miccional (UCM) ou urografia por ressonância magnética nuclear. Essa abordagem atualmente é utilizada para avaliar a gravidade da obstrução, o prognóstico de riscos, determinação do desenvolvimento da lesão renal progressiva mensurável ${ }^{21}$ e a necessidade de cirurgia ${ }^{8}$. Esses exames, na maioria invasivos, apresentam custo elevado e geram angustia para a criança e sua família. Além disso, não apresentam sensibilidade e especificidade suficientes para identificar corretamente os indivíduos que necessitam uma intervenção cirúrgica precoce, no período em que o comprometimento renal ainda é mínimo e reversível $^{3,20}$. As indicações cirúrgicas atuais permanecem baseadas na estimativa de risco pré-natal e pós-natal proposta pelos diversos sistemas de classificação de dilatação do trato urinário. Caracterizam-se pela escassez de consenso e uniformidade da terminologia, definições e classificações, tudo isso levando a equívocos e controvérsias sobre a seleção adequada dos pacientes ${ }^{8}$.

Uropatias obstrutivas, injúria renal aguda (IRA) isquêmica, doença cística renal e rejeição do transplante renal compartilham o mesmo processo patogenético caracterizado pela desordem tubulointersticial ${ }^{22,23}$. Há poucas informações disponíveis sobre a correlação entre esses dados e as características histológicas que representam o marcador de prognóstico mais fidedigno ${ }^{11}$. Não há definição sobre um marcador, ou mais provavelmente, um painel confiável de marcadores, para selecionar e tratar os pacientes 
com dilatação obstrutiva persistente e progressiva, antes que ocorra a deterioração da função renal.

A obstrução fetal grave é uma área de interesse na qual a utilização de biomarcadores pode ter um papel na tomada da decisão clínica precoce. O diagnóstico dessa condição se baseia no momento atual, em índices do fluido amniótico indicativos de disfunção renal avançada $(\mathrm{Na}>100 \mathrm{mg} / \mathrm{dL}, \mathrm{Cl}>110 \mathrm{mg} / \mathrm{dL}$, Osmolaridade $>210$ $\mathrm{mOsm} / \mathrm{L}$ ) para determinar a indicação de intervenção fetal (derivação vesico-amniótica ou pielo-amniótica), que naturalmente resulta em pouco benefício para a criança ${ }^{24}$.

Os estudos com proteômica especificamente relacionada à urologia pediátrica são limitados. Várias tentativas foram feitas com o objetivo de identificar marcadores diagnósticos não invasivos de UOC, principalmente em casos de estenose da JUP, refluxo vesico-ureteral (RVU) com ou sem cicatriz, VUP etc., para definição daqueles que se beneficiariam de uma intervenção cirúrgica precoce. Com os resultados promissores, estes estudos revelaram os padrões de polipeptideos $<30 \mathrm{kDa}$, com a alta precisão preditiva de $94 \%$. Os mesmos demonstraram que o momento gestacional do surgimento da UOC prevê com maior precisão a necessidade de intervenção terapêutica, em comparação com os preditores atualmente utilizados, a saber, o grau da dilatação do trato urinário, a evolução da sua progressão e os marcadores tardios como, por exemplo, creatinina $(\mathrm{Cr})^{21,24-26}$. Recentemente, o interesse de nefro-urologistas pediátricos se concentrou no potencial dos novos biomarcadores renais mais promissores, séricos e urinários, já testados em diversos cenários clínicos, com objetivo de verificar a sua eficiência e utilidade em $\mathrm{UOC}^{20,27-30}$.

Sabe-se atualmente que a perda da função renal $>10 \%$ em relação à função renal basal é associada à grande probabilidade de lesão histológica e resultados terapêuticos pobres. O responsável pelo processo de transformação epitélio-mesenquimal das células tubulares renais em fibrose túbulo-intersticial renal é o fator transformador de crescimento - $\beta 1$ (TGF- $\beta 1$ ) cuja síntese é induzida pela ativação do sistema reninaangiotensina-aldosterona em resposta compensatória à obstrução ureteral. Por este motivo, surgiram ideias de dosar este fator na urina e usá-lo como um biomarcador que poderia prever precocemente o risco para a nefropatia crônica intersticial em pacientes com UOC, antes que ocorra a perda progressiva da função renal ${ }^{11}$. Além do TGF- $\beta 1$, os marcadores com resultados particularmente encorajadores são cistatina $\mathrm{C}$ sérico (CyCs), 
um marcador da função e maturação glomerular, e biomarcadores urinários da lesão tubular: lipocalina associada à gelatinase neutrofílica (NGAL), proteína ligadora de retinol (RBP), molécula de injúria renal-1 (KIM-1) e cistatina $\mathrm{C}$ na urina $(\mathrm{CyCu})$.

Apesar do surgimento de novos testes na área da pediatria e neonatologia para detecção precoce da IRA ou previsão de desfechos clínicos, como mortalidade, a aplicação e verificação dos biomarcadores nas populações vulneráveis permanece o grande desafio ${ }^{31}$. A avaliação dos biomarcadores renais em lactentes e recém-nascidos (RN), saudáveis ou com desordem renal, é delicada e complexa para realizar, o que limita mais ainda a sua validação. Nesses grupos, numerosos fatores podem interferir na interpretação dos resultados como, por exemplo, ocorre com CyC e RBP, cujo valor depende de processos funcionais modificados pela maturação renal, dificultando desse modo a caracterização das concentrações de referência da normalidade no primeiro ano de $\operatorname{vida}^{31,32}$. Dentre as questões metodológicas que dificultam a comparação dos resultados entre os estudos existentes, citamos aquelas relacionadas à coleta de amostras (micção involuntária, estado de hidratação) e a sua conservação, às diferenças entre os kits de biomarcadores produzidos por diferentes fabricantes, aos diferentes métodos de análise utilizados para avaliação de biomarcadores e, acima de tudo, à falta da definição da injúria renal universalmente aceita na população neonatal e dos lactentes ${ }^{33-35}$.

Diante do exposto, permanece a necessidade de identificação e validação de um marcador, ou mais provavelmente, um painel de marcadores, capaz de detectar precocemente a lesão renal na UOC. 


\subsection{Biomarcadores}

Biomarcadores são testes que ajudam a distinguir entre dois ou mais estados biológicos atuando como um guia das decisões clínicas. Para se tornar um biomarcador, o teste deve ser rigorosamente validado para demonstrar que há implicação clínica definida $^{36}$. Os biomarcadores de injúria renal devem possuir as seguintes características ${ }^{37}$ :

- $\quad$ Especificidade diagnóstica para detectar lesão tubular renal;

- Detecção precoce de lesões renais - na ausência de sintomas clínicos típicos e antes do aumento do nível sérico da creatinina $(\mathrm{CrS})$ e da ureia;

- Correlação entre a concentração na urina e intensidade da lesão renal;

- Capacidade de predizer/prever o desenvolvimento/evolução da doença e o desfecho clínico desfavorável;

- $\quad$ Oferecer suporte para seleção das melhores opções de tratamento.

\subsubsection{Lipocalina Associada a Gelatinase de Neutrófilo (NGAL)}

A NGAL foi identificada como proteína de $25 \mathrm{kDa}$ covalentemente ligada a gelatinase de neutrófilos. Normalmente está presente em níveis muito baixos em vários tecidos humanos, tais como rim, pulmão, estômago e cólon. A expressão de NGAL é significativamente induzida no epitélio lesado $^{38}$. Recentemente o gene que codifica NGAL, também conhecido como lcn2, foi identificado como um dos mais suprarregulados, e a proteína NGAL, como uma das proteínas mais rapidamente induzidas no rim afetado por isquemia ou nefrotoxicidade ${ }^{39}$. No rim pós-isquêmico, NGAL é suprarregulado em numerosos segmentos de néfron, acumulando-se principalmente nas células proliferativas do túbulo proximal. Acredita-se que NGAL poderia ser expresso pelos túbulos lesados para induzir re-epitelização e reduzir apoptose. Os estudos mostram que o aumento da concentração de NGAL de 10 vezes no sangue e de 100 vezes na urina precede o aumento do CrS. As concentrações de NGAL na urina e no sangue correlacionam-se com a CrS. Essa observação levou a hipótese de que a concentração de NGAL na urina é sensível, altamente preditiva, precoce e pode 
diferenciar a injúria aguda pré-renal da injúria renal propriamente dita $^{39-43}$. O método mais usado para a detecção da NGAL no sangue e urina é o imunoensaio enzimático quantitativo (ELISA), já disponível no comércio.

A NGAL, sérica e urinária, foi testada como marcador da DRC e da sua gravidade em pacientes com doença policística renal autossômica dominante, nefropatia por IgA e nefrite lúpica ${ }^{44,45}$. Nestes estudos, os níveis de NGAL mostraram correlação significativa com $\mathrm{CrS}$, ritmo de filtração glomerular (RFG) e proteinúria.

\subsubsection{Proteína Ligadora de Retinol (RBP)}

Proteína ligadora de retinol (Retinol-Binding Protein - RBP) é uma proteína com peso molecular de $21 \mathrm{kDa}$ ligada em algum grau às pré-albuminas plasmáticas com função de transportar a vitamina A. Nas ultimas décadas do século passado foi reportada, em geral, como marcador sérico do estado nutricional em crianças e adultos ${ }^{46-48}$. RBP é produzida no fígado, de forma relativamente constante, facilmente filtrada pelos glomérulos e quase completamente reabsorvida nos túbulos proximais. Nenhuma condição clínica conhecida leva à sua hiperprodução ${ }^{49}$. Apesar do seu potencial como biomarcador urinário da filtração glomerular e da função tubular renal ser reconhecido, ainda não foi integralmente estudado ${ }^{50-52}$. Mesmo uma pequena redução da função tubular renal pode levar ao aumento da excreção dessa proteína na urina. Uma vantagem da RBP como biomarcador é a sua estabilidade em pH ácido e temperatura ambiental ${ }^{37}$. 


\subsubsection{Molécula de Injúria Renal - 1 (KIM-1)}

A KIM-1 é uma proteína de origem tubular recentemente descrita. Mostra-se altamente supra-regulada nas células dos túbulos proximais desdiferenciados dos rins pós-isquêmicos de ratos (modelo animal). O seu segmento extracelular, proteoliticamente processado pelas metaloproteinases, é facilmente detectado na urina, inclusive na urina dos pacientes com injúria renal aguda (IRA) isquêmica confirmada por biópsia ${ }^{53}$. Usando o padrão northern blot ou western blot de análise e imunocitoquimica, a expressão proteica do gene da KIM-1 não é detectável no rim normal. Quando ocorre a injúria renal, principalmente nas áreas da lesão túbulo-intersticial (com inflamação e fibrose), há produção rápida do ácido ribonucleico mensageiro (mRNA) de KIM-1 e a proteína codificada é localizada em alta concentração na membrana apical do epitélio tubular proximal mais comprometido. A KIM-1 representa um receptor "scavenger" localizado na célula epitelial do túbulo proximal renal capaz de transforma-la num fagócito que facilitará a remoção de detrito apoptótico da luz tubular ${ }^{54}$. Portanto, a KIM-1 pode ter um papel importante na limitação da resposta autoimune à injúria. As características mais importantes da KIM-1 como biomarcador são ${ }^{37,54}$ :

- $\quad$ Ausência de expressão da KIM-1 no rim normal;

- Evidente suprarregulação e inserção na membrana apical do túbulo proximal;

- Persistência na célula epitelial até a sua recuperação completa;

- Clivagem rápida e vigorosa do seu ectodomínio e estabilidade ex-vivo em temperatura ambiente.

A KIM-1 não se expressa significativamente em localizações extra-renais. A KIM1 urinária mostrou capacidade para diferenciar a IRA isquêmica da azotemia pré-renal e da DRC. Uma vantagem da KIM-1 sobre NGAL parece ser sua maior especificidade para a isquemia ou injúria renal por nefrotoxicidade, não sendo significativamente afetado por DRC ou infecção do trato urinário (ITU) ${ }^{38}$. Vários estudos pré-clínicos com grande diversidade de insultos renais, inclusive toxinas, demonstraram a maior sensibilidade da KIM-1, em comparação a ureia e CrS, como o marcador de injúria renal ${ }^{37,55}$. 


\subsubsection{Cistatina C (CyC)}

A Cistatina C é um inibidor endógeno de protease de cisteína de $13 \mathrm{kDa}$ que é sintetizada e liberada no sangue pelas células nucleadas com taxa relativamente constante. Nos glomérulos, a CyC é livremente filtrada e completamente reabsorvida nos túbulos proximais. Após os primeiros dois anos de idade, os níveis de CyCs não são afetados significativamente pela idade, sexo, etnia, ou massa muscular, motivo pelo qual este marcador é melhor preditor de filtração glomerular do que a $\mathrm{CrS}$ nos pacientes com $\mathrm{DRC}^{56}$. A relação entre a $\mathrm{CyCu}$ e $\mathrm{CrS}$ é um bom indicador de disfunção tubular renal. Adicionalmente, CyC não é afetada pelas condições de armazenamento da amostra, ciclos de congelamento e descongelamento, presença de substâncias interferentes ou etiologia da injúria renal ${ }^{38}$. Junto com $\mathrm{NGAL}, \mathrm{CyCu}$ representa um biomarcador de utilidade promissora no diagnóstico precoce de IRA e DRC ${ }^{57,58}$.

\subsubsection{Fator Transformador de Crescimento- $\beta 1$ (TGF- $\beta 1)$}

O TGF- $\beta 1$ é uma citocina produzida pelo rim, responsável pelo desenvolvimento através da comunicação intercelular, bem como pelo apoptose de células epiteliais e deposição exagerada de matriz extracelular. O TGF- $\beta 1$ representa o principal modulador do processo de regeneração após a lesão tecidual, produzido como resultado do aumento da formação da angiotensia II durante a hiperfiltração glomerular. Normalmente, quando a regeneração se completa, cessa a liberação do TGF- $\beta 1$ pelo mecanismo do "feedback". Se a liberação do TGF- $\beta 1$ permanecer ativa, ocorre o acúmulo dos componentes de matriz extracelular (colágeno) e, consequentemente, a fibrose tecidual ${ }^{59,60}$. O TGF- $\beta 1$ é um dos fatores chave nos mecanismos comuns que levam à fibrose tecidual e ao desenvolvimento de DRC avançada. A elevada produção intra-renal do TGF- $ß 1$, junto com a aumentada excreção de outras proteínas como são RBP e $\alpha_{1}$-microglobulina, e suas elevadas concentrações na urina, representam indicadores da lesão ou disfunção das células epiteliais dos túbulos renais em vários tipos de doenças renais ${ }^{61-63}$. 
As análises imuno-histológicas de fetos humanos com displasia renal secundária à UOC mostram túbulos displásicos cercados por colares de células do estroma expressando o TGF- $\beta 1^{23}$. A apoptose tubular está significativamente aumentada em nefropatia ureteral unilateral fetal humana e também nos modelos animais após a obstrução ureteral unilateral ${ }^{20,23}$. Existe uma correlação linear entre a apoptose tubular e a dilatação tubular ${ }^{23}$. A excreção urinária de TGF- $\beta 1$ encontra-se aumentada na urina da pelve renal e na urina da bexiga das crianças com obstrução de JUP e VUP, portanto sugerindo o TGF- $\beta 1$ como um potencial biomarcador de gravidade de obstrução ${ }^{20,64,65}$. Os trabalhos citados mostram ainda uma queda de níveis de TGF- $\beta 1$ nos primeiros meses após a correção cirúrgica (pieloplastia), que se torna estatisticamente significativo somente após um ano de seguimento ${ }^{20,64}$, o que faz do TGF- $\beta 1$ um potencial biomarcador não-invasivo para seguimento em longo prazo dos pacientes com OTUS submetidos à cirurgia corretiva.

\subsubsection{Microalbuminúria $(\mu \mathrm{ALB})$}

Apesar de controvérsias que acompanham a $\mu$ ALB em relação a sua origem renal (tubular, glomerular ou mista), ainda permanece considerado muito útil e um biomarcador importante na DRC em adultos, enquanto o seu uso em população pediátrica aguarda novos estudos ${ }^{34,66}$, especialmente em lactentes e $\mathrm{RN}^{32}$. O papel de $\mu$ ALB como biomarcador da disfunção endotelial é particularmente enfatizado, uma vez que, além das doenças renais, parece ser capaz de prever eventos cardiovasculares ao longo prazo, desde a primeira infância ${ }^{67}$. Alguns, senão todos os novos biomarcadores renais, quando analisados em combinação com $\mu \mathrm{ALB}$ obtida de amostra isolada de urina, podem apresentar ainda melhor sensibilidade e predição da lesão renal em diferentes cenários clínicos e períodos da coleta ${ }^{32,68}$. 


\subsection{Combinação de biomarcadores}

Uma proposta recentemente mais atrativa é a criação de um painel de biomarcadores proteicos para detecção da disfunção tubular renal ao invés da aplicação de um único biomarcador. A literatura sugere a aplicação de painéis nas seguintes situações especificas ${ }^{17,32,69}$ :

- $\quad$ Para distinguir os tipos e etiologias de injúria renal (aguda);

- $\quad$ Para diferenciar a gravidade da injúria renal;

- $\quad$ Para definir o tempo do início e duração de injúria renal, e

- $\quad$ Para definir o prognóstico de regressão da injúria renal.

A Tabela 1 demonstra os painéis de biomarcadores mais promissores até a presente data. Valores de referência para estes biomarcadores em $\mathrm{RN}$ e lactentes no primeiro ano de vida não foram determinados, uma vez que os estudos já realizados descrevem casuísticas muito pequenas.

Tabela 1 - Área de aplicação dos biomarcadores para detecção precoce da injúria renal obstrutiva: diferenciação, diagnóstico precoce e estimativa da gravidade da lesão renal

Área de aplicação:

Uropatia obstrutiva congênita

Painel dos biomarcadores

Diferenciação e detecção precoce

$\mathrm{CyCs}+\mathrm{CyCu}+\mathrm{NGAL}$

Estimativa da gravidade da lesão renal

TGF- $\beta 1+$ RBP

Biomarcadores ainda não estudados na

$\mathrm{KIM}-1+\mathrm{RBP}$

literatura, com utilidade potencial

Fonte: Chevalier RL. Pediatr Radiol. 2008; 38(Suppl 1): p. S35-40.

Fonte: DeFreitas MJ et al. Pediatr Nephrol. 2016; 31: p. 1179-1188.

Fonte: Che M et al. Nephron Clin Pract. 2010; 115(1): p. c66-72 


\subsection{Justificativa}

No cotidiano da nefrologia pediátrica persiste um conjunto de situações clínicas que são verdadeiros desafios diagnósticos, entre elas, a progressão da perda funcional renal nas UOC. A detecção precoce de injúria renal permite a instituição de terapias que evitariam a lesão renal definitiva e no caso das UOC, seriam utilizadas para indicação mais precoce de procedimentos cirúrgicos de desobstrução de vias urinárias. Isso resultaria na preservação da função renal e monitorização da resposta ao tratamento, minimizando a necessidade de instituição de tratamento de substituição renal e assim reduzindo a morbimortalidade destes pacientes. Consequentemente, as medidas citadas visam a preservação da qualidade de vida do paciente e a racionalização dos recursos disponíveis, reservando-os para os casos irremediáveis. 
OBJETIVOS 


\section{OBJETIVOS}

Este estudo tem como objetivo principal avaliar o perfil evolutivo de dois biomarcadores séricos: creatinina $(\mathrm{CrS})$ e cistatina $\mathrm{C}(\mathrm{CyCs})$; e seis biomaracadores renais urinários: lipocalina associada à gelatinase neutrofílica (NGAL), proteína ligadora de retinol (RBP), molécula de injúria renal-1 (KIM-1), cistatina $\mathrm{C}$ na urina $(\mathrm{CyCu})$, fator transformador de crescimento-beta 1 (TGF-B1) e microalbuminúria ( $\mu \mathrm{ALB})$ durante o primeiro ano de vida:

a) em uma coorte de $\mathrm{RN}$ e lactentes saudáveis;

b) em uma coorte de $\mathrm{RN}$ e lactentes com diagnóstico de UOC afetando o trato urinário superior e/ou baixo, com acometimento unilateral ou bilateral, em comparação a um grupo controle de $\mathrm{RN}$ e lactentes saudáveis.

O objetivo secundário constitui na avaliação das características do desempenho (especificidade e sensibilidade) dos biomarcadores séricos e urinários (individualmente ou em combinação):

a) em relação a detecção precoce da progressão de lesão renal em UOC;

b) em relação à sua capacidade de prever a necessidade de intervenção cirúrgica em UOC para desobstrução. 
MÉTODOS 


\section{MÉTODOS}

\subsection{Desenho do estudo e seleção amostral}

Esse é um estudo longitudinal e prospectivo, de coorte de lactentes saudáveis e com diagnóstico de UOC que foram acompanhados do nascimento até dois anos de idade no complexo do Hospital das Clínicas da Faculdade de Medicina da Universidade de São Paulo (HCFMUSP), que incluiu Instituto da Criança (ICr), Berçário Anexo a Maternidade (BAM), Laboratório de Investigações Clínicas 36 (LIM-36), Unidade de Medicina Fetal (UMF) do Departamento da Ginecologia e Obstetrícia e Unidade de Urologia Pediátrica da Divisão da Urologia do HCFMUSP.

\subsubsection{Critérios de inclusão dos pacientes}

Foram incluídos os pacientes com as seguintes características:

- $\mathrm{RN}$ com diagnóstico pré-natal de HN/HUN unilateral ou bilateral, confirmada após o nascimento como estenose de JUP e/ou estenose de JUV através da ultrassonografia (USG) seriada, renograma estático e dinâmico (RE-DMSA e RD-DTPA- ${ }^{99 m}$ Tc respectivamente), parâmetros de função glomerular e tubular e após a cirurgia, nos casos operados;

- RN com diagnóstico pré-natal de OTUB, confirmada após o nascimento, através da USG seriada, RE-DMSA, RD-DTPA- ${ }^{99 m}$ Tc, UCM, cistoscopia e parâmetros de função glomerular e tubular.

O recrutamento dos candidatos ocorreu na UMF durante as consultas de acompanhamento pré-natal que incluía exame USG, entre $16^{\circ}$ e $32^{\circ}$ semana da IG. A definição de HN/HUN pré-natal baseou-se em dados do diâmetro anteroposterior da pelve renal (DAP), grau da dilatação calicial e espessamento parenquimatoso ${ }^{8,70}$. Foram incluídos no estudo apenas casos com DAP grau III ou maior ${ }^{70}$. No caso de OTUB, o diagnóstico foi realizado através da avaliação ultrassonográfica do volume do liquido 
amniótico, presença de anormalidades do córtex renal, parede vesical (espessamento, megabexiga), dilatação fusiforme da uretra (“keyhole sign”) etc. A suspeita de estenose de JUV foi identificada quando havia progressiva dilatação do ureter (megaureter) com parâmetros normais da bexiga ${ }^{8,71}$.

\subsubsection{Critérios de inclusão do grupo-controle}

No grupo-controle foram incluídos:

- RN saudáveis, pareados no recrutamento, aos casos, por idade gestacional (IG) e sexo, com ausência de acometimento renal confirmada através da USG, e parâmetros de função glomerular e tubular normais, no ambulatório de Neonatologia (BAM) do ICr-HCFMUSP.

$\mathrm{O}$ convite para participação dos $\mathrm{RN}$ saudáveis ocorreu na maternidade do HCFMUSP na ocasião das admissões das gestantes em trabalho de parto ou com parto programado por indicação obstétrica.

\subsubsection{Critérios de exclusão do estudo}

Foram excluídas as crianças com diagnostico de doença genética, malformações congênitas, doença sistêmica (e.g. síndrome de desconforto respiratório, enterocolite necrotizante, sepse, asfixia grave etc.), hiperbilirrubinemia $>10 \mathrm{mg} / \mathrm{dL}$ após o $6^{\circ}$ dia de vida $^{72}$, anemia hemolítica, ITU de repetição (após o $2^{\circ}$ episódio confirmado por urocultura positiva no primeiro semestre, ou após o $3^{\circ}$ episódio no primeiro ano de observação $^{73}$. Foram excluídos também RN cujas mães tiveram hipertensão arterial sistêmica crônica ou gestacional descontrolada ${ }^{74}$ (e.g. pré-eclâmpsia e eclampsia), diabete gestacional de difícil controle, qualquer outra doença sistêmica materna grave ou história familiar incompleta. 


\subsection{Aspectos bioéticos do estudo}

Este estudo foi aprovado pela Comissão de Ética para Análise de Projetos de Pesquisa (CAPPesq) da Diretoria Clínica do HCFMUSP em assembleia realizada em 27 de julho de 2011, sob protocolo $\mathrm{N}^{\mathrm{o}}$ 0383/11. A pesquisa foi desenvolvida e realizada com apoio da Fundação do Amparo à Pesquisa do Estado de São Paulo - FAPESP e registrada sob no $2012 / 50337-9$.

O Termo de Consentimento Informado Livre e Esclarecido (Anexo A e Anexo B), redigido de acordo com as recomendações da Resolução $n^{0} 196$ de 10 de outubro de 1996 do Conselho Nacional de Saúde, foi obtido de todos os responsáveis dos participantes incluídos neste estudo.

\subsection{Planejamento e logística}

Todas as gestantes realizaram o pré-natal no Departamento de Obstetrícia do HCFMUSP, responsável pela condução do parto dos participantes, sendo o seguimento pós-natal realizado em conjunto pelos especialistas em neonatologia do BAM e nefrologia pediátrica da Unidade de Nefrologia Pediátrica do ICr-HCFMUSP. As visitas ambulatoriais seguiam o cronograma previsto pelo protocolo, quando foram coletadas as amostras de sangue e urina e realizados os exames de imagem, durante o primeiro ano de vida.

Conforme os critérios de inclusão baseados nos achados clínico-radiológicos, todos os pacientes foram distribuídos em três grupos:

a) grupo com diagnóstico pós-natal de $\mathrm{HN} / \mathrm{HUN}$ unilateral - $\mathrm{HU}$;

b) grupo com diagnóstico pós-natal de HN/HUN bilateral - HB;

c) e grupo com diagnóstico pós-natal de OTUB.

Como nem todas as indicações cirúrgicas ocorreram no primeiro ano de vida, o seguimento clínico dos participantes foi estendido até o final do $2^{\circ}$ ano. Baseado em 
características clínicas e período de indicação cirúrgica, todos os pacientes foram posteriormente divididos em 4 subgrupos:

a) grupo operado precocemente (GOP), com cirurgia realizada durante os primeiros 2 meses de vida;

b) grupo intermediário (GOI), com cirurgia realizada entre $3^{\circ}$ e $12^{\circ}$ mês de vida;

c) grupo operado tardiamente (GOT), com cirurgia realizada no $2^{\circ}$ ano de vida;

d) grupo não operado (GNO), que incluiu pacientes que não encontraram critérios atuais para cirurgia, nos primeiros dois anos de vida.

Conforme a rotina pré-existente no complexo HCFMUSP, os pacientes com UOC foram acompanhados pela equipe da urologia pediátrica, que permaneceu "cega" para o presente estudo até o final do seguimento de dois anos. Todas as amostras foram coletadas em duplicata, e prontamente processadas e guardadas no freezer sob temperatura de até $80{ }^{\circ} \mathrm{C}$. Posteriormente, em 8 etapas programadas, foram descongeladas e analisada pela equipe do LIM-36. Os exames de imagem foram realizados no ICr, Instituto de Radiologia - InRad-HCFMUSP e Instituto Central - HCFMUSP.

\subsection{Protocolo do estudo}

No grupo dos pacientes, as amostras de sangue foram coletadas do cordão umbilical ao nascimento e posteriormente através da punção venosa entre o $3^{\circ}$ e $7^{\circ}$ dia de vida, $1^{\circ}$, $2^{\circ}, 3^{\circ}, 6^{\circ}, 9^{\circ}$ e $12^{\circ}$ mês de vida. Amostras de urina foram obtidas na mesma ocasião, através do saco coletor. USG foi realizada na $1^{\mathrm{o}}$ semana de vida, aos 6 meses e aos 12 meses de vida. RD-DTPA- ${ }^{99}$ mc e RE-DMSA foram marcados aos 6 meses de idade, com possibilidade de realização antecipada ou repetida, conforme indicação clínico-cirúrgica. UCM foi realizado em todos os pacientes do grupo-OTUB ao nascimento, e nos demais grupos com HN/HUN de acordo com a indicação dos especialistas. Nos poucos casos pós-cirúrgicos nos quais ocorreram ITU, as amostras de urina para determinação de BM, foram coletadas novamente: no mínimo 14 dias após o termino da antibioticoterapia e com urocultura negativa confirmada. 
O grupo-controle seguiu o mesmo cronograma do grupo-paciente, com exceção da coleta de sangue que ocorria ao nascer (do cordão umbilical), entre o $3^{\circ}$ e $7^{\circ}$ dia, no $6^{\circ}$ e $12^{\circ}$ mês de vida. USG foi realizada na primeira semana e aos 12 meses de vida.

Dados complementares foram obtidos a partir das informações dos prontuários: IG ao diagnóstico de uropatia por USG e ao nascimento, sexo, peso e comprimento do nascimento, Apgar no $1^{\circ}$ e $5^{\circ}$ minuto, intercorrências da gestação e perinatais, dados antropométricos durante o seguimento (peso, estatura), pressão arterial, descrição das cirurgias, dos exames radiológicos etc.

\subsection{Decisão cirúrgica e definição da injúria renal}

Não há padrão ouro para o diagnóstico de obstrução renal em crianças. $O$ diagnóstico atualmente é feito com base no conjunto de dados de imagem que inclui USG seriada de rins e vias urinárias, RE-DMSA (\% da função em separado) e/ou RD-DTPA${ }^{99 \mathrm{~m}} \mathrm{Tc}$ com diurético repetidos $\left(\mathrm{T}_{1 / 2}\right.$ de drenagem maior ou igual a 20 min e curva de "wash $o u t$ " na fase diurética com padrão obstrutivo) e UCM, no caso de OTUB, comparando as alterações durante o seguimento. A decisão cirúrgica, neste estudo, foi tomada na base das recomendações atuais da estratificação do risco para deterioração da função renal em $\mathrm{UOC}^{8,22}$. Os mesmos critérios, junto com parâmetros clínico-laboratoriais convencionais (e.g. aumento do nível de $\mathrm{CrS}^{75}$, RFG, presença de microalbuminúria ou acidose tubular renal) foram usados para definir a lesão renal estabelecida.

$\mathrm{O}$ RFG de CyC e CrS foi estimado através das formulas consideradas adequadas para o uso em lactentes abaixo de um ano de idade: $\mathrm{RFGe}_{\mathrm{CyC}}=70,69 \times([\mathrm{CyCs}])^{-0,931} \mathrm{e}$ $\mathrm{RFGe}_{\mathrm{CrS}}=\mathrm{k} \times$ estatura/[CrS] $(\mathrm{k}=0,33$ para $\mathrm{RN}$ pequenos para $\mathrm{IG}, \mathrm{k}=0,45$ para $\mathrm{RN}$ termos e adequados para IG), respectivamente ${ }^{76}$.

Para comparação correta dos valores de $\mathrm{RFGe}_{\mathrm{CyC}}$ com os valores de referência já reportados, porém obtidos através do método nefelométrico ou turbidimetrico ${ }^{34,77}$, foi necessário aplicar o fator de normalização de 0,66 uma vez que neste estudo a analise da CyC foi realizada por ELISA. Assim, a formula final aplicada para estimar o RFG por $\mathrm{CyCs}^{35,78}$ foi: $\mathrm{RFGe}_{\mathrm{CyC}}=70,69 \times(0,66 \times[\mathrm{CyCs}])^{-0,931}$. 


\subsection{Análise dos biomarcadores renais séricos}

As amostras de sangue, para mensuração de $\mathrm{CyCs}$ e $\mathrm{CrS}$, foram coletadas conforme o cronograma, utilizando $1 \mathrm{~mL}$ de sangue venoso. Até 30 min após a punção, o sangue foi centrifugado a $3000 \mathrm{rpm}$ por $10 \mathrm{~min}$ (centrifuga Sorvall ${ }^{\circledR}$, modelo rt6000b, Thermo Fischer Scientific, Waltham, MA, USA) para obter o soro, que foi aliquotado e armazenado no freezer sob temperatura de -70 a $-80{ }^{\circ} \mathrm{C}$.

A CyCs foi mensurada utilizando o imunoensaio enzimático quantitativo “sanduiche", Cat. № DSCTC0, Quantikine ${ }^{\circledR}$ ELISA, R\&D Systems Inc., Minneapolis, $M N, U S A^{79}$. A amostra de soro após descongelada, foi diluída com o próprio diluente do Kit ( $20 \mu \mathrm{L}$ soro $+580 \mu \mathrm{L}$ diluente). Conforme as instruções do fabricante, aplica-se 100 $\mu \mathrm{L}$ de diluente em cada poço da placa, e em seguida, $50 \mu \mathrm{L}$ do soro diluído. Após a incubação lavam-se todos os poços (4 ciclos). Em seguida, aplica se $200 \mu \mathrm{L}$ da CyC conjugada e deixa incubar por uma hora. Repetem-se 4 ciclos de lavagem dos poços. Aplica-se $200 \mu \mathrm{L}$ da solução substrato em cada poço e após $30 \mathrm{~min}$ da incubação acrescenta-se $50 \mu \mathrm{L}$ da solução "STOP". Os resultados foram obtidos através do método espectrofotométrico. O limite inferior da detecção (LID) de CyCs pelo método é 553 $\mathrm{ng} / \mathrm{mL}$.

As amostras de CrS, foram analisadas pelo método de reação de Jaffé tamponada sem desproteinização, usando "Siemens Dimension ${ }^{\circledR}$ RxL Max ${ }^{\circledR}$ Integrated Chemistry System, Siemens Healthcare GmbH, Erlangen, Germany”, disponível no laboratório do ICr-HCFMUSP.

\subsection{Análise dos biomarcadores renais urinários}

As amostras de urina foram coletadas na sequência, utilizando o saco coletor. Coletou-se no mínimo $3 \mathrm{~mL}$ de urina, tentando minimizar a contaminação das amostras, mantendo o saco coletor no máximo 30 min sob observação direta, para remoção imediata após a micção obtida. As micções que ocorreram simultaneamente com as evacuações foram desconsideradas e a coleta foi repetida. A coleta foi suspensa em vigência da ITU. 
Amostra de urina foi aliquotada no tubo de polipropileno, centrifugado a $5000 \mathrm{rpm}$ (Eppendorf $^{\circledR}$, modelo 5403, Thermo Fischer Scientific, Waltham, MA, USA) durante 20 min, sob refrigeração a $4{ }^{\circ} \mathrm{C}$, cujo sobrenadante foi separado em tubo de $1,5 \mathrm{~mL}$ $\left(\right.$ Eppendorf $\left.^{\circledR}\right)$ e armazenado no freezer com gerador sob temperatura de -70 a $-80{ }^{\circ} \mathrm{C}$, conforme as instruções do fabricante dos biomarcadores (R\&D Systems Inc, Minneapolis, $M N, U S A)$.

\subsubsection{Processamento da NGAL}

A NGAL foi mensurada através de "Human Lipocalin-2/NGAL Immunoassay" Cat. $\mathrm{N}^{\mathrm{o}}$ DLCN20, Quantikine ${ }^{\circledR}$ ELISA, R\&D Systems Inc., Minneapolis, MN, USA ${ }^{80}$. De acordo com as instruções do fabricante, aplicam-se em cada poço da placa $100 \mu \mathrm{L}$ de diluente e $50 \mu \mathrm{L}$ de urina ou solução padrão, incubando por 2 horas. Realiza-se lavagem dos poços (4 ciclos). Aplica-se $200 \mu \mathrm{L}$ de Lipocalina conjugada e deixa incubar por mais 2 horas. Repete-se lavagem (4 ciclos). Aplica-se $200 \mu \mathrm{L}$ da solução substrato em cada poço e após 30 min acrescenta-se $50 \mu \mathrm{L}$ da solução "STOP". O LID da NGAL é 0,4 $\mathrm{ng} / \mathrm{mL}$ pelo método.

\subsubsection{Processamento da KIM-1}

KIM-1 foi mensurada utilizando o imunoensaio enzimático quantitativo "sanduiche": "Human KIM-1 Sandwich ELISA" Cat. No DY1750, Quantikine ${ }^{\circledR}$ ELISA, R\&D Systems Inc., Minneapolis, MN, USA ${ }^{81}$. De acordo com as instruções do fabricante, aplicam-se em cada poço da placa $100 \mu \mathrm{L}$ de diluente e $50 \mu \mathrm{L}$ de urina ou solução padrão, incubando por 2 horas. Realiza-se lavagem dos poços (4 ciclos). Aplica-se $200 \mu \mathrm{L}$ do KIM-1 conjugado e deixa incubar por mais 2 horas. Repete-se lavagem (4 ciclos). Aplicase $200 \mu \mathrm{L}$ da solução substrato em cada poço e após 30 min acrescenta-se $50 \mu \mathrm{L}$ da solução “STOP”. O LID de KIM-1 é 0,156 ng/mL. 


\subsubsection{Processamento de TGF- $\beta 1$}

TGF-ß1 foi mensurado através de "Human TGF- $\beta 1$ Immunoassay" Cat. $\mathrm{N}^{\mathrm{o}}$ DB100B, Quantikine ${ }^{\circledR}$ ELISA, R\&D Systems Inc, Minneapolis, MN, USA ${ }^{82}$. De acordo com as instruções do fabricante, é necessário inicialmente ativar a amostra de urina com TGF- $\beta 1$ utilizando reagente HEPES (não é incluído no KIT, necessitou da compra separada). Após a ativação, aplica-se $50 \mu \mathrm{L}$ de diluente em cada poço da placa, e mais 50 $\mu \mathrm{L}$ de amostra ativada e controle padrão. Após a lavagem dos poços, aplica-se $100 \mu \mathrm{L}$ de TGF- $\beta 1$ conjugado em cada poço. Após mais 5 séries de lavagem, aplica-se $100 \mu \mathrm{L}$ de solução substrato, incubando 30 min e mais $100 \mu \mathrm{L}$ de solução "STOP”. O LID de TGF$\beta 1$ é $15,15 \mathrm{pg} / \mathrm{mL}$.

\subsubsection{Processamento da RBP}

A RBP foi mensurada através do imunoensaio enzimático quantitativo "sanduiche": “Human RBP4 Sandwich ELISA" Cat. № DRB400, Quantikine ${ }^{\circledR}$ ELISA, R\&D Systems Inc., Minneapolis, MN, USA ${ }^{83}$. De acordo com as instruções do fabricante, amostra de urina necessita da diluição de 5 vezes $(100 \mu \mathrm{L}$ de amostra $+400 \mu \mathrm{L}$ de diluente). Aplicase $200 \mu \mathrm{L}$ de diluente em cada poço e mais $20 \mu \mathrm{L}$ de amostra previamente diluída 5 vezes e deixa-se no "shaker" horizontal $(500 \mathrm{rpm})$ por uma hora. Em seguida lavam-se os poços - 3 ciclos. Preenchem-se os poços com $200 \mu \mathrm{L}$ de RBP conjugado e mantem-se mais uma hora no "shaker". Novamente se repete lavagem dos poços (3 ciclos), em seguida, aplicase $200 \mu \mathrm{L}$ de solução substrato e procede-se à incubação por $30 \mathrm{~min}$. Em sequência, preenche-se com $50 \mu \mathrm{L}$ da solução “STOP”. O LID de RBP urinária é 1,56 ng/mL.

\subsubsection{Processamento da CyC urinária}

Foi mensurada utilizando o imunoensaio enzimático quantitativo "sanduiche": Cat. $\mathrm{N}^{\mathrm{o}}$ DSCTC0, Quantikine ${ }^{\circledR}$ ELISA, R\&D Systems Inc., Minneapolis, MN, USA ${ }^{79}$. Conforme as instruções do fabricante, aplica-se $100 \mu \mathrm{L}$ de diluente em cada poço da placa, e em seguida $50 \mu \mathrm{L}$ da urina descongelada. Após incubação lavam-se todos os poços (4 ciclos). Em seguida aplica-se $200 \mu \mathrm{L}$ da CyC conjugada e deixa-se incubar por 
uma hora. Repete-se 4 ciclos de lavagem dos poços. Aplica-se $200 \mu \mathrm{L}$ da solução substrato em cada poço e após $30 \mathrm{~min}$ da incubação acrescenta-se $50 \mu \mathrm{L}$ da solução “STOP”. O LID da CyCu é 3,13 ng/mL.

\subsubsection{Processamento de $\mu \mathrm{ALB}$, creatinina urinária e normalização dos biomarcadores}

Creatinina na urina $(\mathrm{CrU})$, da mesma forma como $\mathrm{CrS}$, foi analisada pelo método de reação de Jaffé tamponada sem desproteinização, usando "Siemens Dimension ${ }^{\circledR} R x L$ Max ${ }^{\circledR}$ Integrated Chemistry System, Siemens Healthcare GmbH, Erlangen, Germany”. Amostras para analise bioquímica e $\mu \mathrm{ALB}$ foram processadas no analisador químico “Roche Cobas C501 ${ }^{\circledR}$, Roche Diagnostics, Indianapolis, IN, USA” pelo método nefelométrico, disponível no laboratório do ICr-HCFMUSP. $\mu$ ALB foi dosada em relação à excreção urinária de $\mathrm{Cr}$ com valor considerado alterado quando acima de $30 \mathrm{mg} / \mathrm{g} \mathrm{CrU}$.

Todas as dosagens de biomarcadores foram realizadas em duplicata. Os resultados foram normalizados aos valores da $\mathrm{CrU}$ e apresentados em unidade de biomarcador respectivo por mg de $\mathrm{Cr}$. O coeficiente permitido de variação intra e interensaio para NGAL, RBP, CyC, KIM-1 e TGF- $\beta 1$ foi de até $10 \%$.

\subsection{Análise estatística}

Os dados foram expressos através de frequências absolutas e percentuais para as variáveis categóricas e das medidas estatísticas: média, desvio padrão, mediana e quartis para as variáveis numéricas. Para a comparação entre os grupos ou subgrupos em relação às variáveis categóricas foram utilizados os testes estatísticos Qui-quadrado de Pearson ou Exato de Fisher quando a condição para utilização do teste Qui-quadrado não foi verificada. Para as variáveis numéricas foram utilizados testes t-Student com variâncias iguais, t-Student com variâncias desiguais ou Mann-Whitney na comparação entre os grupos e F (ANOVA) ou Kruskal-Walis na comparação entre os subgrupos no grupo dos pacientes. No caso de diferenças significativas pelo teste de Kruskal-Wallis foram realizadas comparações múltiplas de Tukey (quando foi comprovada igualdade de 
variâncias) ou de Tamanhe (quando a igualdade de variâncias foi rejeitada). Ressalta-se que a escolhas dos testes t-Student e F (ANOVA) ocorreram nas situações em que foi verificada a normalidade dos dados e os testes Mann-Whitney e Kruskal-Wallis nos casos em que a hipótese de normalidade dos dados foi rejeitada. A verificação da hipótese de normalidade foi realizada através do teste Shapiro-Wilk e a igualdade de variâncias através do teste $\mathrm{F}$ de Levene.

Para avaliar o grau de discriminação dos desfechos foram obtidas curvas ROC e área sob a curva com respectivo intervalo de confiança para o citado parâmetro e pontos de corte que maximizam o valor da soma da sensibilidade e especificidade. Para detecção da lesão renal os resultados foram comparados com o conjunto de parâmetros clínicoslaboratoriais e radiológicos (US/DMSA) utilizados tradicionalmente. Em relação a indicação cirúrgica foram utilizados os critérios recomendados na literatura mais recente, que se baseiam nos parâmetros radiológicos (US/DTPA) em conjunto com dados clínicolaboratoriais ${ }^{8,71}$.

Todas as hipóteses testadas são bicaudais. A margem de erro utilizada nas decisões dos testes estatísticos foi de 5\% e os intervalos foram obtidos com 95,0\% de confiança. Os dados foram digitados na planilha EXCEL e os programas utilizados para obtenção dos cálculos estatísticos foram o SPSS ${ }^{\circledR}$ na versão 24 (Statistical Package for the Social Sciences, IBM ${ }^{\circledR}$, USA, 2016) e MedCalc ${ }^{\circledR}$ na versão 14.8.1 (MedCalc Software, Ostend, Belgium, 2014) e GraphPad Prism ${ }^{\circledR}$ na versão 7 (GraphPad Software, La Jolla, CA, USA, 2017). 
RESULTADOS 


\section{RESULTADOS}

\subsection{Dados demográficos e características dos participantes do estudo}

Todos os participantes do estudo foram recrutados no período entre junho de 2012 até junho de 2016 (Figura 1). Não foram encontradas diferenças significativas entre o grupo dos pacientes e grupo-controle em relação ao sexo, IG, peso e comprimento do nascimento e aos 12 meses de vida, etnia, escore de APGAR e pressão arterial (Tabela 2), com exceção do grupo-OTUB, que apresentava apenas participantes do sexo masculino.
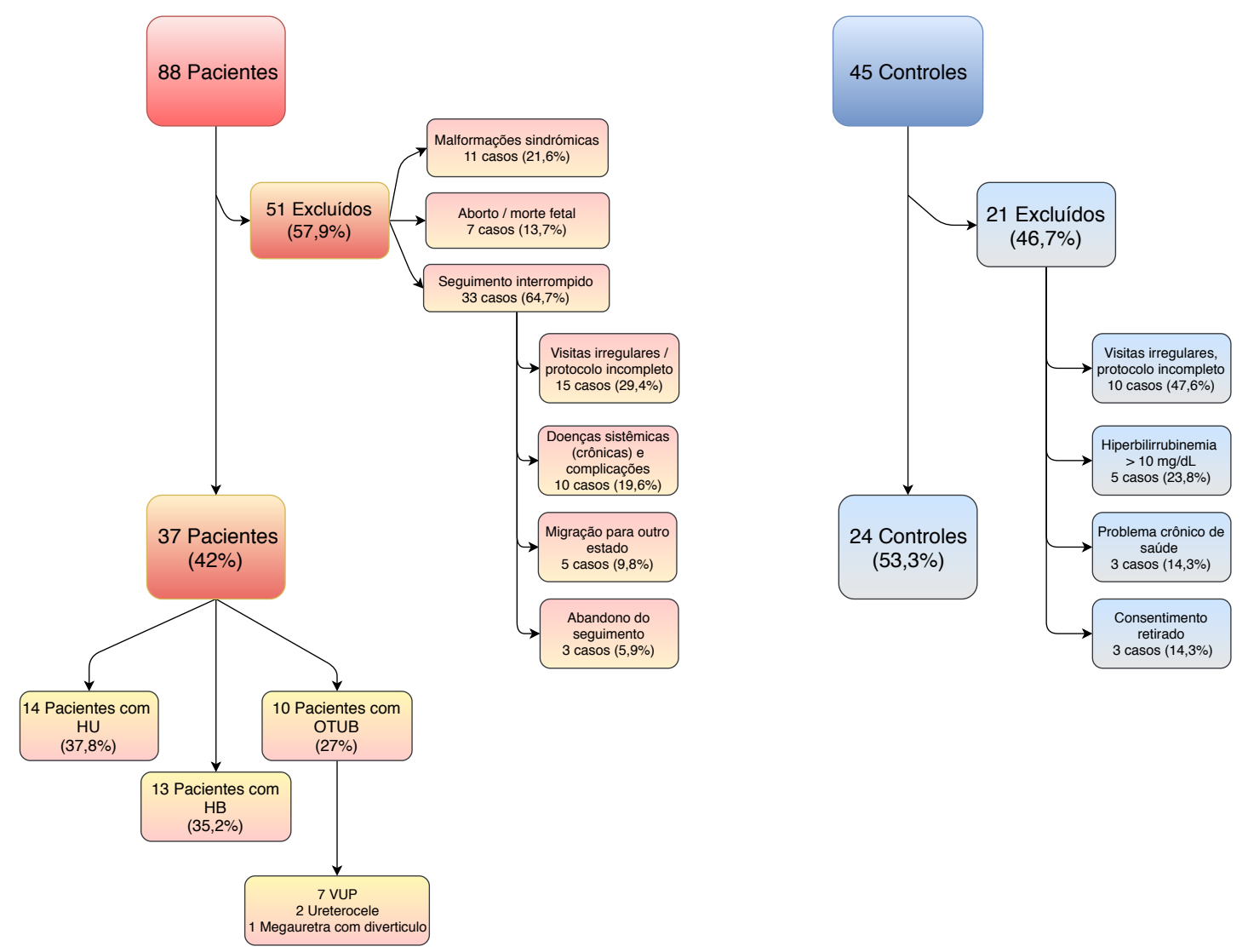

Figura 1 - Dinâmica de recrutamento dos controles saudáveis e dos pacientes, no período de junho 2012 a junho 2016

HU: hidro(uretero)nefrose unilateral; HB: hidro(uretero)nefrose bilateral; OTUB: obstrução do trato urinário baixo. 
Tabela 2 - Características demográficas, medidas antropométricas e valores da pressão arterial durante o seguimento no primeiro ano de vida dos pacientes com UOC e do grupocontrole

\begin{tabular}{|c|c|c|c|}
\hline Características da coorte & $\begin{array}{l}\text { Pacientes } \\
n=37\end{array}$ & $\begin{array}{l}\text { Controles } \\
n=24\end{array}$ & valor $p$ \\
\hline Idade materna (anos) $)^{\llbracket}$ & $28,1 \pm 6,2$ & $30,5 \pm 4,7$ & $\mathrm{p}=0,13^{1}$ \\
\hline Masculino & $29(78,4 \%)$ & $14(58,3 \%)$ & $\mathrm{p}=0,094^{1, *}$ \\
\hline Feminino & $8(21,6 \%)$ & $10(41,7 \%)$ & \\
\hline \multicolumn{4}{|l|}{ Etnia } \\
\hline pardo e negro & $19(51,3 \%)$ & $12(50 \%)$ & $\mathrm{p}=0,373^{1}$ \\
\hline branco & $18(48,6 \%)$ & $12(50 \%)$ & \\
\hline Idade gestacional (semanas) & $38,1 \pm 2.4$ & $38,9 \pm 1,4$ & $p=0,734^{3}$ \\
\hline \multicolumn{4}{|l|}{ Classificação do RN pela IG $^{84}$} \\
\hline AIG & $28(75,7 \%)$ & $21(87,5 \%)$ & $\mathrm{p}=0,233^{2}$ \\
\hline PIG & $2(5,4 \%)$ & $2(8,3 \%)$ & \\
\hline GIG & $7(18,9 \%)$ & $1(4,2 \%)$ & \\
\hline \multicolumn{4}{|l|}{$\begin{array}{l}\text { Classificação do RN pelo peso do } \\
\text { nascimento }^{84}\end{array}$} \\
\hline peso normal & $33(89,2 \%)$ & $22(91,7 \%)$ & $\mathrm{p}=1,00^{2}$ \\
\hline baixo peso & $3(8,1 \%)$ & $1(4,2 \%)$ & \\
\hline macrossomico & $1(2,7 \%)$ & $1(4,2 \%)$ & \\
\hline Peso do nascimento $(\mathrm{g})^{\pi}$ & $3177,5 \pm 613,5$ & $3105 \pm 401,5$ & $\mathrm{p}=1,00^{3}$ \\
\hline Peso aos 12 meses $(\mathrm{g})^{\natural}$ & $9805 \pm 1210^{\dagger, 3}$ & $9590 \pm 1080$ & $\mathrm{p}=0,48^{3}$ \\
\hline Comprimento ao nascimento $(\mathrm{cm})^{\pi}$ & $47,9 \pm 2,8$ & $48,0 \pm 1,6$ & $p=0,57^{3}$ \\
\hline Comprimento aos 12 meses $(\mathrm{cm})^{\pi}$ & $75,0 \pm 2,3^{\S, 3}$ & $75,1 \pm 2,3$ & $\mathrm{p}=0,98^{3}$ \\
\hline $\begin{array}{l}\text { Pressão arterial sistólica } \\
\text { aos } 12 \text { meses }(\mathrm{mmHg})^{\natural}\end{array}$ & $92,3 \pm 10,2$ & $89 \pm 5,7$ & $\mathrm{p}=0,42^{3}$ \\
\hline $\begin{array}{l}\text { Pressão arterial diastólica } \\
\qquad \text { aos } 12 \text { meses }(\mathrm{mmHg})^{\natural}\end{array}$ & $59,7 \pm 8,3$ & $50 \pm 7,1$ & $\mathrm{p}=0,78^{3}$ \\
\hline
\end{tabular}

${ }^{\natural}$ média \pm desvio padrão. ${ }^{*}$ no subgrupo OTUB não houveram pacientes com sexo feminino. ${ }^{\dagger}$ no subgrupo HB, do nascimento até 2 meses de vida completos, $\mathrm{p}=0,024$; no subgrupo OTUB do $1^{\circ}$ mês até 2 meses de vida completos, $\mathrm{p}=0,034 .{ }^{\S}$ no subgrupo OTUB, do $1^{\circ}$ mês até 3 meses de vida completos, $\mathrm{p}=0,037$.

${ }^{1}$ verificado através do teste Qui-quadrado de Pearson. Significância estatística em $\mathrm{p}<0,05$.

${ }^{2}$ verificado através do teste exato de Fisher. Significância estatística em $\mathrm{p}<0,05$.

${ }^{3}$ verificado através do teste t-Student com variâncias iguais. Significância estatística em $\mathrm{p}<0,05$.

AIG: adequado para IG; PIG: pequeno para IG; GIG: grande para IG; IG: idade gestacional; RN: recémnascido; OTUB: obstrução do trato urinário baixo; HB: hidro(uretero)nefrose bilateral.

A comparação do peso e da estatura entre os subgrupos, ao longo do período observacional (Figura 2), demonstrou perda significativa de peso, nos primeiros dois meses no subgrupo HB e três meses no OTUB em relação aos grupos controle e HU. No 
mesmo período de observação verificou-se perda de canais de crescimento no grupo OTUB em relação aos demais participantes. Ao final de 12 meses de observação, não se verificou diferença significativa entre peso e estatura final entre os subgrupos de participantes.
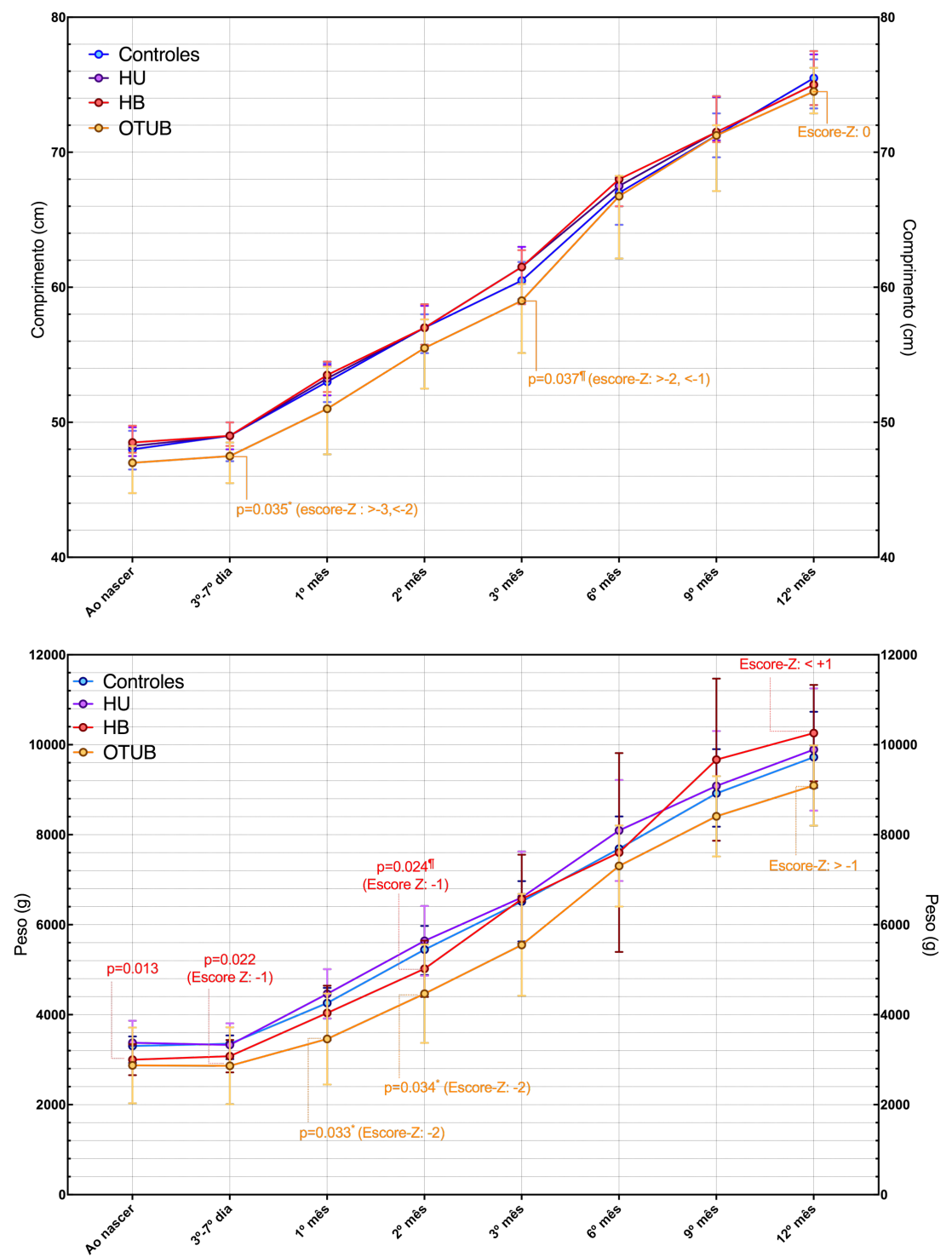

Figura 2 - Peso e estatura do grupo controle e subgrupos com HU, HB e OTUB, durante o primeiro ano de vida, apresentados como média com desvio padrão

HU: hidro(uretero)nefrose unilateral, OTUB: obstrução do trato urinário baixo; HB: hidro(uretero)nefrose bilateral. Significância estatística entre os valores dos subgrupos e o grupo-controle foi verificada através do teste ${ }^{*}$ t-Student e o teste "Mann-Whitney, com significância em $\mathrm{p}<0,05$. 


\subsection{Grupo-controle: o perfil dos biomarcadores renais}

O grupo controle constituiu-se de 24 lactentes saudáveis, e é caracterizado pela distribuição homogênea de sexo (58,3\% masculino, 47,1\% feminino), etnia, idade gestacional, parâmetros antropométricos e pressão arterial sistêmica. Apenas 1/24 mães que participaram relataram tabagismo antes de engravidar. Durante a gestação 4/24 $(16,7 \%)$ informaram o uso de cefalexina de curta duração, $2 / 24(8,3 \%)$ necessitaram de medicação anti-hipertensiva para controle de níveis pressóricos. 6/24 (25\%) relataram o uso de apenas um dos seguintes medicamentos: levotiroxina, metronidazol, insulina e cloroquina. Não houve relato de outras intercorrências gestacionais. Todos os RN registraram no mínimo 8 na escala de APGAR no $1^{\circ}$ min, e 18/24 (75\%) alcançaram 10 no $5^{\circ}$ min de vida. Durante o acompanhamento clínico, os lactentes não apresentaram maiores intercorrências, com exceção de 3 casos (14,3\%), que desenvolveram problemas crônicos de saúde, e foram subsequentemente excluídos do estudo. Durante o período de observação, todos apresentaram parâmetros normais da função glomerular e tubular, com achados da USG renal sem anormalidades. A Figura 3 mostra o perfil dos valores séricos de $\mathrm{CrS}$ e CyCs e dos RFGe correspondentes, durante o primeiro ano de vida, no grupo controle.
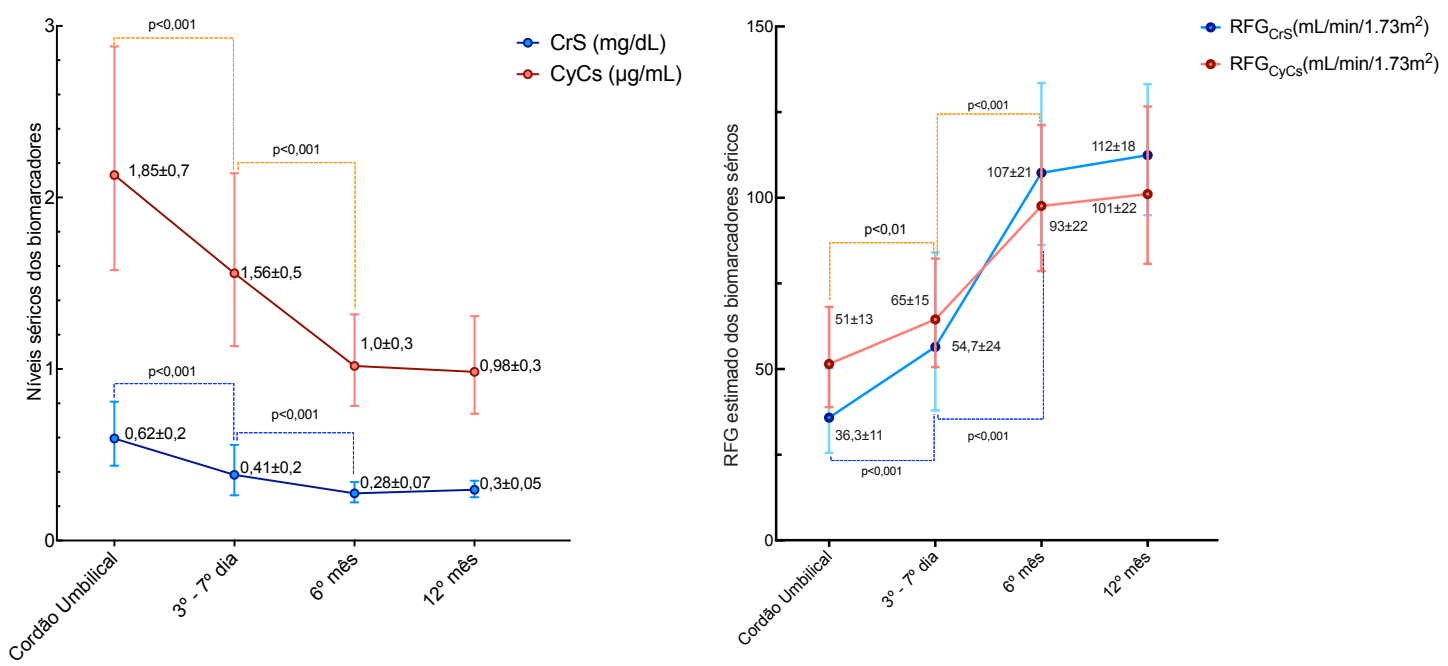

Figura 3 - Análise comparativa do perfil dos valores séricos de $\mathrm{CrS}$ e $\mathrm{CyCs}$ e dos RFGe correspondentes, apresentados como média e desvio padrão, nos primeiros 12 meses de vida, no grupo controle

* Significância estatística em relação ao valor da medida anterior (através do teste t-Student, p $<0,05)$. CrS: creatinina sérica; CyCs: cistatina $\mathrm{C}$ sérica; RFG: ritmo de filtração glomerular. 
O perfil dos valores de biomarcadores renais urinários durante o primeiro ano de vida no grupo controle, encontram-se na Figura 4.

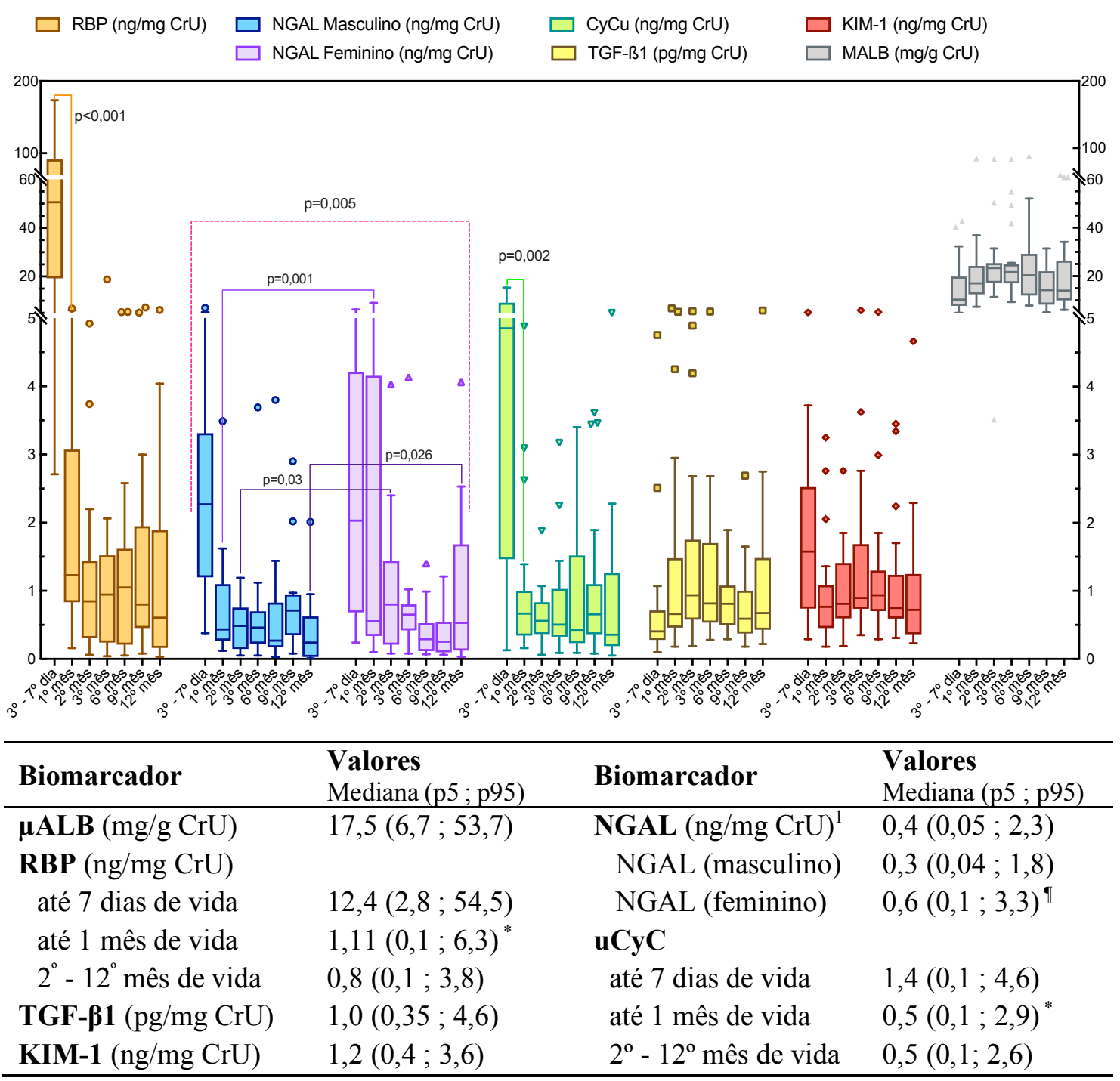

Figura 4 - Análise comparativa do perfil de valores dos biomarcadores renais urinários ( $\mu$ ALB, RBP, TGF- $\beta 1$, KIM-1, NGAL e CyCu), descritos como mediana (p5 ; p95), durante o primeiro ano de vida no grupo controle

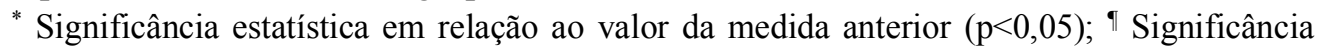
estatística entre os valores do sexo masculino e feminino durante o primeiro ano de vida $(\mathrm{p}<0,05) ;{ }^{1}$ Todos os pacientes (sexo masculino e feminino).

Os valores são apresentados como mediana e $(5 ; 95)$ percentis, verificados através do teste tStudent. Os valores com as variâncias desiguais foram confirmados através do teste MannWhitney, com significância em $\mathrm{p}<0,05$.

RBP: proteína ligadora de retinol; NGAL: lipocalina associada à gelatinase neutrofílica; $\mu \mathrm{ALB}$ : microalbuminúria; $\mathrm{CyCu}$ : cistatina $\mathrm{C}$ na urina; KIM-1: molécula de injúria renal-1; TGF-ß1: fator transformador de crescimento-beta 1; CrU: creatinina na urina. 


\subsection{Grupo-pacientes: lesão renal e perfil dos biomarcadores renais}

No grupo de 37 pacientes, os diagnósticos pré e pós-natais, complicações e procedimentos realizados durante o seguimento são apresentados na Tabela 3.

Tabela 3 - Diagnóstico pré e pós-natal, complicações e procedimentos no grupo e nos subgrupos de pacientes com HU, HB e OTUB

\begin{tabular}{|c|c|c|c|c|}
\hline Parâmetro & $\begin{array}{c}\mathbf{H U} \\
n(\%)\end{array}$ & $\begin{array}{c}\text { HB } \\
n(\%)\end{array}$ & $\begin{array}{c}\text { OTUB } \\
n(\%) \\
\end{array}$ & $\begin{array}{l}\text { Todos } \\
n(\%) \\
\end{array}$ \\
\hline Diagnóstico fetal & 15 & 12 & 10 & 37 \\
\hline $\begin{array}{l}\text { Diagnóstico } \\
\text { pós-natal }\end{array}$ & $14(100 \%)$ & $13(100 \%)$ & $10(100 \%)$ & $37(100 \%)$ \\
\hline estenose de JUP & $12(85,7 \%)$ & $10(76,9 \%)$ & - & $22(59,5 \%)$ \\
\hline estenose de JUV & $2(14,3 \%)$ & $3(23,1 \%)$ & - & $5(13,5 \%)$ \\
\hline VUP & - & - & $7(70 \%)$ & $7(18,9 \%)$ \\
\hline outros & - & - & $3(30 \%)$ & $3(8,1 \%)$ \\
\hline \multicolumn{5}{|l|}{ DAP classificação } \\
\hline HN ausente & - & - & $1(10 \%)$ & $1(2,7 \%)$ \\
\hline grau III & $10(71,4 \%)$ & $6(46,2 \%)$ & $1(10 \%)$ & $17(45,9 \%)$ \\
\hline grau IV & $2(14,3 \%)$ & $6(46,2 \%)$ & $7(70 \%)$ & $15(40,5 \%)$ \\
\hline grau V & $2(14,3 \%)$ & $1(7,7 \%)$ & $1(10 \%)$ & $4(10,8 \%)$ \\
\hline \multicolumn{5}{|l|}{ Complicações } \\
\hline ATR & $4(28,6 \%)$ & $2(15,4 \%)$ & $7(70 \%)$ & $13(35,1 \%)$ \\
\hline $\mathrm{DRC}$ & $1(7,1 \%)$ & - & $7(70 \%)$ & $8(21,6 \%)$ \\
\hline hipercalemia & $1(7,1 \%)$ & $4(30,8 \%)$ & $5(50 \%)$ & $10(27 \%)$ \\
\hline \multicolumn{5}{|l|}{ Procedimentos } \\
\hline nefrectomia ${ }^{*}$ & $1(7,1 \%)$ & $1(7,7 \%)$ & - & $2(5,4 \%)$ \\
\hline pieloplastia & $6(42,8 \%)$ & $6(46,2 \%)$ & $3(30 \%)$ & $15(40,5 \%)$ \\
\hline fulguração & - & - & $7(70 \%)$ & $7(18,9 \%)$ \\
\hline ureterostomia & - & $2(15,4 \%)$ & $2(20 \%)$ & $4(10,8 \%)$ \\
\hline \multicolumn{5}{|l|}{ Período da cirurgia } \\
\hline$<2$ meses & - & $3(23,1 \%)$ & $5(50 \%)$ & $8(21,6 \%)$ \\
\hline 2-12 meses & $5(35,7 \%)$ & $1(7,7 \%)$ & $3(30 \%)$ & $9(24,3 \%)$ \\
\hline$>12$ meses & $3(21,4 \%)$ & $3(23,1 \%)$ & $1(10 \%)$ & $7(18,9 \%)$ \\
\hline
\end{tabular}

${ }^{*}$ todas as nefrectomias foram realizadas após 12 meses completos de vida.

HU: hidro(uretero)nefrose unilateral, OTUB: obstrução do trato urinário baixo; HB: hidro(uretero)nefrose bilateral; HN: hidro(uretero)nefrose; DAP: diâmetro anteroposterior da pelve renal; JUP: junção ureteropiélica; JUV: junção ureterovesical; VUP: válvula de uretra posterior; ATR: acidose tubular renal; DRC: doença renal crônica. 
A USG realizada no primeiro mês de vida revelou sinais da nefropatia parenquimatosa (NP) em 4/14 (28,6\%) dos pacientes do grupo HU, 2/13 (15,4\%) com HB e 2/10 (20\%) com OTUB. Um aumento de 50\% da NP foi identificado por USG realizada aos 6 meses de vida, particularmente nos subgrupos com HU e HB. Aos 12 meses de vida, NP unilateral foi observada em $64,2 \%$ dos pacientes do subgrupo HU, $77 \%$ do $\mathrm{HB}$ e $60 \%$ do OTUB. NP bilateral foi presente em 1/3 dos participantes portadores de HB e OTUB.

RE-DMSA realizada aos 6 meses de vida mostrou cicatrizes renais em 43,2\% dos pacientes, mais frequentemente encontrados e maiores no subgrupo OTUB (50\% com cicatrizes unilaterais e $20 \%$ com bilaterais).

\subsubsection{Desempenho dos biomarcadores em relação a lesão renal}

A análise comparativa dos biomarcadores séricos (CrS e CyCs) e RFGe, entre os grupos e subgrupos, com o respectivo perfil evolutivo ao longo do primeiro ano de vida, são apresentados nas Figuras 5, 6 e 7 e na Tabela 4.

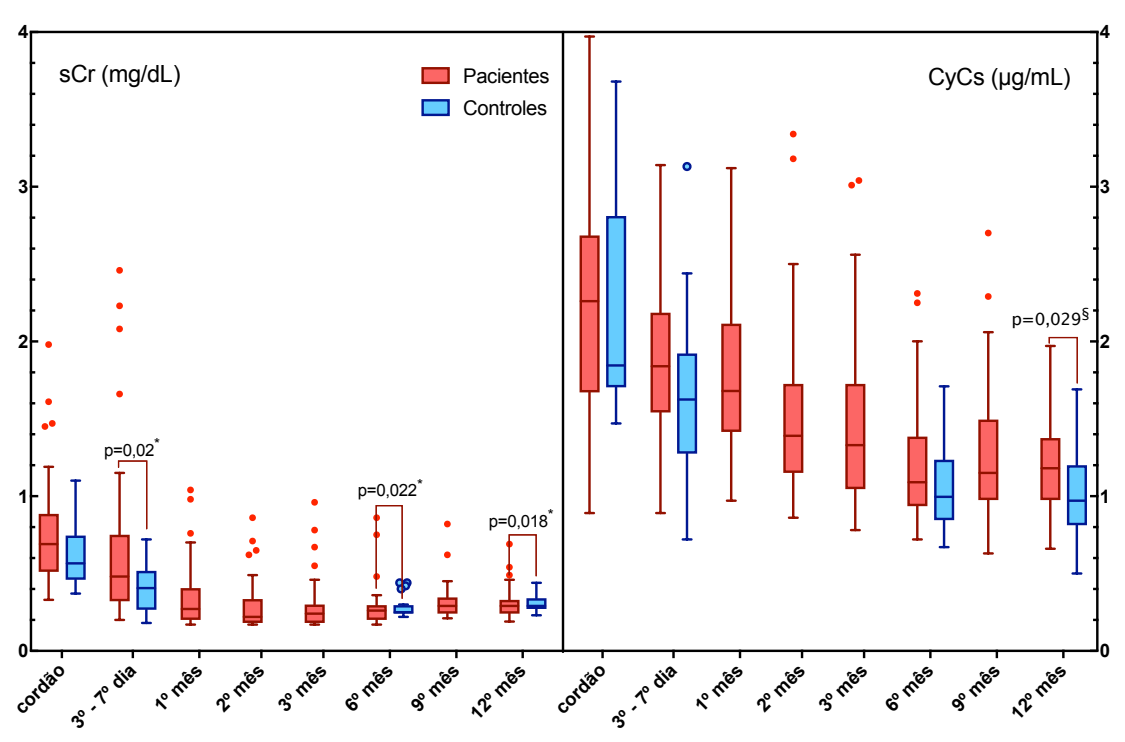

Figura 5 - Análise comparativa dos biomarcadores séricos ( $\mathrm{CrS}$ e $\mathrm{CyCs}$ ), descritos como mediana (p5 ; p95), no primeiro ano de vida entre os grupos controle e pacientes * teste t-Student;

$\S$ teste Mann-Whitney. Valores apresentados como mediana e $(5 ; 95)$ percentis. Significância em $p<0,05$.

CrS: creatinina sérica; $\mathrm{CyCs}$ : cistatina $\mathrm{C}$ sérica. 

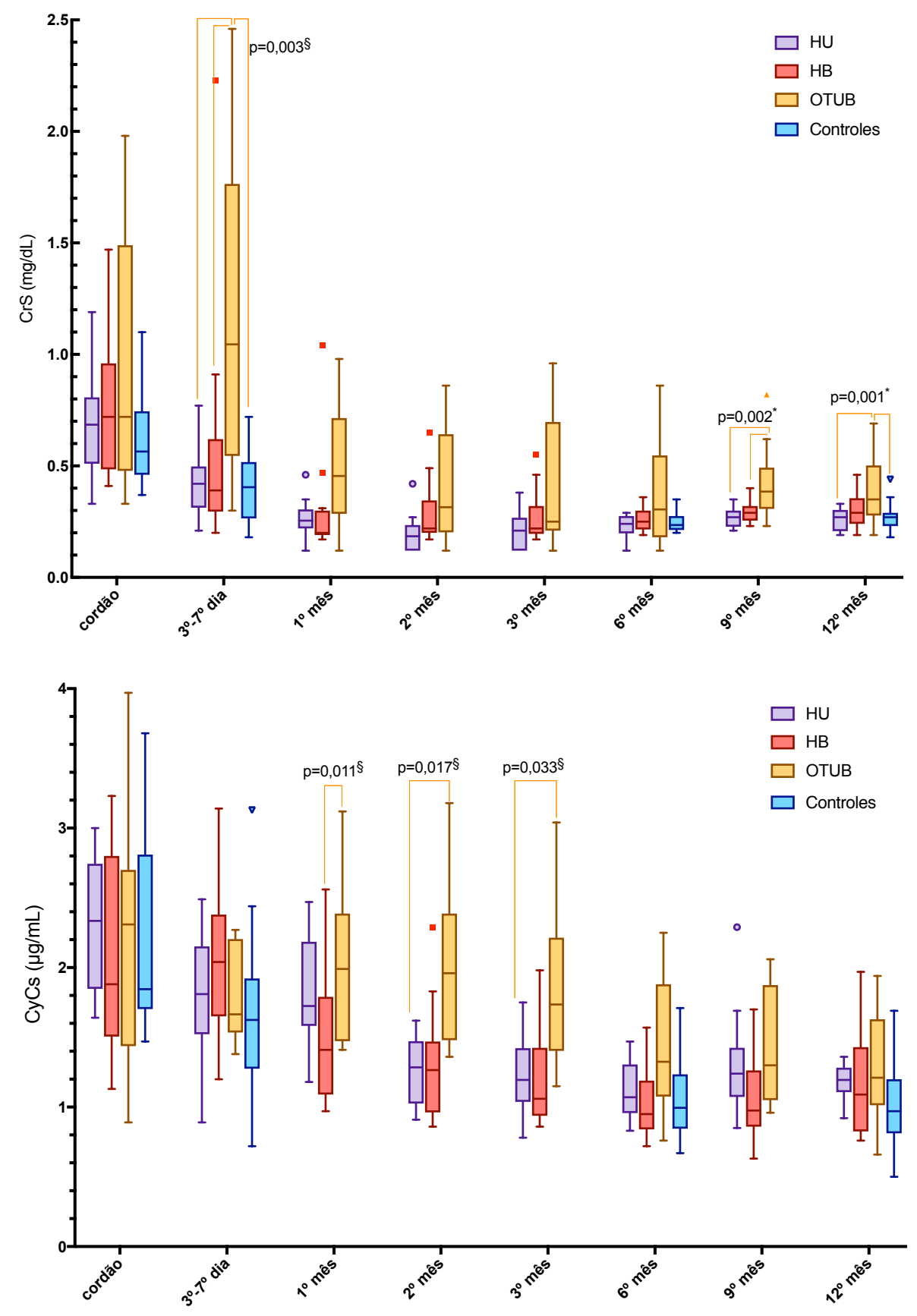

Figura 6 - Análise comparativa dos biomarcadores séricos ( $\mathrm{CrS}$ e CyCs), descritos como mediana (p5; p95), no $1^{\circ}$ ano de vida, entre os grupo controle e subgrupos HU, HB e OTUB

${ }^{*}$ teste H de Kruskal-Wallis.

$\S$ teste F(ANOVA) com comparações múltiplas de Tukey.

Valores apresentados como mediana e $(5 ; 95)$ percentis. Significância em $\mathrm{p}<0,05$.

CrS: creatinina sérica; CyCs: cistatina $\mathrm{C}$ sérica; HU: hidro(uretero)nefrose unilateral; HB: hidro(uretero)nefrose bilateral; OTUB: obstrução do trato urinário baixo. 


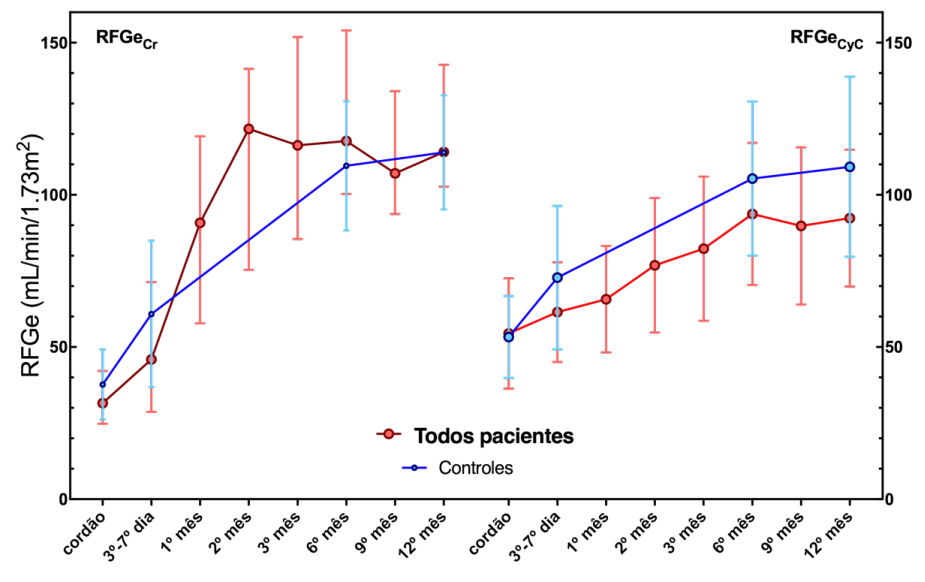

Figura 7 - Análise comparativa do RFGe dos biomarcadores séricos (CrS e CyCs), descritos como mediana (p5 ; p95), no primeiro ano de vida entre o grupo-controle, grupo dos pacientes e subgrupos $\mathrm{HU}, \mathrm{HB}$ e OTUB

Valores apresentados como mediana e $(5 ; 95)$ percentis.

RFGe: ritmo de filtração

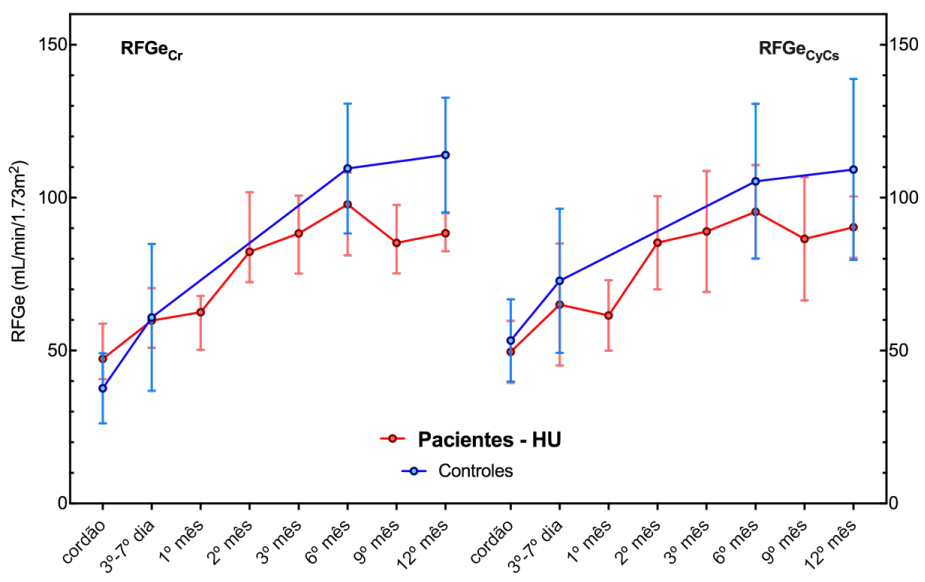
glomerular estimado;

CrS: creatinina sérica; CyCs: cistatina $\mathrm{C}$ sérica;

HU: hidro(uretero)nefrose unilateral;

HB: hidro(uretero)nefrose bilateral;

OTUB: obstrução do trato urinário baixo.
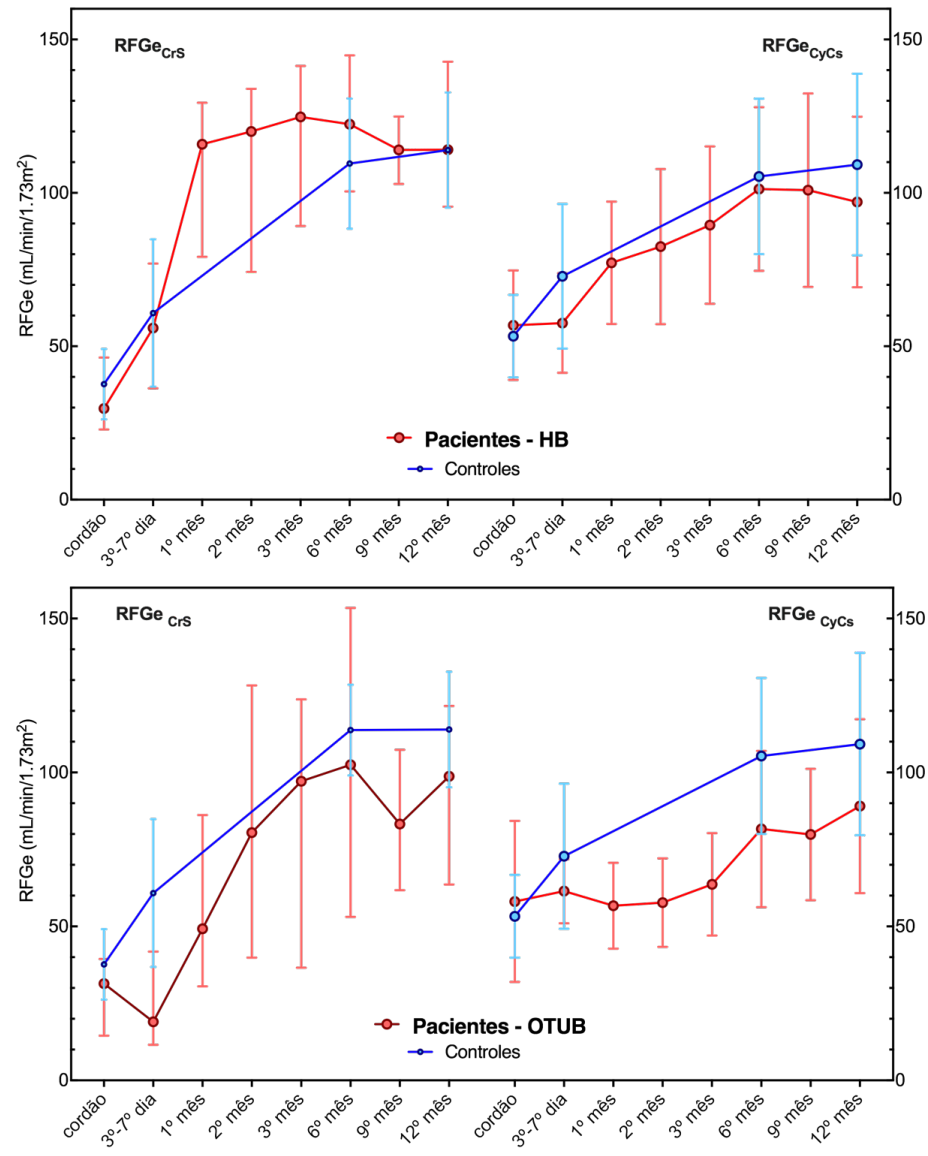
Tabela 4 - Ritmo de filtração glomerular estimado de creatinina sérica e cistatina $C$ sérica no primeiro ano de vida nos subgrupos dos pacientes com UOC e controles saudáveis, apresentados como média com desvio padrão

Creatinina sérica $\left(\mathrm{mL} / \mathrm{min} / 1,73 \mathrm{~m}^{2}\right)$

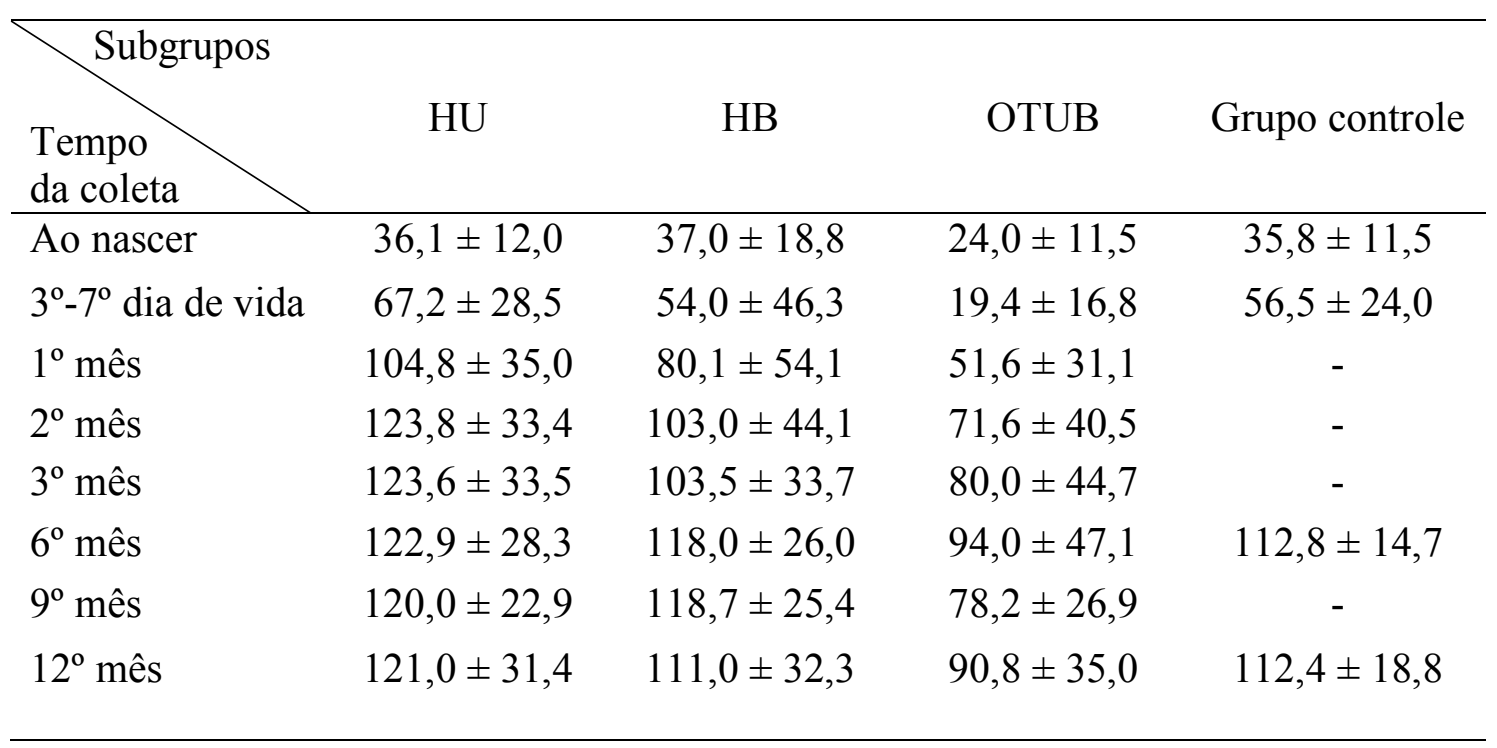

Cistatina C sérica $\left(\mathrm{mL} / \mathrm{min} / 1,73 \mathrm{~m}^{2}\right)$

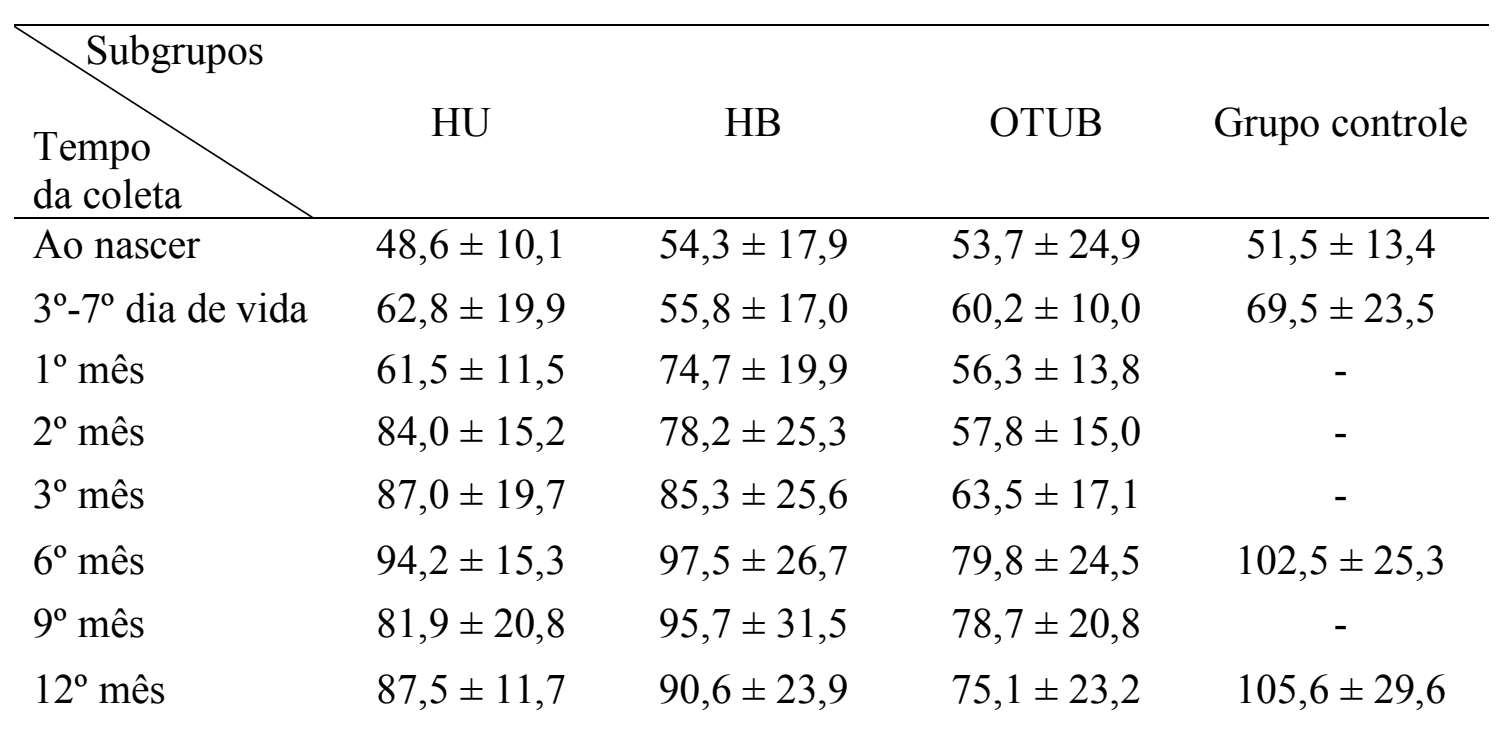

HU: hidro(uretero)nefrose unilateral, OTUB: obstrução do trato urinário baixo;

HB: hidro(uretero)nefrose bilateral; UOC: uropatias obstrutivas congênitas; 
As Figuras 8 e 9 apresentam o perfil dos valores dos biomarcadores renais urinários: RBP, NGAL, CyCu, KIM-1, TGF-ß1 e $\mu \mathrm{ALB}$ ao longo do primeiro ano de vida, nos grupos controle e pacientes e nos subgrupos HU, BH e OTUB.

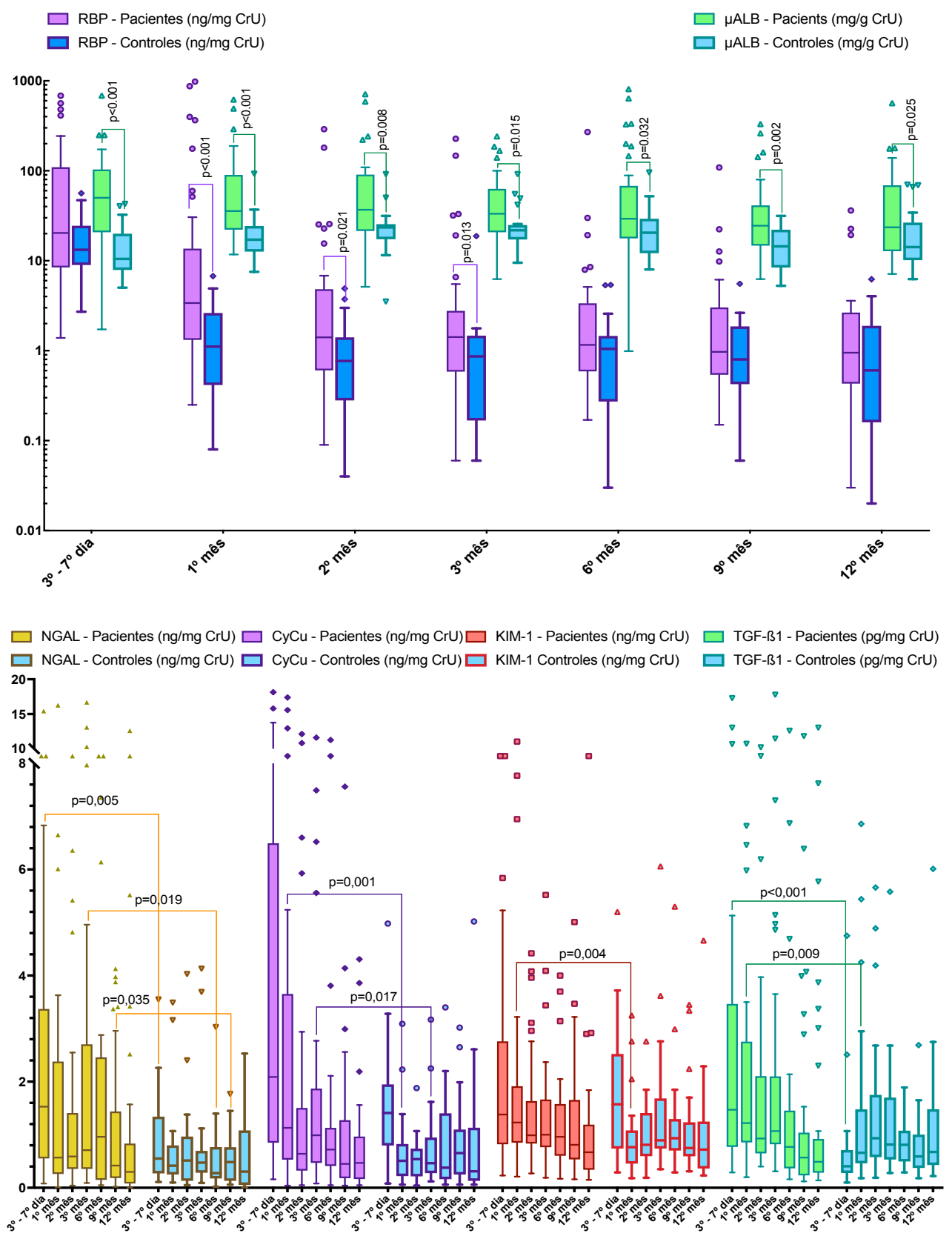

Figura 8 - Análise do perfil dos biomarcadores renais urinários: RBP, NGAL, CyCu, KIM-1, TGF-ß1 e $\mu$ ALB ao longo do primeiro ano de vida, nos grupos controle e pacientes Valores apresentados como mediana e $(5 ; 95)$ percentis. Significância em $\mathrm{p}<0,05$ verificada através do teste Mann-Whitney.

RBP: proteína ligadora de retinol; NGAL: lipocalina associada à gelatinase neutrofílica; $\mu \mathrm{ALB}$ : microalbuminúria; $\mathrm{CyCu}$ : cistatina $\mathrm{C}$ na urina; KIM-1: molécula de injúria renal 1; TGF-ß1: fator transformador de crescimento-beta 1; CrU: creatinina na urina. 

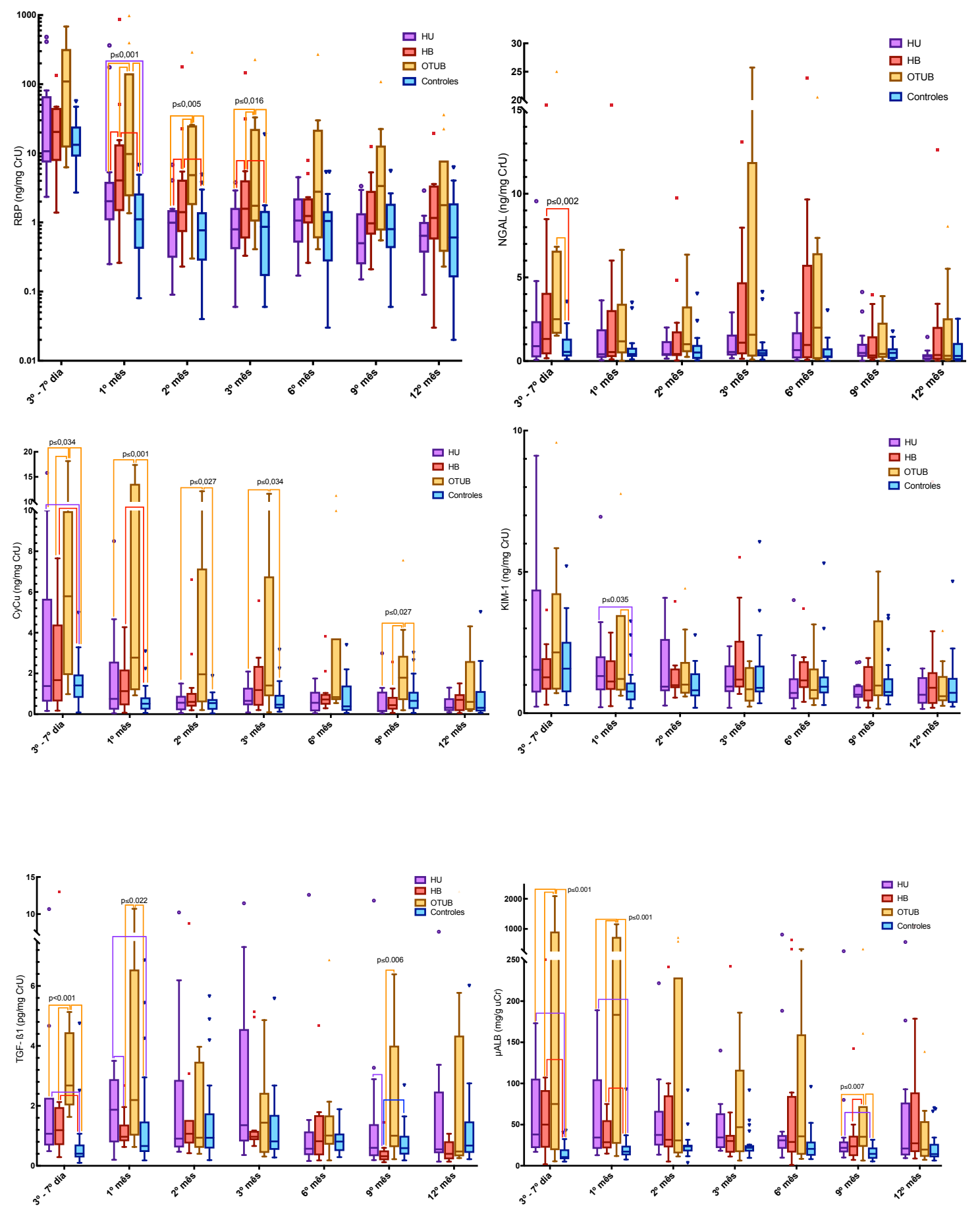

Figura 9 - Análise do perfil dos biomarcadores renais urinários: RBP, NGAL, CyCu, KIM-1, TGF- $\beta 1$ e $\mu$ ALB ao longo do $1^{\circ}$ ano de vida, nos grupos controle e nos subgrupos $\mathrm{HU}$, BH e OTUB

Valores apresentados como mediana e $(5 ; 95)$ percentis. Significância em $p<0,05$, verificada através do teste $\mathrm{H}$ de Kruskal-Wallis. RBP: proteína ligadora de retinol; NGAL: lipocalina associada à gelatinase neutrofílica; $\mu \mathrm{ALB}$ : microalbuminúria; $\mathrm{CyCu}$ : cistatina $\mathrm{C}$ na urina; KIM-1: molécula de injúria renal-1; TGF-ß1: fator transformador de crescimento-beta 1; CrU: creatinina na urina; HU: hidro(uretero)nefrose unilateral; HB: hidro(uretero)nefrose bilateral; OTUB: obstrução do trato urinário baixo. 
A análise das curvas ROC, apresentada na Figura 10 e nas Tabelas 5 e 6, foi empregada para determinação do poder discriminativo dos biomarcadores na identificação da lesão renal ou da sua progressão em pacientes com UOC.

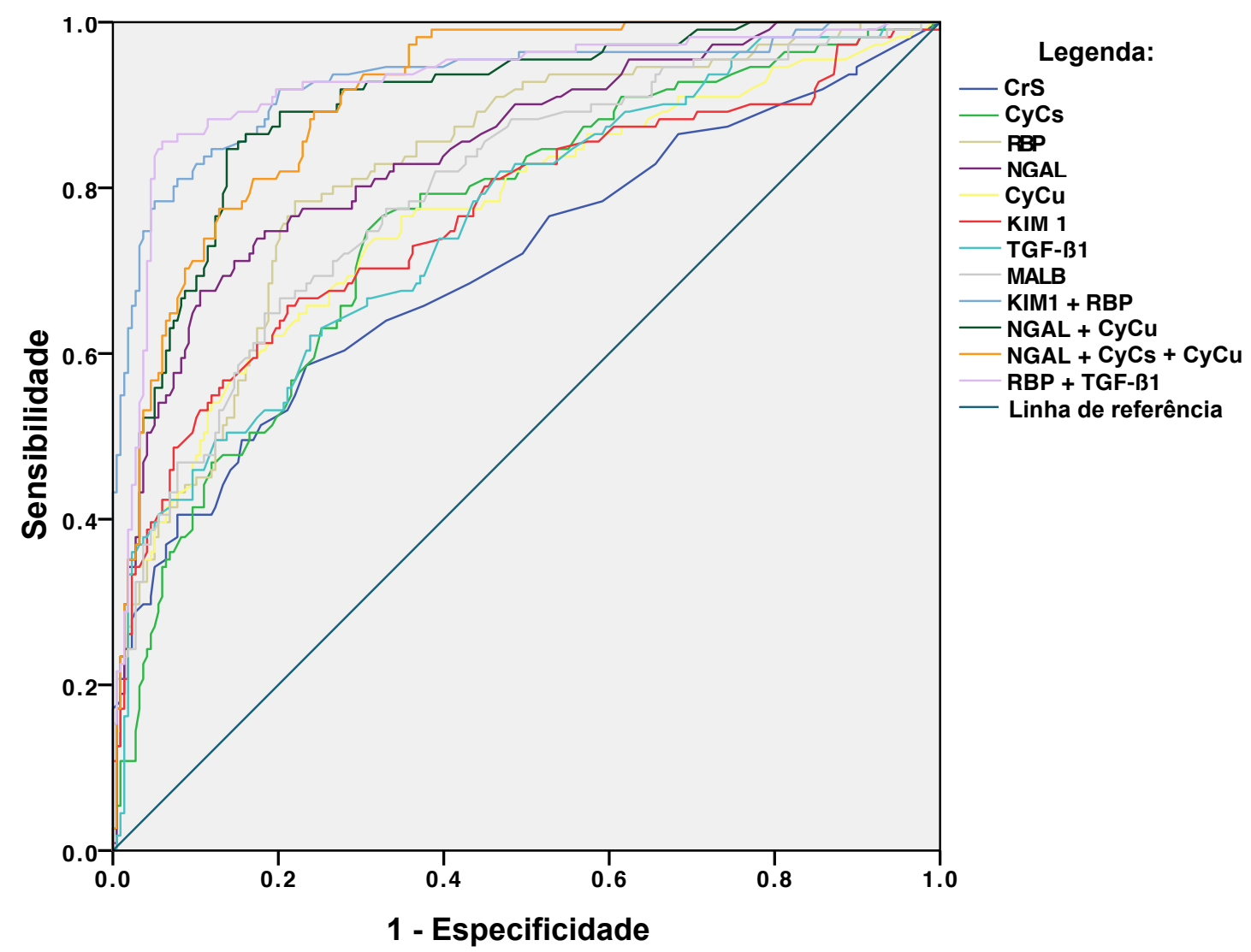

Figura 10 - Análise do poder discriminativo dos biomarcadores renais para identificação da lesão renal ou da sua progressão em UOC no primeiro ano de vida através de curvas ROC ROC: „receiver operating characteristics curve“; CrS: creatinina sérica; CyCs: cistatina C sérica; RBP: proteína ligadora de retinol; NGAL: lipocalina associada à gelatinase neutrofílica; MALB: microalbuminúria; $\mathrm{CyCu}$ : cistatina $\mathrm{C}$ na urina; KIM-1: molécula de injúria renal-1; TGF-ß1: fator transformador de crescimento-beta 1; CrU: creatinina na urina.

A RBP alcançou o melhor resultado, quando os biomarcadores foram analisados individualmente, com a sensibilidade de $86,4 \%$ e especificidade de $94,3 \%$ no subgrupo OTUB, e sensibilidade de $83,3 \%$ e especificidade de $94,3 \%$ no subgrupo HB. O subgrupo com HU, KIM-1 (com valores absolutos) demonstrou o melhor desempenho individual, com sensibilidade de $70,7 \%$ e especificidade de $82,7 \%$. Os demais biomarcadores neste subgrupo tiveram a sensibilidade menor de $63 \%$. 
Tabela 5 - Desempenho individual dos biomarcadores renais séricos e urinários em relação à identificação da lesão renal ou a sua progressão em UOC durante o primeiro ano de vida

\begin{tabular}{|c|c|c|c|c|}
\hline Biomarcador & $\begin{array}{c}\text { AUC } \\
\text { (IC 95\%) }\end{array}$ & $\begin{array}{l}\text { Valor de } \\
\text { corte }\end{array}$ & $\begin{array}{l}\text { Sens. } \\
(\%)\end{array}$ & $\begin{array}{c}\text { Espec. } \\
(\%)\end{array}$ \\
\hline \multicolumn{5}{|l|}{ CrS (mg/dL) } \\
\hline$<1^{\circ}$ mês de vida & 0,706 & 0,56 & 36,8 & 77,8 \\
\hline$>1^{\circ}$ mês de vida & $(0,64-0,77)$ & $\mathbf{0 , 3 5}$ & 44,5 & 92,5 \\
\hline \multicolumn{5}{|l|}{ CyCs $(\mu \mathrm{g} / \mathrm{dL})$} \\
\hline$<1^{\circ}$ mês de vida & 0,759 & 2,09 & 56,5 & 84,2 \\
\hline$>1^{\circ}$ mês de vida & $(0,70-0,81)$ & 1,30 & 78,6 & 75,0 \\
\hline \multicolumn{5}{|l|}{ RBP (ng/mg CrU) } \\
\hline$<1^{\circ}$ mês de vida & 0,844 & 47,1 & 79,0 & 95,0 \\
\hline $1^{\circ}-2^{\circ}$ mês de vida & $(0,80-0,89)$ & 5,50 & 87,5 & 97,8 \\
\hline$\geq 2^{\circ}$ mês de vida & & 2,90 & 77,0 & 95,7 \\
\hline \multicolumn{5}{|l|}{ NGAL (ng/mg CrU) } \\
\hline Masculino & 0,840 & 1,54 & 67,0 & 97,6 \\
\hline Feminino & $(0,79-0,89)$ & 2,30 & 72,2 & 93,5 \\
\hline$\mu \mathrm{ALB}(\mathrm{mg} / \mathrm{g} \mathrm{CrU})$ & $\begin{array}{c}0,814 \\
(0,77-0,86)\end{array}$ & 31,0 & 74,1 & 78,1 \\
\hline \multicolumn{5}{|l|}{$\mathrm{CyCu}(\mathrm{ng} / \mathrm{mg} \mathrm{CrU})$} \\
\hline$<1^{\circ}$ mês de vida & 0,779 & 2,75 & 75,0 & 92,7 \\
\hline $1^{\circ}-2^{\circ}$ mês de vida & $(0,72-0,83)$ & 2,28 & 68,8 & 97,8 \\
\hline$\geq 2^{\circ}$ mês de vida & & 1,49 & 62,0 & 93,3 \\
\hline \multicolumn{5}{|l|}{ KIM-1 } \\
\hline KIM-1 (ng/mg CrU) & 0,768 & 2,41 & 48,4 & 94,2 \\
\hline $\mathrm{KIM}-1(\mathrm{ng} / \mathrm{mL})^{*}$ & $(0,71-0,82)$ & 0,24 & 70,4 & 83,0 \\
\hline TGF-B1 (pg/mg CrU) & $\begin{array}{c}0,755 \\
(0,70-0,81)\end{array}$ & 2,68 & 52,0 & 96,3 \\
\hline
\end{tabular}

UOC: uropatias obstrutivas congênitas; CrS: creatinina sérica; CyCs: cistatina $\mathrm{C}$ sérica; RBP: proteína ligadora de retinol; NGAL: lipocalina associada à gelatinase neutrofílica; $\mu \mathrm{ALB}$ : microalbuminúria; $\mathrm{CyCu}$ : cistatina $\mathrm{C}$ na urina; KIM-1: molécula de injúria renal-1; TGF- $\beta 1$ : fator transformador de crescimento-beta 1; CrU: creatinina na urina; AUC: área sob a curva (,area under curve“); Sens.: sensibilidade; Espec.: especificidade. 
Nos subgrupos OTUB e HB, CyCs, NGAL, CyCu, $\mu$ ALB e KIM-1 obtiveram melhor desempenho na identificação da lesão renal quando comparados com os seus resultados no subgrupo HU, com sensibilidade entre 70 e $85 \%$ e especificidade acima de $80 \%$.

Tabela 6 - Desempenho da combinação dos biomarcadores renais em relação à identificação da lesão renal ou a sua progressão em UOC durante o primeiro ano de vida

\begin{tabular}{|c|c|c|c|}
\hline Combinação dos biomarcadores & $\begin{array}{c}\text { AUC } \\
\text { (IC 95\%) }\end{array}$ & $\begin{array}{l}\text { Sens. } \\
(\%)\end{array}$ & $\begin{array}{l}\text { Espec. } \\
(\%)\end{array}$ \\
\hline RBP+KIM-1 (todos) & \multirow{8}{*}{$\begin{array}{c}0,896 \\
(0,86-0,94)\end{array}$} & 74,1 & 94,4 \\
\hline $\mathrm{HU}$ & & 45,7 & 92,6 \\
\hline $\mathrm{HB}$ & & 83,3 & 92,1 \\
\hline OTUB & & 90,7 & 91,3 \\
\hline RBP+KIM-1 (todos) ${ }^{*}$ & & 86,8 & 81,1 \\
\hline $\mathrm{HU}$ & & 73,2 & 82,2 \\
\hline $\mathrm{HB}$ & & 91,9 & 79,3 \\
\hline OTUB & & 95,3 & 79,5 \\
\hline RBP+TGF-R1 (todos) & \multirow{4}{*}{$\begin{array}{c}0,934 \\
(0,90-0,97)\end{array}$} & 89,4 & 92,8 \\
\hline HU & & 83,3 & 91,4 \\
\hline $\mathrm{HB}$ & & 89,7 & 92,5 \\
\hline OTUB & & 93,3 & 91,6 \\
\hline NGAL+CyCu (todos) & \multirow{4}{*}{$\begin{array}{c}0,872 \\
(0,83-0,91)\end{array}$} & 81,7 & 92,7 \\
\hline $\mathrm{HU}$ & & 65,7 & 91,3 \\
\hline $\mathrm{HB}$ & & 83,9 & 90,4 \\
\hline OTUB & & 89,8 & 90,0 \\
\hline $\mathrm{NGAL}+\mathrm{CyCu}+\mathrm{CyCs}$ (todos) & \multirow{4}{*}{$\begin{array}{c}0,867 \\
(0,83-0,91)\end{array}$} & 92,4 & 79,5 \\
\hline HU & & 82,5 & 81,4 \\
\hline $\mathrm{HB}$ & & 97,2 & 83,4 \\
\hline OTUB & & 96,4 & 82,6 \\
\hline
\end{tabular}

*valor absoluto

UOC: uropatias obstrutivas congênitas; $\mathrm{CrS}$ : creatinina sérica; CyCs: cistatina $\mathrm{C}$ sérica; RBP: proteína ligadora de retinol; NGAL: lipocalina associada à gelatinase neutrofílica; $\mu \mathrm{ALB}$ : microalbuminúria; $\mathrm{CyCu}$ cistatina $\mathrm{C}$ na urina; KIM-1: molécula de injúria renal-1; TGF-ß1: fator transformador de crescimento-beta 1; CrU: creatinina na urina; AUC: área sob a curva (,area under curve“); Sens.: sensibilidade; Espec.: especificidade. 


\subsection{Indicação cirúrgica e os biomarcadores em UOC}

Durante o primeiro ano de seguimento, a cirurgia foi indicada em 17/37 (45,9\%) pacientes, sendo 5/14 (35,7\%) com HU, 4/13 (30,7\%) com HB e 8/10 (80\%) com OTUB.

No segundo ano de observação foram indicadas mais 7 cirurgias, totalizando 23/37 (64,7\%) pacientes operados, sendo $8 / 14(57,1 \%)$ do grupo HU, 7/13 (53,8\%) do grupo HB e 9/10 (90\%) do grupo OTUB. Os grupos dos pacientes operados e não operados, mostraram-se comparáveis em relação ao sexo (com exceção de subgrupo OTUB), IG, etnia, escore APGAR, parâmetros antropométricos e pressão arterial (Anexo C; Tabela 7). Os diagnósticos pré e pós-natais, complicações e os procedimentos realizados em relação ao tempo observacional, estão expostos na Tabela 8 (Anexo D). A reabordagem cirúrgica foi necessária em 4/7 (57,1\%) dos pacientes operados do subgrupo HB e 2/9 $(22,2 \%)$ do subgrupo OTUB. A infecção do trato urinário ocorreu no período pósoperatório em $3 / 30$ procedimentos $(10 \%)$.

RD-DTPA- ${ }^{99 m}$ Tc foi sugestiva para obstrução mecânica em 48,6\% de todos os pacientes. Padrão obstrutivo significativo foi mais frequente no subgrupo $\mathrm{HB}(61,5 \%$, $p=0,027)$, com obstrução bilateral encontrada em dois casos $(15,4 \%)$.

\subsubsection{Desempenho dos biomarcadores em relação a indicação cirúrgica}

A intervenção cirúrgica resultou na diminuição dos níveis de todos os biomarcadores urinários, com exceção da $\mu \mathrm{ALB}$, em todos os subgrupos de pacientes. $\mathrm{Na}$ análise do grupo total dos pacientes, os valores de NGAL demonstraram queda de $82,4 \%$, seguido por redução de $67,3 \%$ dos níveis de RBP. Todos os demais biomarcadores testados apresentaram queda de até $50 \%$ no período pós-operatório. A análise por subgrupos, de forma semelhante, mostra redução pós-operatória dos valores dos biomarcadores urinários: no subgrupo OTUB observou-se a diminuição de no mínimo 50\% (RBP, p=0,012; $\mathrm{CyCu}, \mathrm{p}=0,005 ; \mathrm{TGF}-\beta 1, \mathrm{p}=0,025 ; \mathrm{KIM}-1, \mathrm{p}=0,03$; NGAL, $\mathrm{p}<0,001$; verificado através do teste t-Student para dados pareados); no subgrupo $\mathrm{BH}$ 
observou-se a diminuição de no mínimo 33,5\% (apenas KIM-1, $\mathrm{p}<0,048$; verificado através do teste t-Student para dados pareados); no subgrupo com HU foi registrada a redução de no mínimo 22,9\% (RBP, $p \leq 0,043$, NGAL, $p \leq 0,043$; TGF- $ß 1, p \leq 0.034$; KIM$1, \mathrm{p} \leq 0.016$; verificado através dos testes t-Student e Wilcoxon para dados pareados) dos valores no pós-operatório.

A análise comparativa do perfil dos biomarcadores séricos e urinários no grupo operado, não operado e grupo-controle é apresentada nas Figuras 11-14.

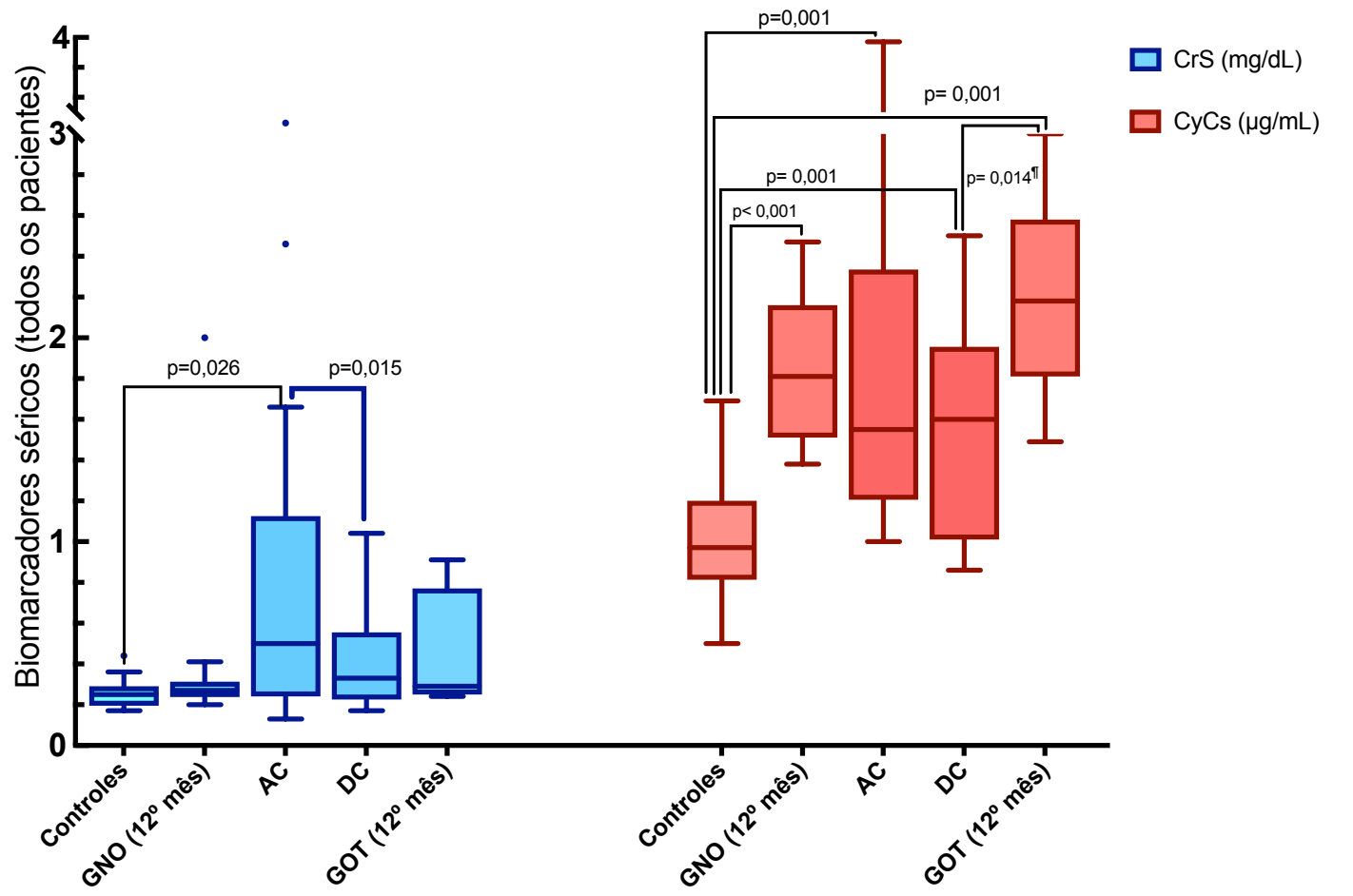

Figura 11 - Comparação dos valores de biomarcadores séricos ( $\mathrm{CrS}$ e $\mathrm{CyCs}$ ), descritos como mediana e $(5$; 95) percentis, entre os valores do grupo-controle, dosagens pré e posoperatórias nos pacientes do grupo operado precocemente (GOP) e em tempo intermediário (GOI) com os valores obtidos em pacientes do grupo não operado (GNO) e grupo operado tardio (GOT) aos 12 meses de idade

A significância estatística em $\mathrm{p}<0,05$ verificada através dos testes t-Student e ${ }^{\text {TWilcoxon para }}$ dados pareados.

UOC: uropatias obstrutivas crônicas; GOP: grupo operado precoce; GOI: grupo operado intermediário; GNO grupo não operado; $\mathrm{AC}$ : antes da cirurgia; $\mathrm{DC}$ : depois da cirurgia; $\mathrm{CrS}$ : creatinina sérica; CyCs: cistatina sérica. 

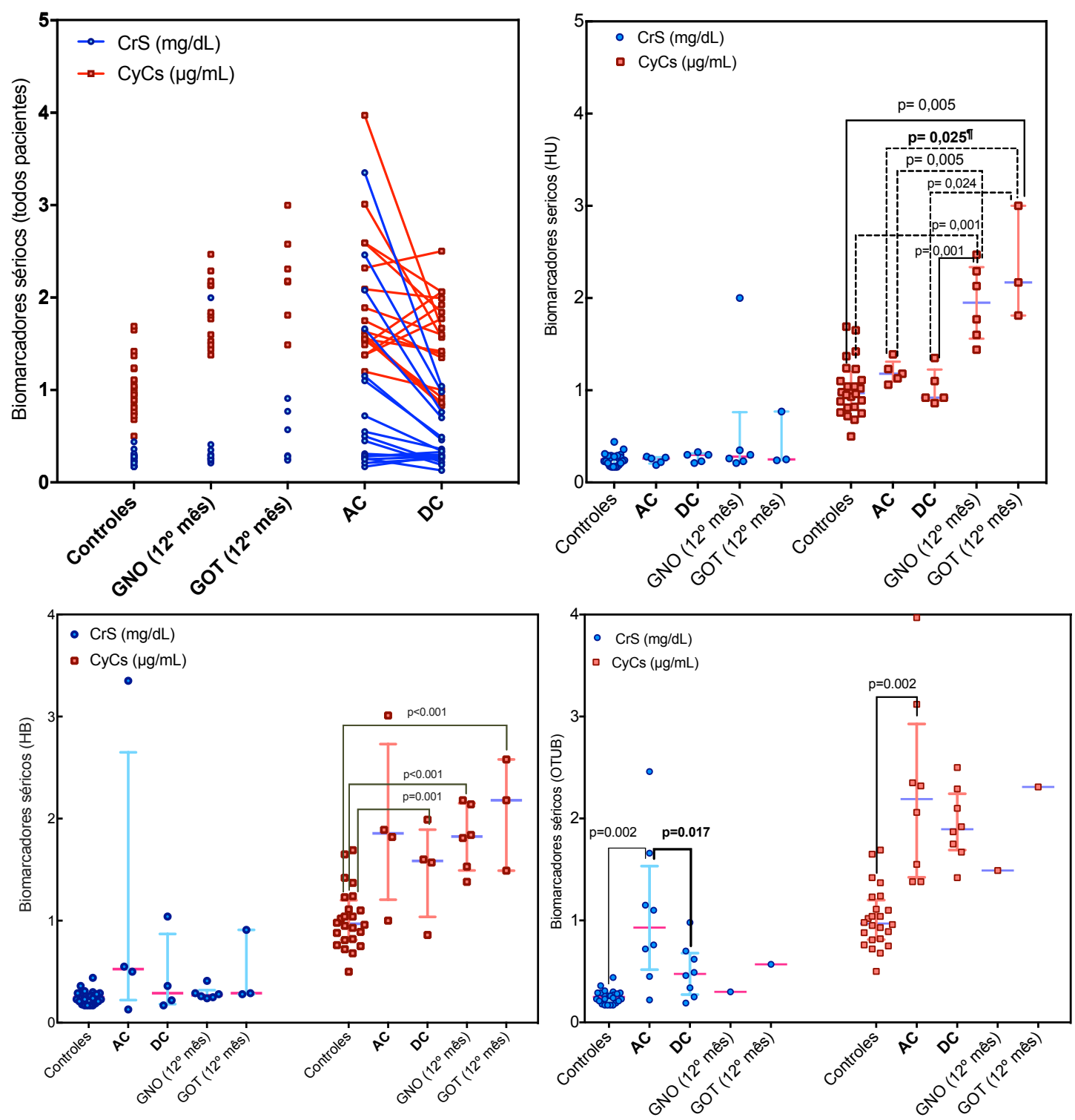

Figura 12 - Comparação dos valores de biomarcadores séricos ( $\mathrm{CrS}$ e $\mathrm{CyCs})$, descritos como mediana e $(5 ; 95)$ percentis, entre o grupo controle, dosagens pré e pós-operatórias nos pacientes operados precocemente (GOP) e em tempo intermediário (GOI) com valores obtidos em pacientes não operados (GNO) e operados tardiamente (GOT) aos 12 meses de idade, de acordo com subgrupos HU, HB, OTUB

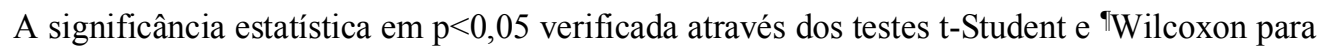
dados pareados.

UOC: uropatias obstrutivas crônicas; GOP: grupo operado precoce; GOI: grupo operado intermediário; GNO grupo não operado; AC: antes da cirurgia; DC: depois da cirurgia; CrS: creatinina sérica; CyCs: cistatina sérica; HU: hidro(uretero)nefrose unilateral; HB: hidro(uretero)nefrose bilateral; OTUB: obstrução do trato urinário baixo. 

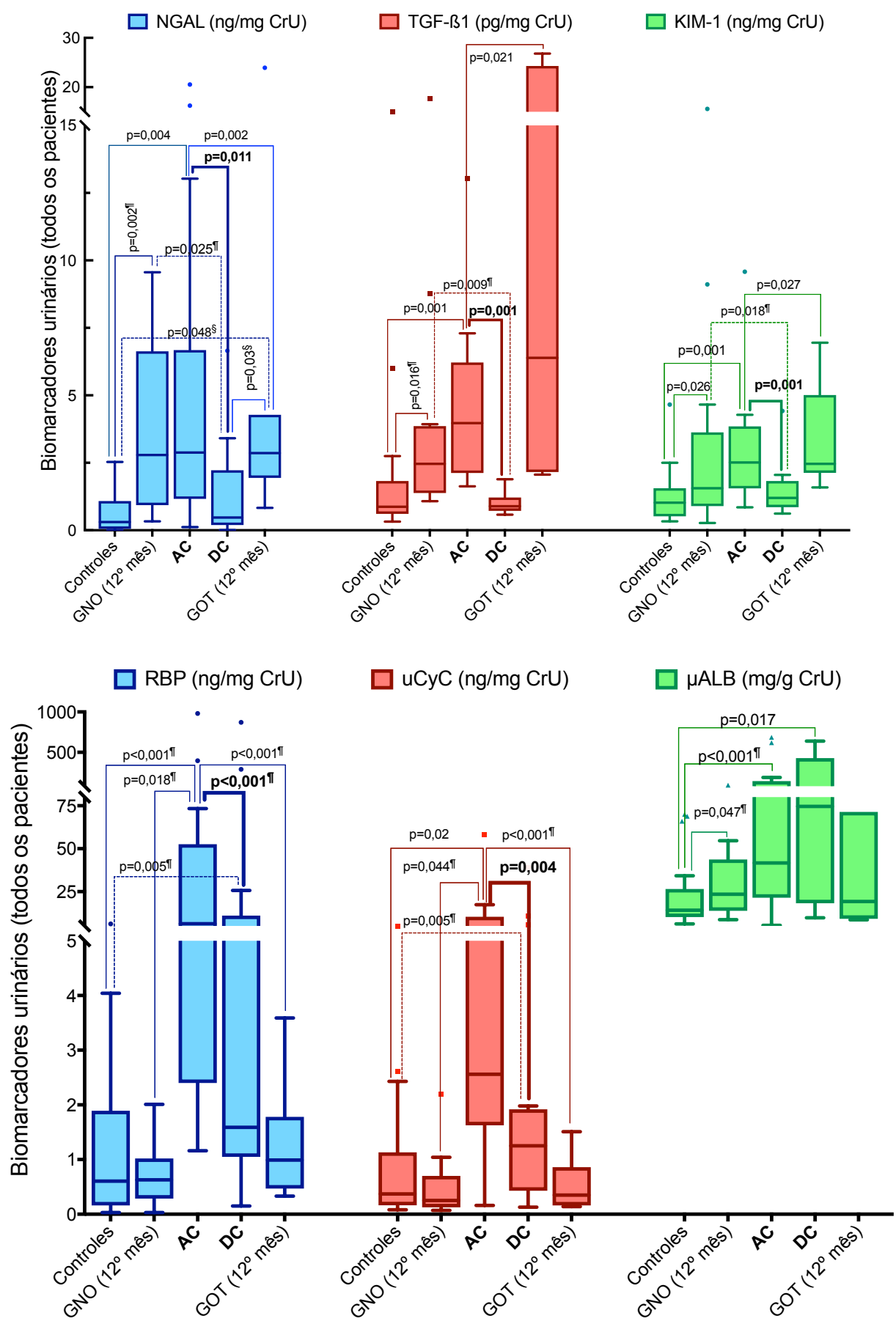

Figura 13 - Comparação dos valores de biomarcadores urinários, descritos como mediana e (5 ; 95) percentis, entre o grupo controle, dosagens pré e pós-operatórias nos pacientes do GOP e GOI com valores obtidos em pacientes do GNO e GOT aos 12 meses de idade A significância estatística em $\mathrm{p}<0,05$ verificada através dos testes ${ }^{\S t-S t u d e n t ~} \mathrm{e}$ "Wilcoxon para dados pareados. UOC: uropatias obstrutivas crônicas; GOP: grupo operado precoce; GOI: grupo operado intermediário; GNO grupo não operado; AC: antes da cirurgia; DC: depois da cirurgia; RBP: proteína ligadora de retinol; NGAL: lipocalina associada à gelatinase neutrofílica; $\mu \mathrm{ALB}$ : microalbuminúria; $\mathrm{CyCu}$ : cistatina $\mathrm{C}$ na urina; $\mathrm{KIM}-1$ : molécula de injúria renal 1; TGF-ß1: fator transformador de crescimento-beta 1; CrU: creatinina na urina. 

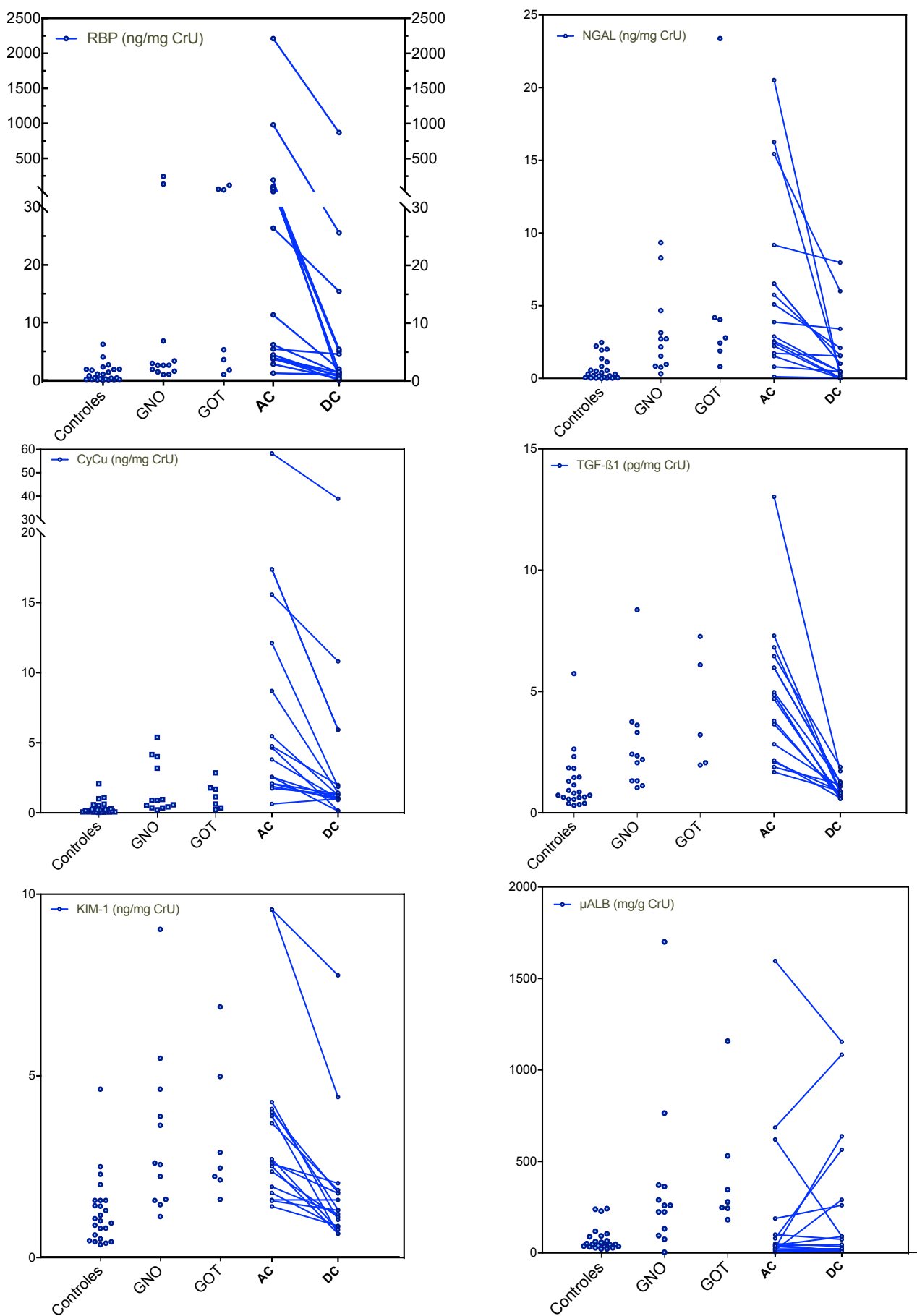

Figura 14 - Comparação dos valores individuais dos biomarcadores urinários entre o grupo controle, dosagens pré e pós-operatórias nos pacientes do GOP e GOI com valores obtidos em pacientes do GNO e GOT aos 12 meses de idade

UOC: uropatias obstrutivas crônicas; GOP: grupo operado precoce; GOI: grupo operado intermediário; GNO grupo não operado; $\mathrm{AC}$ : antes da cirurgia; DC: depois da cirurgia; RBP: proteína ligadora de retinol; NGAL: lipocalina associada à gelatinase neutrofílica; $\mu$ ALB: microalbuminúria; $\mathrm{CyCu}$ : cistatina $\mathrm{C}$ na urina; $\mathrm{KIM}-1$ : molécula de injúria renal 1; TGF-ß1: fator transformador de crescimento-beta 1; CrU: creatinina na urina. 
Quando observados os valores pré e pós cirúrgicos pelos subgrupos dos pacientes, os resultados mais evidentes e promissores foram obtidos com NGAL, RBP, TGF-ß1 e KIM-1, no subgrupo com HU ( $\mathrm{p}=0,043$; através do teste Wilcoxon), e no OTUB no qual todos os biomarcadores demonstraram a queda significante com exceção para $\mu$ ALB ( $\mathrm{p} \leq 0.03$; através do t-Student e Wilcoxon para dados pareados). No subgrupo com HB apesar de evidente, a redução dos níveis pós cirúrgicos não se mostrou significante.

A análise das curvas ROC, apresentada na Figura 15 e detalhada nas Tabelas 9 e 10, foi empregada para determinação dos valores-cortes dos biomarcadores como preditores da necessidade cirúrgica em UOC.

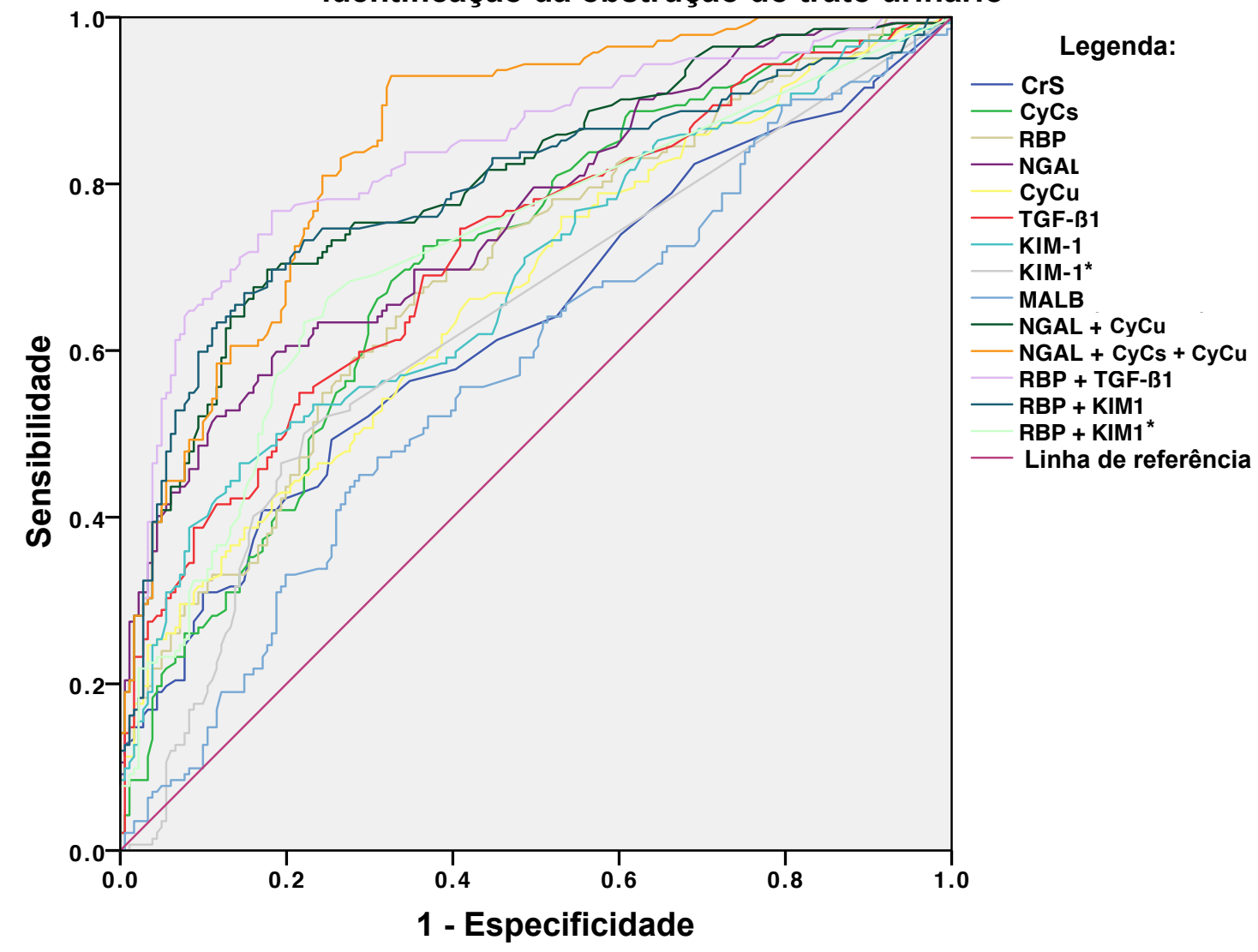

Figura 15 - Análise do poder discriminativo dos biomarcadores renais como preditores da indicação de abordagem cirúrgica em UOC no primeiro ano através de curvas ROC * valor absoluto; ROC: „receiver operating characteristics curve “; CrS: creatinina sérica; CyCs: cistatina $\mathrm{C}$ sérica; RBP: proteína ligadora de retinol; NGAL: lipocalina associada à gelatinase neutrofílica; MALB: microalbuminúria; $\mathrm{CyCu}$ : cistatina $\mathrm{C}$ na urina; $\mathrm{KIM}-1$ : molécula de injúria renal 1; TGF-ß1: fator transformador de crescimento-beta 1; CrU: creatinina na urina. 
Tabela 9 - Desempenho individual dos biomarcadores renais séricos e urinários em relação à identificação da obstrução do trato urinário com indicação de abordagem cirúrgica em UOC durante o primeiro ano de vida

\begin{tabular}{|c|c|c|c|c|}
\hline Biomarcador & $\begin{array}{c}\text { AUC } \\
\text { (IC 95\%) }\end{array}$ & $\begin{array}{l}\text { valor de } \\
\text { corte }\end{array}$ & $\begin{array}{l}\text { Sens. } \\
(\%)\end{array}$ & $\begin{array}{c}\text { Espec. } \\
(\%)\end{array}$ \\
\hline \multicolumn{5}{|l|}{ CrS (mg/dL) } \\
\hline$<1^{\circ}$ mês de vida & 0,633 & 0,56 & 35,0 & 76,5 \\
\hline$\geq 1^{\circ}$ mês de vida & $(0,57-0,70)$ & 0,35 & 36,1 & 90,4 \\
\hline \multicolumn{5}{|l|}{$\operatorname{CyCs}(\mu \mathrm{g} / \mathrm{dL})$} \\
\hline$<1^{\circ}$ mês de vida & 0,715 & 2,09 & 60,0 & 82,3 \\
\hline$\geq 1^{\circ}$ mês de vida & $(0,66-0,77)$ & 1,30 & 72,6 & 80,1 \\
\hline \multicolumn{5}{|l|}{ RBP (ng/mg CrU) } \\
\hline$<1^{\circ}$ mês de vida & 0,752 & 47,1 & 79,0 & 94,9 \\
\hline $1^{\circ}-2^{\circ}$ mês de vida & $(0,70-0,81)$ & $\mathbf{5 , 5 0}$ & 73,7 & 97,6 \\
\hline$\geq 2^{\circ}$ mês de vida & & 2,90 & 62,8 & 94,2 \\
\hline$\mu \mathrm{ALB}(\mathrm{mg} / \mathrm{g} \mathrm{CrU})$ & $\begin{array}{c}0,585 \\
(0,52-0,65)\end{array}$ & 30,0 & 60,1 & 78,2 \\
\hline \multicolumn{5}{|l|}{ NGAL (ng/mg CrU) } \\
\hline Masculino & 0,801 & 1,54 & 63,4 & 96,6 \\
\hline Feminino & $(0,75-0,85)$ & 2,30 & 60,0 & 93,4 \\
\hline \multicolumn{5}{|l|}{ KIM-1 } \\
\hline KIM-1 (ng/mg CrU) & 0,701 & 2,41 & 48,1 & 93,8 \\
\hline KIM-1 (ng/mL) ${ }^{*}$ & $(0,64-0,76)$ & 0,24 & 72,0 & 84,2 \\
\hline \multicolumn{5}{|l|}{ CyCu (ng/mg CrU) } \\
\hline$<1^{\circ}$ mês de vida & & 2,75 & 75,0 & 92,7 \\
\hline $1^{\circ}-2^{\circ}$ mês de vida & $(0,64-0,77)$ & 2,28 & 57,9 & 97,6 \\
\hline$\geq 2^{\circ}$ mês de vida & & 1,49 & 55,2 & 93,3 \\
\hline TGF-B1 (pg/mg CrU) & $\begin{array}{c}0,719 \\
(0,66-0,78)\end{array}$ & 2,68 & 60,8 & 92,8 \\
\hline
\end{tabular}

${ }^{*}$ valor absoluto

UOC: uropatias obstrutivas congênitas; $\mathrm{CrS}$ : creatinina sérica; $\mathrm{CyCs}$ : cistatina $\mathrm{C}$ sérica; RBP: proteína ligadora de retinol; NGAL: lipocalina associada à gelatinase neutrofílica; $\mu \mathrm{ALB}$ : microalbuminúria; $\mathrm{CyCu}$ : cistatina $\mathrm{C}$ na urina; KIM-1: molécula de injúria renal-1; TGF-ß1: fator transformador de crescimento-beta 1; CrU: creatinina na urina; AUC: área sob a curva (,,area under curve“); Sens.: sensibilidade; Espec.: especificidade. 
Tabela 10 - Desempenho da combinação dos biomarcadores renais em relação à identificação da obstrução do trato urinário com indicação de abordagem cirúrgica em UOC durante o primeiro ano de vida

\begin{tabular}{lccc}
\hline Combinação dos biomarcadores & AUC & $\begin{array}{c}\text { Sens. } \\
(\%)\end{array}$ & $\begin{array}{c}\text { Espec. } \\
(\%)\end{array}$ \\
\hline RBP+KIM-1 (todos) & & $\mathbf{6 8 , 3}$ & $\mathbf{9 0 , 6}$ \\
HU & & 51,3 & 90,8 \\
HB & & 79,4 & 90,2 \\
OTUB & 0,862 & 85,4 & 86,8 \\
RBP+KIM-1 (todos) ${ }^{*}$ & $(0,82-0,90)$ & $\mathbf{8 0 , 8}$ & $\mathbf{7 9 , 1}$ \\
HU & & 70,5 & 80,2 \\
HB & & 89,5 & 77,8 \\
OTUB & & 95,3 & 76,5 \\
& 0,874 & & \\
RBP+TGF-B1 (todos) & $(0,84-0,91)$ & $\mathbf{7 4 , 6}$ & $\mathbf{9 2 , 2}$ \\
HU & & 71,1 & 90,7 \\
HB & & 90,6 & 92,4 \\
OTUB & & 86,4 & 89,6 \\
& 0,881 & & \\
NGAL+CyCu+CyCs (todos) & $(0,85-0,92)$ & $\mathbf{8 7 , 7}$ & $\mathbf{8 2 , 2}$ \\
HU & & 77,8 & 81,9 \\
HB & & 91,9 & 83,3 \\
OTUB & & 96,2 & 81,6 \\
& & & \\
NGAL+CyCu (todos) & 0,870 & $\mathbf{7 3 , 9}$ & $\mathbf{9 1 , 6}$ \\
HU & $(0,83-0,91)$ & 64,9 & 90,4 \\
HB & & 79,4 & 89,8 \\
OTUB & & 90,5 & 86,7 \\
\hline * & & &
\end{tabular}

valor absoluto

UOC: uropatias obstrutivas congênitas; $\mathrm{CrS}$ : creatinina sérica; CyCs: cistatina $\mathrm{C}$ sérica; RBP: proteína ligadora de retinol; NGAL: lipocalina associada à gelatinase neutrofílica; $\mu \mathrm{ALB}$ : microalbuminúria; $\mathrm{CyCu}$ : cistatina $\mathrm{C}$ na urina; KIM-1: molécula de injúria renal 1; TGF-ß1: fator transformador de crescimento-beta 1; CrU: creatinina na urina; AUC: área sob a curva (,area under curve“); Sens.: sensibilidade; Espec.: especificidade.

Neste estudo, a RBP registrou o melhor desempenho para identificação da obstrução do trato urinário na analise isolada dos biomarcadores. A sensibilidade e especificidade nos primeiros dois meses de vida mostraram-se acima de 73,7\% e 95\% respectivamente em todos os subgrupos. Ao longo do período observacional RBP individualmente atingiu o melhor resultado no subgrupo OTUB, com sensibilidade de $76,2 \%$ e especificidade de $91,8 \%$, e no subgrupo HB foi registrada a sensibilidade e especificidade de $83,3 \%$ e de $94,7 \%$, respectivamente. 
No subgrupo HU, KIM-1 (em valores absolutos, sensibilidade de 62,5\% e especificidade $82,1 \%$ ) e NGAL (sensibilidade de 63,3\% e especificidade de 96,7\%) demonstraram melhores desempenhos quando testados isoladamente. Os demais biomarcadores demonstraram a sensibilidade inferior a 62\%, no mesmo subgrupo.

TGF-ß1 mostrou modesto desempenho quando observado nos subgrupos HU e OTUB, com a sensibilidade de 59,4\% e $67 \%$, respectivamente, enquanto foi abaixo de $50 \%$ no subgrupo HB. Quando em combinação com a RBP, a sensibilidade aumenta para $73,7 \%$ no caso de pacientes com HU, $87.5 \%$ para HB e $89,4 \%$ para OTUB.

O potencial benefício dos biomarcadores na tomada das decisões sobre a indicação cirúrgica a tempo, comparado com os métodos diagnósticos tradicionais, está exposto na Tabela 11 (Anexo E) e Tabela 12 (Anexo F). 
DISCUSSÃO 


\section{DISCUSSÃO}

\subsection{Perfil dos biomarcadores para detecção precoce de injúria renal em lactentes e recém-nascidos saudáveis}

Poucos estudos observacionais de longa duração, utilizando conhecimentos da proteômica urinária, foram realizados em $\mathrm{RN}$ e lactentes para acompanhamento dos processos da adaptação e maturação funcional renal pós-natal.

A comparação dos resultados do presente estudo com os dados existentes na literatura é dificultada por diferenças metodológicas na coleta e processamento de amostras, na questionável normalização dos valores absolutos dos diversos biomarcadores com a $\mathrm{CrU}$, na diversidade das características das casuísticas descritas, assim como pela falta de um biomarcador padrão ouro e de uma definição única da injúria renal $^{33-35,85}$. Estas diferenças serão apontadas ao longo da discussão.

A coorte dos lactentes saudáveis deste estudo apresentou características homogêneas quanto ao sexo, etnia, IG e peso. O perfil dos biomarcadores funcionais e da maturação renal: $\mathrm{CrS}, \mathrm{CyCs}, \mathrm{CyCu}$ e RBP, mostrou tendências semelhantes, sendo os valores significativamente maiores nas primeiras semanas de vida, em relação àqueles das amostras coletadas subsequentemente.

Achados semelhantes foram descritos em diferentes estudos ${ }^{32,58,77,86}$. Esse fenômeno se deve aos processos de maturação renal que ocorrem no primeiro ano de vida, promovendo um estado de equilíbrio entre a produção e excreção destas matérias. No caso de CyCs, o intervalo anteriormente descrito de $0,57-1,12 \mathrm{mg} / \mathrm{L}^{34,77,86}$, para valores de referência de crianças acima de um ano de idade, se aproxima dos valores encontrados neste estudo $(0,97 \pm 0,30 \mathrm{mg} / \mathrm{L})$. No entanto, estudos anteriores utilizaram diferentes métodos de análise dos biomarcadores, a saber, nefelometria, turbidimetria e ELISA, o que dificulta a validação da CyC nesta população. Para que a comparação pudesse ocorrer entre os três métodos, foi necessária a normalização do método ELISA através da multiplicação do valor dosado pelo fator $0,66^{35,78}$. Diversas formulas foram validadas 
para o cálculo do RFGe em crianças e lactentes, através da mensuração de CyCs $\left(\mathrm{RFGe}_{\mathrm{CyCs}}\right)$, isentas das influências da massa corporal ou da idade ${ }^{87}$. Os valores do $\mathrm{RFGe}_{\mathrm{CyCs}}$ apresentados neste estudo, após a multiplicação pelo fator 0,66, mostraram-se significativamente mais elevados do que os valores previamente relatados, através dos métodos nefelométrico e turbidimétrico $(\mathrm{p}<0,002)$, mas se assemelharam a valores publicados para o RFG de inulina ${ }^{35,87}(\mathrm{p}=0,127)$. Uma abordagem alternativa seria o uso de equações multivariadas de RFGe, que em sua base utilizam a combinação de valores da $\mathrm{CrS}, \mathrm{CyCs}$ e parâmetros como sexo e crescimento $^{88}$. Devido ao uso do método de "Jaffé modificado" neste estudo, não foi possível a aplicação destas equações combinadas, uma vez que utilizam analise enzimática da $\mathrm{CrS}$ e $\mathrm{CrU}$.

Os níveis de $\mathrm{CrS}$ e $\mathrm{CrU}$ apresentados neste trabalho se assemelham aos valores publicados previamente nos estudos que utilizaram a mesma metodologia ${ }^{35,77,89}$. Apesar disso, os valores do $\mathrm{RFGe}_{\mathrm{CrS}}$ foram discretamente acima daqueles encontrados na literatura disponível que, em geral, se baseia na metodologia enzimática da análise de $\mathrm{Cr}^{35,90}$. Mesmo utilizando creatinina por dosagem enzimática, os valores do RFGe $\mathrm{CrS}_{\text {, }}$ mostram a tendência para superestimar o RFG quando comparados com o RFGe $\mathrm{CyC}^{34}$. A creatinina permanece um marcador padrão "ouro imperfeito" especialmente quando utilizado em RN e lactentes com o fim de definir DRC ou IRA ${ }^{35,76}$. CyCs não atravessa a barreira placentária e, diferente da $\mathrm{CrS}$, não é secretada, mas reabsorvida e metabolizada pelos túbulos proximais. Dados preliminares sugeriram que os níveis de CyCs não seriam afetados por massa corporal, dieta, drogas, infecções ou estados inflamatórios. Mais recentemente, essas afirmações têm sido desafiadas. Embora a maioria dos dados sugira que a CyC seja um marcador mais robusto do RFG que a $\mathrm{Cr}$, há menor definição sobre quais fatores poderiam influenciá-la ${ }^{34,86}$. Estas características aumentaram a sua importância como um marcador da função renal promissor e atrativo nas últimas décadas. A relativa escassez da precisão das equações univariadas do RFGe persiste como um problema não resolvido, para utilização de $\mathrm{CrS}$ e $\mathrm{CyCs}$, na faixa etária neonatal e de lactentes menores de um ano de vida ${ }^{35,88}$. Após o primeiro ano de idade, o intervalo dos valores de referência da CyCs varia pouco, portanto não há necessidade de calcular o $\mathrm{RFGe}^{91}$.

Recentemente, tem-se discutido a utilidade do NGAL sérico e CyCs como preditores de IRA quando comparados com os respectivos valores urinários ${ }^{92}$. Os dados 
mostram a vantagem da $\mathrm{CyCu}$ sobre $\mathrm{CyCs}$ na população neonatal e infantil com diferença significativa em vários cenários de comprometimento renal agudo ${ }^{57,92,93}$. No presente estudo, o perfil do $\mathrm{CyCu}$ demonstrou padrão semelhante ao $\mathrm{CrS}$ e $\mathrm{CyCs}$, com concentrações mais elevadas nas primeiras semanas de vida. A partir do segundo mês de vida a sua razão de produção-excreção entra no equilíbrio dinâmico, como foi previamente descrito por De Freitas et $\mathrm{al}^{32}$. Surpreendentemente, há muito poucos relatos disponíveis na literatura, com valores de referência deste promissor biomarcador urinário, como mencionado na revisão sistemática e metanálise realizada por Nakhjavan-Shahraki et al. $^{92}$, que analisaram os estudos com cenário clínico agudo, sem seguimento de casuística.

Os valores de referência previamente publicados de RBP urinária, em lactentes, são baseados em números relativamente pequenos de participantes e obtidos por metodologias diferentes ${ }^{49,50,52}$. Os resultados dessa pesquisa são comparáveis aos resultados do Smith et al. $^{50}$, que usaram o mesmo ensaio. Todos os estudos em concordância mostram a redução significante da excreção da RBP nos primeiros dois meses de vida, o que reflete a maturação do túbulo convoluto proximal renal. Esse processo pode-se estender durante os primeiros dois anos de vida e, em crianças maiores de três anos, a RBP atinge os níveis de referência independentes da idade ${ }^{49}$. Segundo os achados desse estudo, o perfil da RBP demonstrou que a imaturidade tubular é muito maior e de maturação mais lenta em comparação com a imaturidade glomerular.

KIM-1, NGAL e TGF-ß1 representam alguns dos biomarcadores urinários tubulares da lesão renal mais promissores, cujos valores de referência para a população de $\mathrm{RN}$ e lactentes saudáveis, até recentemente, constam em pequeno número de publicações. Neste estudo, conforme esperado, tais biomarcadores mantiveram níveis muito baixos ao longo do período observacional, refletindo a ausência de qualquer dano renal ou do trato urinário nos participantes. No rim saudável, a expressão do KIM-1 não é detectável ou é muito baixa. A sua suprarregulação é detectada em condições como isquemia renal e intoxicações, promovendo apoptose celular e remoção das células necróticas ${ }^{54}$. KIM-1 é, em geral, muito pouco ou nem um pouco afetado pelas características físicas e químicas da urina e suas componentes ${ }^{37}$. Apesar de todos os estudos anteriores, que envolvem a dosagem do KIM-1 na urina da população infantil saudável, terem utilizado diferentes tipos de ensaios e terem avaliado um número 
relativamente pequeno de sujeitos, os valores absolutos obtidos neste trabalho estão em concordância com os reportados, uma vez que se mantiveram abaixo do LID pelo método $(0,156 \mathrm{ng} / \mathrm{mL})$ na maioria dos participantes. Os valores do presente estudo, quando normalizados por $\mathrm{CrU}$, não mostraram correlação com idade, sexo e etnia como foi publicado previamente ${ }^{94,95}$. Com base nesses achados, qualquer aumento da concentração urinária do KIM-1 é sugestivo de dano renal iminente. Portanto KIM-1, pode ser considerado como um biomarcador promissor e útil para detecção precoce da lesão renal do túbulo proximal.

NGAL é um dos biomarcadores urinários funcionais mais bem estudados, não apenas em situações de IRA, mas também nos cenários da progressão da $\mathrm{DRC}^{37,66}$. Sua expressão em níveis baixos nos tecidos humanos extra-renais, como e.g. no pulmão, intestino delgado e fígado, é bem conhecida. Suas outras possíveis funções são: inibição do crescimento bacteriano, metabolismo de ferro e indução do crescimento epitelial ${ }^{38,96}$. Nas últimas décadas, vários estudos surgiram trazendo valores de referências do NGAL urinário, em sua maioria para crianças maiores de um ano de idade e adultos ${ }^{94,}$ 95, 96. Zwiers et al. ${ }^{94}$, em 2014 publicaram um estudo de revisão muito abrangente sobre os valores de referência para KIM-1 e NGAL na população infantil. Mesmo considerando um número relativamente pequeno de sujeitos, diferentes faixas etárias e ensaios empregados, semelhante aos achados dos estudos de Rybi-Szuminska et al. ${ }^{97}$, e Zwiers et al. ${ }^{94}$, os níveis urinários da NGAL no presente estudo, no sexo feminino, foram significativamente mais altos do que os do sexo masculino $(p=0,005)$. Nessa pesquisa os valores de NGAL se mantiveram estáveis durante o período observacional, com exceção dos valores absolutos que foram mais altos em ambos os sexos na primeira semana de vida. De modo geral, os valores normais de NGAL dessa pesquisa, absolutos e normalizados por $\mathrm{CrU}$, foram semelhantes aos valores reportados no estudo de RybiSzuminska et al. ${ }^{97}$, porém mais baixos em comparação aos valores normais publicados pelo Zwiers et $\mathrm{al}^{94}$. As características comuns de todos os estudos consistem em pequeno número de participantes, distribuição assimétrica dos gêneros, metodologia variável da coleta, armazenamento e análise de urina. A normalização das amostras com CrU, analisada com ensaios diferentes, também poderia explicar as discrepâncias encontradas entre os estudos. As vantagens da normalização dos biomarcadores do túbulo renal com CrU, inclusive NGAL e KIM-1, especialmente quando aplicados no contexto de IRA, 
foram recentemente questionadas, levando em consideração a instabilidade na excreção de $\mathrm{Cr}$, que depende da idade, podendo assim causar interpretações equivocadas ${ }^{68,98,99}$.

Além da necessidade imperativa de um ou mais biomarcadores para diagnóstico precoce da IRA, os mesmos podem se tornar preditores da progressão da doença, indispensáveis para definir a transição da IRA à DRC, principalmente nos seus estágios iniciais. Os marcadores tradicionais séricos (ureia, $\mathrm{Cr}$ ) e urinários ( $\mu \mathrm{ALB}$ ) ainda estão em uso para os fins diagnósticos e prognósticos, embora a sua baixa sensibilidade e especificidade sejam bem conhecidas. Além disso, não refletem diretamente a lesão da organização estrutural interna no nível das vias de sinalização intercelular renal ${ }^{66}$. Neste estudo, os níveis do TGF-ß1, no grupo controle, mostraram comportamento semelhante ao do KIM-1, mantendo os níveis absolutos muito baixos durante o período inteiro de observação (abaixo do LID pelo método: 15,15 pg/mL), como esperado. Após a normalização com $\mathrm{CrU}$, as concentrações apresentaram valores menores em relação aos reportados em estudos anteriores ${ }^{63,100,101}$. Durante o período observacional, de modo semelhante ao padrão do KIM-1, os valores do TGF-ß1 não variaram com a idade, gênero e etnia ( $p>0,05)$, o que está de acordo com os relatos prévios, permanecendo estáveis depois do primeiro ano de vida ${ }^{63-65,100-102}$.

Poucos estudos apresentam os valores de referências para $\mu$ ALB normalizada por $\mathrm{CrU}(\mu \mathrm{ALB} / \mathrm{CrU})$ no primeiro ano de vida dos lactentes saudáveis ${ }^{49,52,67,103}$. Nesse estudo, os valores da $\mu \mathrm{ALB} / \mathrm{CrU}$ permaneceram estáveis durante o período de observação, em

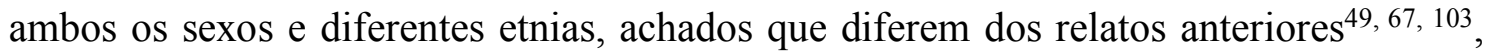
porém estão em concordância com a publicação de Lehrnbecher et $\mathrm{al}^{52}$. Como os referidos autores enfatizam, os poucos estudos presentes na literatura sobre a excreção fisiológica de albumina em crianças, apresentam dificuldades nas comparações por motivos mencionados para outros marcadores: diferentes faixas etárias envolvidas, metodologias utilizadas e unidades de expressão não padronizadas. 


\subsection{Perfil dos biomarcadores para detecção precoce de injúria renal em UOC durante o primeiro ano de vida}

Este é o primeiro estudo que simultaneamente e continuamente avaliou o desempenho e o potencial diagnóstico de seis biomarcadores urinários (RBP, NGAL, $\mathrm{CyCu}$, TGF-ß1, KIM-1 e $\mu \mathrm{ALB}$ ) e dois biomarcadores séricos ( $\mathrm{CrS}$ e $\mathrm{CyCs}$ ), no âmbito de UOC, em lactentes acompanhados do período neonatal até 1 ano de idade e, adicionalmente, até o final do segundo ano de vida para observação das repercussões clinico-cirúrgicas.

Analisando os dados da coorte inteira, CyCs demonstrou valores significativamente mais elevados em comparação ao grupo-controle aos 12 meses de idade, enquanto $\mathrm{CrS}$ manteve-se elevada em relação ao grupo controle, durante o período inteiro de observação, principalmente devido aos níveis altos do subgrupo OTUB, refletindo assim a DRC em instalação. O RFGe $_{C y C s}$ manteve-se 12 a $15 \mathrm{~mL} / \mathrm{min}$ mais baixo em comparação com o grupo-controle durante a maior parte do período observacional em todos os subgrupos, enquanto o $\mathrm{RFGe}_{\mathrm{CrS}}$ apresentou valores com elevação de 15 a 30 $\mathrm{mL} / \mathrm{min}$ do segundo a sexto mês de vida, especialmente por conta do subgrupo HB. Miklovicova et al. ${ }^{104}$, em estudo semelhante com participantes com HU e HB e idade média de 6 anos no momento da coleta, apresentaram achados semelhantes aos do presente estudo em relação aos níveis séricos de CyCs, $\mathrm{CrS}$ e $\mathrm{RFGe}_{\mathrm{CyCs}}$.

Os resultados do $\mathrm{RFGe}_{\mathrm{CrS}}$ no subgrupo com HB e OTUB chamaram a atenção (Figura 7). Quando comparados com outros subgrupos e com os padrões do RFGe CyCs, $_{\text {, }}$ os valores do $\mathrm{RFGe}_{\mathrm{CrS}}$ demonstraram um aumento inesperado no início do segundo mês de vida, mantendo as taxas elevadas no subgrupo HB em relação ao grupo controle até o fim do período observacional. Uma análise mais detalhada demonstrou baixo ganho ponderal significativo durante os dois primeiros meses de vida em ambos subgrupos (BH e OTUB) e diminuída velocidade de crescimento, significante apenas no subgrupo OTUB, nos primeiros 3 meses de vida (Figura 2). O baixo peso e o retardo do crescimento refletiram na redução de valores da $\mathrm{CrS}$ e consequentemente no aumento do $\mathrm{RFGe}_{\mathrm{CrS}}$, calculado pela formula original do $\mathrm{Schwartz}^{76}$, utilizada neste estudo. Esta 
fórmula apresenta a estatura do paciente no numerador e $\mathrm{CrS}$ no denominador. A perda da massa muscular modifica o denominador, podendo gerar valores mais altos de $\mathrm{RFGe}_{\mathrm{CrS}}$ independentemente do estado real da filtração glomerular e assim causar uma impressão falsa de melhora da referida função. No subgrupo OTUB, a recuperação da velocidade de crescimento foi percebida no período entre $3^{\circ}$ e $6^{\circ}$ mês de vida, provavelmente como resposta positiva à intervenção cirúrgica. No subgrupo HB, da mesma forma, após a intervenção cirúrgica, no mesmo período de observação, percebeuse recuperação nutricional. Após o sexto mês em ambos subgrupos, e mais evidentemente no subgrupo HB, com normalização do crescimento e estado nutricional, o RFGe $\mathrm{CrS}_{\mathrm{S}}$ retomou aos valores esperados e comparáveis aos valores do $\mathrm{RFGe}_{\mathrm{CyCs}}$. O grupo $\mathrm{HU}$ apresentou ganho de peso e crescimento dentro dos padrões normais, não apresentando as discrepâncias no perfil do $\mathrm{RFGe}_{\mathrm{CrS}}$ descritas nos outros dois subgrupos.

Esses resultados refletiram a melhor confiabilidade diagnóstica na diferenciação entre o RFG normal e alterado com a utilização da CyCs, em comparação com a CrS, achado que está em concordância com os dados descritos por Miklovicova et al ${ }^{104}$.

Os valores dos biomarcadores urinários mostraram-se notadamente mais elevados no primeiro mês de vida, enquanto NGAL, TGF- $\beta 1$ e $\mu$ ALB mostraram-se significativamente aumentados desde o nascimento, quando comparados com o grupocontrole. Todos os biomarcadores apresentaram valores consideravelmente mais elevados nos subgrupos HU, HB e OTUB, quando comparados com o grupo-controle com exceção de NGAL no subgrupo HU na primeira semana de vida,

$\mathrm{RBP}, \mathrm{CyCu}$ e $\mu \mathrm{ALB}$ apresentaram os valores significativamente elevados durante o primeiro mês de vida em todos os subgrupos. RBP manteve valores muito elevados durante o primeiro trimestre, de forma significativa no subgrupo OTUB e HB, em semelhança aos resultados do estudo de Tomlinson et al. ${ }^{105}$, que encontraram nível consideravelmente aumentado de RBP nas crianças com cicatrizes renais confirmadas no contexto da nefropatia renal por RVU.

KIM-1, TGF- $ß 1$ e CyCu mostraram-se notadamente elevados nos subgrupos $\mathrm{HU}$ e OTUB durante o primeiro mês, quando comparados ao grupo-controle. No período observacional subsequente, as diferenças importantes foram registradas apenas esporadicamente ( $\mathrm{CyCu}$ no $9^{\circ}$ mês: OTUB; $\mu \mathrm{ALB}$ no $9^{\circ}$ mês: OTUB e HU). Esta tendência poderia ser explicada pelo alto número de procedimentos cirúrgicos que 
ocorreram no primeiro semestre (30\%). Os subgrupos HB e OTUB foram submetidos a intervenção cirúrgica, em geral, nas primeiras semanas de vida $(23,1 \%$ e $60 \%$, respectivamente), enquanto no subgrupo HU e no restante dos subgrupos HB e OTUB, cirurgias foram indicadas a partir de quatro ou mais meses de vida $(57,1 \%, 30,8 \%$ e $30 \%$, respectivamente). Fatores como pequeno número de pacientes e a normalização dos biomarcadores por $\mathrm{CrU}$, podem ter interferido no padrão do perfil dos biomarcadores ${ }^{94}$, 97-99. Por esses motivos, tornou-se necessário analisar individualmente (caso a caso) todos os biomarcadores testados.

$\mathrm{Na}$ atualidade, não há um padrão ouro quanto ao manejo clinico das UOC, o planejamento do procedimento cirúrgico para minimização da lesão renal é feito com base em critérios clínicos e radiológicos. A partir do conhecimento do perfil dos biomarcadores na IRA, considerou-se que o melhor potencial diagnóstico de cada biomarcador na identificação da lesão renal, nesta casuística, deveria ser avaliado através de sua compatibilidade com os resultados dos critérios recomendados atualmente para indicação da intervenção cirúrgica ${ }^{8,22,71,75}$.

Para verificar se combinações de biomarcadores atingiriam melhores resultados, especialmente no subgrupo HU, foram testadas algumas combinações. Todas elas mostraram melhora importante no potencial diagnóstico, especialmente no subgrupo HU. Os melhores resultados, para todos os subgrupos, foram observados para combinações: $\mathrm{RBP}+\mathrm{TGF}-\beta 1$ e NGAL+CyCs+CyCu . No subgrupo OTUB, estas combinações alcançaram sensibilidade e especificidade de no mínimo 90\%. No subgrupo HU, atingiram sensibilidade de pelo menos $82,5 \%$ enquanto o subgrupo HB foi semelhante ao subgrupo OTUB para quase todas as combinações verificadas. 


\subsection{Papel dos biomarcadores renais como discriminadores da necessidade de intervenção cirúrgica em lactentes com UOC}

$\mathrm{Na}$ literatura existente, esse é o primeiro estudo que apresenta a utilização de um grupo selecionado de biomarcadores urinários e séricos, para distinguir, no contexto da UOC, os pacientes que necessitam de procedimento cirúrgico, daqueles com baixo risco para desenvolvimento de lesões renais permanentes.

As diferenças encontradas entre os estudos existentes podem ser explicadas pelo uso dos diversos ensaios dos biomarcadores, falta de padronização da definição de lesão renal, participantes avaliados em diferentes idades, diferenças entre métodos de coleta da urina e o intervalo entre as coletas, entre outros. Alguns dos biomarcadores utilizados nesse trabalho foram avaliados, recentemente, em vários estudos, no contexto de estenose de JUP e VUP, conforme apresentado na Tabela 13.

No presente estudo NGAL e KIM-1 apresentaram desempenho comparável com os achados de Karakus et $\mathrm{al}^{28}$. Este mesmo grupo, diferentemente dos achados deste estudo e de Madsen et al. ${ }^{106}$, não demonstraram queda dos valores da $\mathrm{CyCu}$ após a pieloplastia. Uma das possíveis explicações para esta discordância com os achados do presente estudo poderia ser devida a discrepâncias no tempo de coleta e intervalos pós-cirúrgicos muito curtos. Wasilewska et al. ${ }^{107}$, também apresentaram resultados comparáveis aos desse estudo, embora com desempenho da NGAL um pouco superior. Noyan et al. ${ }^{29}$, obtiveram resultados discretamente inferiores para NGAL e consideraram KIM-1 inútil. Além do baixo número de participantes, esses achados nos estudos citados ${ }^{68,94}$ podem ser explicados pela ausência de RN na casuística estudada, uso de ensaios diferentes para os biomarcadores, normalização questionável por CrU e não consideração das influências relacionadas ao gênero do paciente nos valores da NGAL. 
Tabela 13 - Apresentação geral dos estudos disponíveis na literatura sobre o desempenho dos biomarcadores renais em relação a identificação precoce da obstrução das vias urinarias que necessita da intervenção cirúrgica

\begin{tabular}{|c|c|c|c|c|c|c|c|}
\hline $\begin{array}{l}\text { Primeiro autor, } \\
\text { Referência } \\
\text { (Ano) }\end{array}$ & $\mathrm{N}^{\mathrm{o}}(\mathrm{P} / \mathrm{C})$ & $\begin{array}{l}\text { Idade } \\
\mathrm{P} / \mathrm{C} \\
(\text { anos }) \\
\end{array}$ & $\begin{array}{l}\text { Biomarcador } \\
\text { (Tipo de ensaio) }\end{array}$ & $\mathrm{CrU}$ & $\begin{array}{c}\text { Doença de } \\
\text { base }\end{array}$ & $\begin{array}{l}\text { Tempo da coleta } \\
\text { (dias) }\end{array}$ & Principais resultados \\
\hline $\begin{array}{c}\text { Tomlinson et al. }{ }^{105} \\
\text { (1994) }\end{array}$ & $143 / 43$ & $\begin{array}{c}1,6-17,7 \\
/ \\
\text { NR }\end{array}$ & $\begin{array}{l}\text { RBP } \\
\text { (ELISA, própria } \\
\text { instituição) }\end{array}$ & Jaffé & RVU & $\begin{array}{l}\text { uma ou mais amostras } \\
\text { aleatórias; estudo não } \\
\text { prospectivo. }\end{array}$ & $\begin{array}{l}\text { Aumento exponencial da excreção } \\
\text { da RBP com o grau da cicatrização } \\
\text { renal, e comparado aos controles } \\
(p<0,001)\end{array}$ \\
\hline $\begin{array}{l}\text { Karakus et al. }{ }^{28} \\
\quad(2015)\end{array}$ & $27 / 9$ & $\begin{array}{c}0,5-6,4 \\
/ \\
2,9-4,2\end{array}$ & $\begin{array}{l}\text { NGAL } \\
\text { KIM-1 } \\
\text { CyCu } \\
\text { (ELISA, Biospes } \\
\text { Co., China) }\end{array}$ & Jaffé & $\begin{array}{l}\text { HU antenatal } \\
\text { Estenose da } \\
\text { JUP }\end{array}$ & $\begin{array}{l}1 \text { dia antes do } \\
\text { procedimento; } \\
3 \text { meses pós-cirúrgico. }\end{array}$ & $\begin{array}{l}\text { NGAL (valor PO P > C, } \mathrm{p}=0,032 \text { ) } \\
\text { AUC }=0,85[0,68-1,00], \\
\text { sens. } 84,6 \% \text {, espec. } 77,8 \\
\text { corte } 6,67 \text { ng/mg CrU } \\
\text { KIM-1 (valor PO P > C, p=0,001) } \\
\text { AUC }=0,89[0,72-1,00] \text {, } \\
\text { sens. } 92,3 \% \text {, espec. } 83,3 \% \\
\text { corte } 0,69 \text { ng/mg CrU. } \\
\text { CyCu: } \mathrm{NR} \text {, não encontrado útil }\end{array}$ \\
\hline $\begin{array}{l}\text { Wasilewska et al. }{ }^{107} \\
\qquad(2011)\end{array}$ & $40 / 25$ & $\begin{array}{c}0,16-17 \\
/ \\
0,33-16\end{array}$ & $\begin{array}{l}\text { NGAL } \\
\text { (ELISA, BioPorto } \\
\text { Diagnostics, } \\
\text { Dinamarca) } \\
\text { KIM-1 } \\
\text { (ELISA, USCN Life } \\
\text { Science, China) }\end{array}$ & NR & $\begin{array}{l}\text { HU antenatal } \\
\text { Estenose da } \\
\text { JUP }\end{array}$ & $\begin{array}{l}1 \text { dia antes do } \\
\text { procedimento; } \\
3 \text { meses pós cirúrgico. }\end{array}$ & $\begin{array}{l}\text { NGAL (valor PO P }>\text { C, } \mathrm{p}<0,05 \text { ) } \\
\text { AUC: } 0,814[0,71-0,92], \text { sens. } \\
\text { 100\%, espec. } 28.6 \% \\
\text { corte: } 2,158 \mathrm{ng} / \mathrm{mg} \mathrm{CrU} \\
\text { KIM-1(valor PO P > C, p<0,05) } \\
\text { AUC: } 0,80 \text { [0,69-0,91], } \\
\text { sens. } 100 \% \text {, espec. } 71.4 \% \\
\text { valor corte: } 0,462 \mathrm{ng} / \mathrm{mg} \mathrm{CrU}\end{array}$ \\
\hline
\end{tabular}




\begin{tabular}{|c|c|c|c|c|c|c|c|}
\hline $\begin{array}{l}\text { Primeiro autor, } \\
\text { Referência } \\
\text { (Ano) }\end{array}$ & $\mathrm{N}^{\mathrm{o}}(\mathrm{P} / \mathrm{C})$ & $\begin{array}{c}\text { Idade } \\
\mathrm{P} / \mathrm{C} \\
\text { (anos) }\end{array}$ & $\begin{array}{l}\text { Biomarcador } \\
\text { (Tipo de ensaio) }\end{array}$ & $\mathrm{CrU}$ & $\begin{array}{l}\text { Doença de } \\
\text { base }\end{array}$ & $\begin{array}{l}\text { Tempo da coleta } \\
\text { (dias) }\end{array}$ & Principais resultados \\
\hline $\begin{array}{l}\text { Madsen et al. }{ }^{106} \\
\text { (2012) }\end{array}$ & $24 / 13$ & $\begin{array}{l}3,5-14,5 \\
/ \\
3,5-14,5\end{array}$ & $\begin{array}{l}\text { NGAL } \\
\mathrm{CyCu} \\
\text { (Luminex xMAP, } \\
\text { EMD Chemicals Inc, } \\
\text { Alemanha) }\end{array}$ & Enz. & $\begin{array}{l}\text { HU antenatal } \\
\text { Estenose da } \\
\text { JUP }\end{array}$ & $\begin{array}{l}1 \text { dia antes, durante e } 1 \\
\text { dia após a cirurgia; } \\
3 \text { semanas pós-cirúrgico; } \\
3 \text { meses pós-cirúrgico. }\end{array}$ & $\begin{array}{l}\text { NGAL (valor PO P }>\mathrm{C}, \mathrm{p}<0,05 \text { ) } \\
\text { AUC: } 0,923[0,837-1,00] \text {, } \\
\text { sens. } 82 \%, \text { espec. } 100 \% \\
\text { corte: } 20,57 \mathrm{ng} / \mathrm{mg} / \mathrm{CrU} \\
\text { CyCu: (valor PO P/C, } \mathrm{p}>0,05 \text { ) } \\
\text { NGAL e CyCu apresentaram } \\
\text { valores aumentados no pós- } \\
\text { cirúrgico imediato }\end{array}$ \\
\hline $\begin{array}{l}\text { Noyan et al. }{ }^{29} \\
\quad(2015)\end{array}$ & $62^{*} / 20$ & $\begin{array}{l}0,1-4 \\
/ \\
0,1-4\end{array}$ & $\begin{array}{l}\text { NGAL } \\
\text { (ELISA, BioVendor } \\
\text { Diagnostic, } \\
\text { Republica Checa) } \\
\text { KIM-1 } \\
\text { (ELISA, USCN Life } \\
\text { Science, China) }\end{array}$ & NR & $\begin{array}{l}\text { HU antenatal } \\
\text { Disfunção de } \\
\text { JUP }\end{array}$ & $\begin{array}{l}1 \text { única dosagem por } \\
\text { participante em cada } \\
\text { subgrupo; }\end{array}$ & $\begin{array}{l}\text { NGAL (valor PO P }>C, p<0,05 \text { ) } \\
\text { AUC: } 0,68[0,6-0,7], \\
\text { sens. } 58 \% \text {, espec. } 75 \% \\
\text { corte: } 0,16 \mathrm{ng} / \mathrm{mg} \text { CrU } \\
\text { KIM-1: (valor PO P/C, } p>0,05 \text { ) } \\
\text { não foi encontrado como útil }\end{array}$ \\
\hline $\begin{array}{l}\text { Taha et al. }{ }^{65} \\
\text { (2006) }\end{array}$ & $35 / 30$ & $0.5-12$ & $\begin{array}{l}\text { TGF- } 11 \\
\text { (ELISA, Emax } \\
\text { Immunoassay } \\
\text { System, USA) }\end{array}$ & Jaffé & $\begin{array}{l}\text { HU antenatal } \\
\text { Estenose de } \\
\text { JUP }\end{array}$ & $\begin{array}{l}1^{\circ} \text { Dosagem } \\
\text { intraoperatoria, antes da } \\
\text { desobstrução; } \\
\text { As demais amostras } \\
\text { obtidas com 1, 2, 3, 6, } 9 \mathrm{e} \\
12 \text { meses pós-cirúrgico. }\end{array}$ & $\begin{array}{l}\text { TGF-ß1 } \\
\text { (valor PO P }>\text { C, } \mathrm{p}<0,001 \text { ) } \\
\text { Reportado aumento inicial pós } \\
\text { cirurgia com declínio subsequente; } \\
\text { AUC: } \mathrm{NR} \\
\text { sens: } 100 \% \text {, espec. } 80 \% \\
\text { corte: } 190 \mathrm{pg} / \mathrm{mg} \mathrm{CrU}\end{array}$ \\
\hline
\end{tabular}




\begin{tabular}{|c|c|c|c|c|c|c|c|}
\hline $\begin{array}{l}\text { Primeiro autor, } \\
\text { Referência } \\
\text { (Ano) }\end{array}$ & $\mathrm{N}^{\mathrm{o}}(\mathrm{P} / \mathrm{C})$ & $\begin{array}{l}\text { Idade } \\
\mathrm{P} / \mathrm{C} \\
\text { (anos) }\end{array}$ & $\begin{array}{l}\text { Biomarcador } \\
\text { (Tipo de ensaio) }\end{array}$ & $\mathrm{CrU}$ & $\begin{array}{c}\text { Doença de } \\
\text { base }\end{array}$ & $\begin{array}{l}\text { Tempo da coleta } \\
\text { (dias) }\end{array}$ & Principais resultados \\
\hline $\begin{array}{l}\text { Mandelia et al. }{ }^{100} \\
\text { (2013) }\end{array}$ & $30 / 30$ & $\begin{array}{c}0-9 \\
/ \\
\mathrm{NR}\end{array}$ & $\begin{array}{l}\text { TGF- } \beta 1 \\
\text { (ELISA, } \\
\text { RayBiotech, } \\
\text { Norcross, GA) } \\
\text { Microalbuminuria } \\
\text { (imunoensaio } \\
\text { enzimático) }\end{array}$ & Jaffé & VUP & $\begin{array}{l}1^{\mathrm{o}} \text { amostra - no } \\
\text { momento do } \\
\text { procedimento; } \\
\text { As demais amostras } \\
\text { obtidas com } 1,3,6 \text { e } 12 \\
\text { meses pós-cirúrgico. }\end{array}$ & $\begin{array}{l}\text { TGF- } \beta 1 \text { (valor } P>C, p<0,001 \text { ) } \\
\text { Após a fulguração em um } \\
\text { subgrupo ocorreu a redução } \\
\text { significante ao longo do período, } \\
\text { e no outro subgrupo ocorreu } \\
\text { apenas com o uso de IECA } \\
\text { AUC: NR } \\
\mu \text { ALB seguia o mesmo padrão do } \\
\text { TGF- } \beta 1\end{array}$ \\
\hline $\begin{array}{l}\text { Dell et al. }{ }^{108} \\
(2000)\end{array}$ & $14 / 16$ & $\begin{array}{c}3,2-14 \\
/ \\
4,3-20\end{array}$ & $\begin{array}{l}\text { TGF- } ß 1 \\
\text { (ELISA, Predicta, } \\
\text { Genzyme, USA) }\end{array}$ & Jaffé & VUP & $\begin{array}{l}1 \text { única dosagem por } \\
\text { participante em cada } \\
\text { subgrupo; }\end{array}$ & $\begin{array}{l}\text { TGF- } \beta 1(\text { valor } \mathrm{P}>\mathrm{C}, \mathrm{p}<0,01) \\
\text { AUC: } \mathrm{NR}\end{array}$ \\
\hline $\begin{array}{c}\text { Palmer et al. }{ }^{101} \\
\text { (1997) }\end{array}$ & $24^{\pi / 19}$ & $\begin{array}{c}0,1-11 \\
/ \\
0,1-10\end{array}$ & $\begin{array}{l}\text { TGF-ß1 } \\
\text { (ELISA, R\&D } \\
\text { Systems, USA) }\end{array}$ & $\mathrm{NN}$ & $\begin{array}{c}\text { HU antenatal } \\
\text { Estenose de } \\
\text { JUP } \\
/ \\
\text { VUR }\end{array}$ & $\begin{array}{l}1 \text { única dosagem por } \\
\text { participante em cada } \\
\text { subgrupo; } \\
\text { No grupo com HU, no } \\
\text { perioperatório, coletadas } \\
\text { duas amostras ao } \\
\text { mesmo tempo: da pelve } \\
\text { renal e da bexiga. }\end{array}$ & $\begin{array}{l}\text { Significante diferença entre os } \\
\text { valores obtidos da pelve renal e } \\
\text { da bexiga }(p=0,03) \text {. } \\
\text { Urina obtida da bexiga é } \\
\text { indiferente entre os grupos } \\
(p>0,05) \text {, }\end{array}$ \\
\hline
\end{tabular}




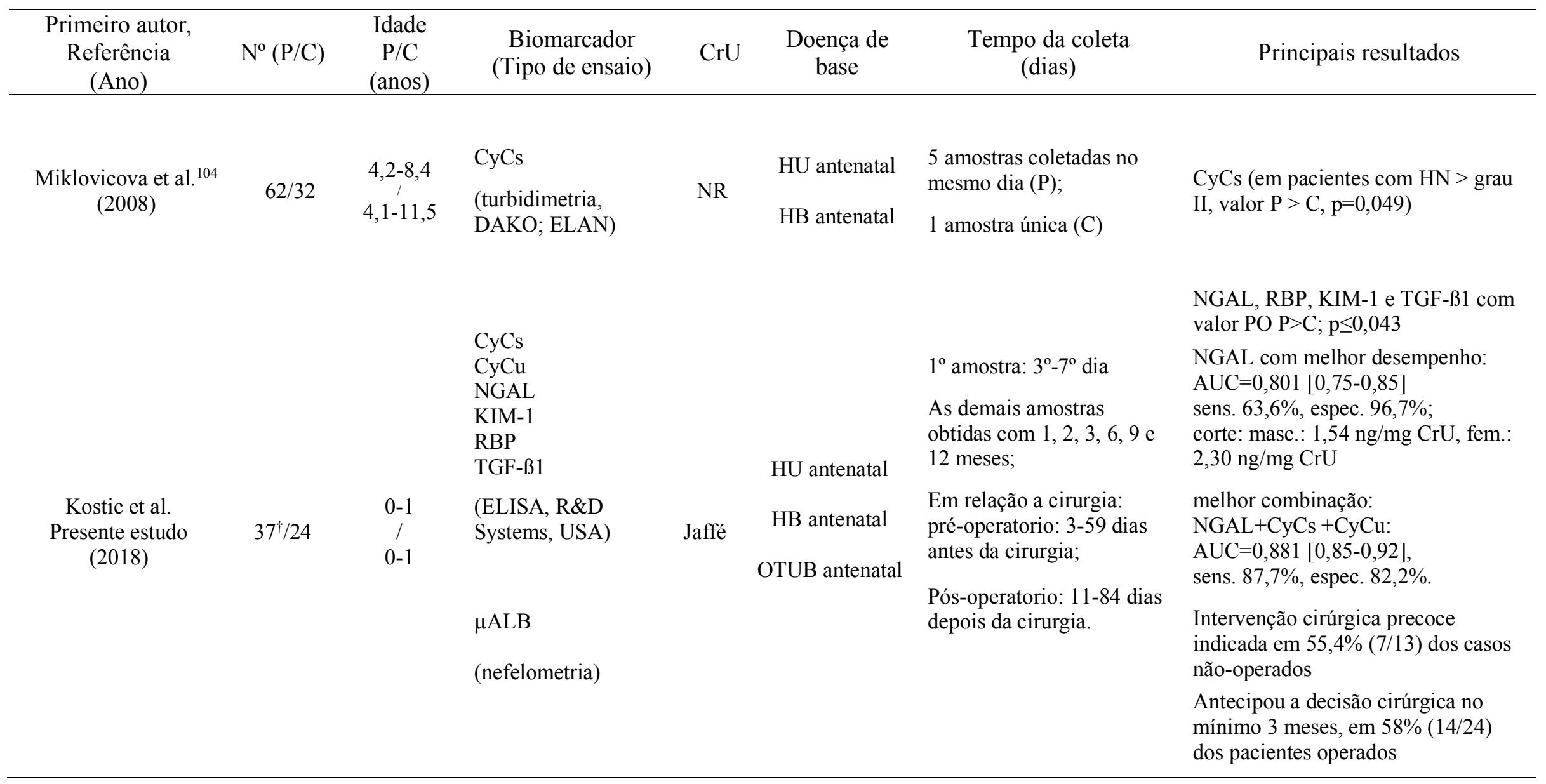

\footnotetext{
* 26 com HN de grau III ou maior; 36 com HU grau I e II; ${ }^{\uparrow} 13$ com estenose de JUP e 11 com VUR. ${ }^{\dagger} 14$ com HU, 13 com HB, 10 com OTUB; NR: informação não reportada; NN: valores não normalizados por CrU; $\mathrm{CrS}$ : creatinina sérica; $\mathrm{CyCs}$ : cistatina $\mathrm{C}$ sérica; $\mathrm{RBP}$ : proteína ligadora de retinol; NGAL: lipocalina associada à gelatinase neutrofílica; $\mu \mathrm{ALB}$ : microalbuminúria; CyCu: cistatina $\mathrm{C}$ na urina; KIM-1: molécula de injúria renal 1; TGF-ß1: fator transformador de crescimento-beta 1; CrU: creatinina na urina; AUC: área sob a curva (,,area under curve“); sens.: sensibilidade; espec.: especificidade; masc.: masculino; fem.: feminino; PO: pré-operatório; P: paciente; C: controle; HN: hidronefrose; HU: hidronefrose unilateral; HB: hidronefrose bilateral; OTUB: obstrução do trato urinário baixo. VUP: válvula de uretra posterior; RVU: refluxo vesico-ureteral; JUP: junção uretero-piélica; ELISA: imunoensaio enzimático quantitativo;
} 
TGF-ß1, um dos marcadores mais bem conhecidos no contexto das UOC, especialmente para estenose de JUP e VUP ${ }^{30,65,109}$, demonstrou, no subgrupo OTUB, padrão semelhante ao da RBP. Furness et al. ${ }^{110}$, Liatsikos et al. ${ }^{111}$, e Taha et al. ${ }^{65}$, descreveram um aumento de até 4 vezes dos níveis urinários de TGF- $\beta 1$, em relação aos níveis registrados no grupo controle, em crianças com OTUS. Portanto, o TGF- $\beta 1$ pode ser clinicamente utilizada para a confirmação do diagnóstico da obstrução da JUP. Os resultados do presente estudo favorecem o TGF- $\beta 1$ como um biomarcador promissor para obstrução grave, principalmente nos pacientes com VUP, como já se observou em estudos realizados nas últimas duas décadas ${ }^{98,108}$. Os valores relativamente baixos na urina obtida da bexiga, no subgrupo com HU, descritos neste estudo, estão em concordância com os achados de Palmer et $\mathrm{al}^{101}$. A concentração do TGF- $\beta 1$ na urina foi inferior nas crianças mais velhas, quando comparado com as crianças no primeiro ano de vida, o que reflete uma produção menor desse fator no caso de uma obstrução de longa data. Os dados deste estudo e dos demais estudos citados sugerem que quanto menor a criança, maior a acurácia deste biomarcador ${ }^{65,101,110,111}$.

Os valores da CyCs mensurados antes do procedimento cirúrgico no GOP e GOI foram significativamente mais elevados, se comparados com o grupo-controle $(p=0,001)$, o que está de acordo com os achados de Miklovicova et $\mathrm{al}^{104}$. A combinação $\mathrm{CyCs}+\mathrm{CyCu}+\mathrm{NGAL}$ atingiu desempenho excelente, com sensibilidade geral de $87.7 \%$, em comparação com o desempenho de cada um destes biomarcadores individualmente.

A análise dos biomarcadores no GNO e GOT revelaram desacordo entre a decisão cirúrgica baseada nos métodos diagnósticos convencionais e a atividade dos biomarcadores em mais da metade dos pacientes, especialmente em GOI com HU, e em GOT e GNO independentemente do subgrupo etiológico. Em geral, todos os biomarcadores poderiam ter antecipado a decisão cirúrgica baseada nos métodos convencionais em pelo menos 3 meses em $38 \%$ de todos os pacientes operados. 


\subsection{Limitações do estudo}

O presente estudo encontrou várias limitações. A primeira a ser comentada é o baixo número de participantes. Essa pesquisa realizou-se em um único centro que representa a referência para gestações de alto risco e uma instituição que acolhe os pacientes do país inteiro. O recrutamento dos pacientes ocorreu no período pré-natal, quando muitos dos potenciais participantes foram perdidos por motivos de morte fetal ou abortamentos, ou devido ao diagnóstico de outras malformações identificadas ao nascimento. Em relação ao recrutamento do grupo-controle, as dificuldades encontradas foram relacionadas à motivação das futuras mães de potenciais $\mathrm{RN}$ saudáveis para participarem de um estudo com 12 meses de duração. Isso resultou em um importante número de abandonos do seguimento, principalmente devido às migrações internas e a dificuldades relacionadas à mobilidade para grandes distâncias geográficas. Devido ao número relativamente pequeno de participantes hígidos, os valores obtidos neste grupo podem ter apresentado algum grau de incerteza nos percentis extremos $(2,5$ e 97,5). Além disso, a comparação entre os valores absolutos e normalizados dos biomarcadores desse estudo, com estudos anteriores, que utilizaram metodologias diferentes, foi um grande desafio. As mesmas dificuldades já foram descritas como obstáculos importantes na validação dos valores de referência na população dos lactentes e $\mathrm{RN}^{32-35, ~ 50, ~ 52, ~ 68, ~ 86, ~ 94, ~} 97$. Outra limitação importante encontrada foi a determinação dos níveis de CrS e CrU através do método de Jaffé modificado, o único disponível na instituição onde foi realizado o estudo, o que pode ter interferido nos resultados da $\mathrm{CrS}, \mathrm{RFGe}_{\mathrm{CrS}}$, e na normalização dos biomarcadores com CrU. Para minimizar as limitações da metodologia do Jaffé modificado, critérios rigorosos de exclusão por hiperbilirrubinemia foram empregados, o que reduziu mais ainda o número final dos participantes. A falta de padrão ouro para a definição da lesão renal em geral, e especificamente no contexto das UOC, também se constituiu num fator limitador importante.

Por motivos éticos e práticos, não foi possível coletar urina através da aspiração suprapúbica ou via cateterismo vesical para evitar possíveis contaminações que a utilização do saco coletor, particularmente quando utilizado no sexo feminino, poderia ter causado. A metodologia de coleta das amostras de urina refere-se especialmente aos 
valores de referência da NGAL, o biomarcador que mais demonstrou a influência do gênero sobre os níveis urinários, segundo Zwiers et al ${ }^{94}$. Estudos futuros que envolverem RN e lactentes devem considerar as novas e mais práticas técnicas de coleta de urina, como é o PeeSpot ${ }^{\circledR}$, uma alternativa ao saco coletor e ao método de bola de algodão.

No sentido de evitar os problemas encontrados nesse estudo recomenda-se: uma abordagem multicêntrica, com maior número de participantes, utilizando uma metodologia padronizada, para que a aplicação de biomarcadores na prática possa ser validada com a finalidade de uso nas decisões clínicas e cirúrgicas. 
CONCLUSÕES 


\section{CONCLUSÕES}

Durante o primeiro ano de vida dos lactentes saudáveis, as medidas sequenciais dos biomarcadores séricos e urinários descritos no presente estudo caracterizaram:

a) maturação glomerular e tubular renal através dos biomarcadores: $\mathrm{CrS}, \mathrm{CyCs}$, $\mathrm{CyCu}$ e RBP e

b) ausência da lesão renal, sua progressão ou qualquer disfunção urinária, através dos valores baixos e estáveis ao longo do tempo dos biomarcadores: KIM-1, NGAL, TGF-ß1 e $\mu$ ALB.

Esses perfis trouxeram potenciais valores de referência dos citados biomarcadores quais podem ser comparados com os dados existentes, embora muito limitados quando se referem à população neonatal e dos lactentes.

Em relação ao poder discriminador para identificação de lesão renal ou da necessidade de intervenção cirúrgica em pacientes com UOC, RBP, NGAL, KIM-1, TGF-ß1 e CyC, separados ou em combinação (principalmente RBP com TGF-ß1, RBP com KIM-1 e NGAL com CyCs e $\mathrm{CyCu}$ ), demonstraram:

a) boa capacidade para detectar dano renal, principalmente nos casos com obstrução severa, e em menor grau, em padrões de obstrução parcial e

b) boa capacidade para diferenciar obstrução severa, parcial e padrões não obstrutivos.

c) ser potencialmente benéficos para embasar a indicação cirúrgica em tempo adequado e no seguimento pós-operatório.

O presente estudo reforça o conceito de que a busca por um biomarcador renal um candidato "escolhido", para servir como uma ferramenta de diagnóstico não-invasivo, fornece os resultados modestos. A combinação de dois ou três biomarcadores com o melhor desempenho individual parece ser uma opção mais realista, na busca de um simples, econômico, prático e confiável painel dos biomarcadores de desordens urinárias. 
ANEXOS 


\section{ANEXOS}

\section{Anexo A - Termo de consentimento livre e esclarecido do grupo pacientes}

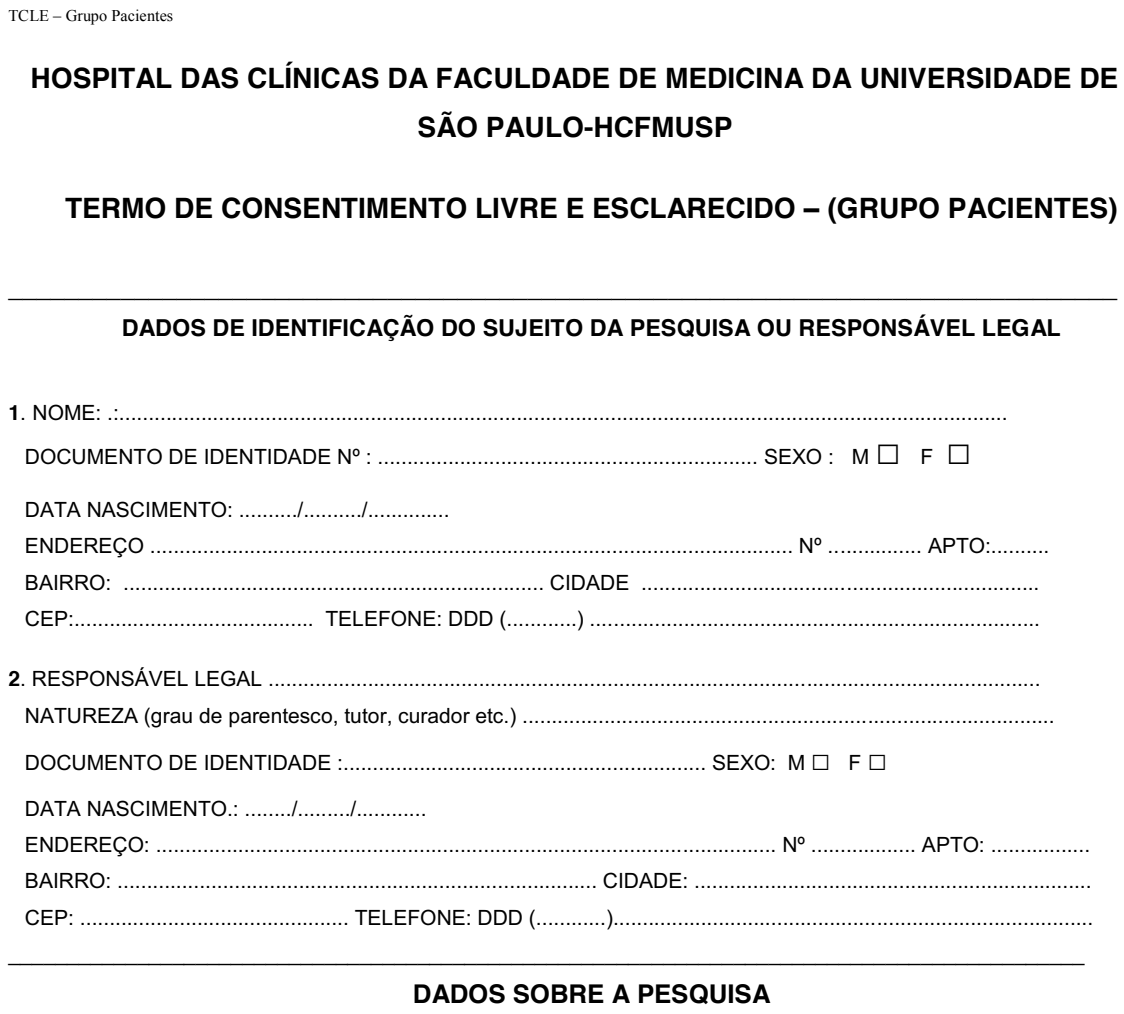

1. TíTULO DO PROTOCOLO DE PESQUISA : "Biomarcadores para diagnóstico precoce de injúria renal em uropatias obstrutivas congênitas".

2. PESQUISADOR : Dra. Vera H. Koch CARGO/FUNÇÃO: Médica Assistente INSCRIÇÃO CONSELHO REGIONAL Nº $\mathbf{4 1 6 2 7}$ UNIDADE DO HCFMUSP: Nefrologia Pediátrica - Instituto da Criança

3. AVALIAÇÃO DO RISCO DA PESQUISA:

$\begin{array}{ll}\text { RISCO MÍNIMO } & X \quad \text { RISCO MÉDIO } \square \\ \text { RISCO BAIXO } \square & \text { RISCO MAIOR } \square\end{array}$

4. DURAÇÃO DA PESQUISA : ...12 meses.

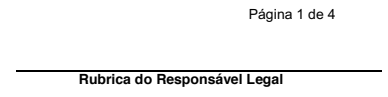




\section{INFORMACCÕES GERAIS DO PROJETO E CONSENTIMENTO INFORMADO PARA GRUPO PACIENTES}

Título: "Biomarcadores para diagnóstico precoce de injúria renal em uropatias obstrutivas congênitas".

1. Você está sendo convidado a autorizar a inclusão do seu filho recém nascido no estudo que visa avaliar a sua função renal através da coleta de amostras de urina e sangue para detecção e mensuração de certas substâncias cujo nível, quando aumentado, poderia revelar a presença da doença renal mais cedo do que com os metodos convencionais. Sabendo da existência da doença do rim com antecedência, teriamos chance de prevenir ou minimizar as consequências que a doença renal leva quando despercebida ou encontrada com atraso.

2. Apos o seu consentimento os procedimentos realizados serão coleta de urina, de sangue e em casos selecionados de líquido amniótico no período pré-natal. Urina será colhida através de uso de saco coletor, sem nenhum rísco ao paciente, nas consultas marcadas com objetivo de dosar substâncias que em pesquisas prévias estão relacionadas a lesão renal. Sangue será coletado por punção da veia (da mão ou do antebraço) em quantidade mínima necessária (até no máximo de 1,0 ml) em condições estéreis, nas consultas marcadas, aproveitando a coleta de rotina realizada para a avaliação ambulatorial durante o seguimento do paciente, com objetivo de dosar substâncias que em pesquisas prévias estão relacionadas a lesão renal. No caso da coleta de sangue a punção será realizada por profissional altamente treinado e experiente do laboratório do ICr-HCFMUSP. Coletas de líquido amniótico serão realizadas somente em casos especiais (quando existe suspeita que o bebê possui algum problema de saúde tal como defeitos congênitos do bebê) seguindo indicação da equipe da Medicina fetal do ICHC-FMUSP com objetivo diagnóstico. Nestes casos utilizaremos uma pequena amostra deste material para dosar as mesmas substâncias sinalizadoras de dano renal que dosaremos posteriormente na urina e sangue após o nascimento da criança. O rísco nestes casos está associado a condição fetal, pois a indicação será determinada exclusivamente pela equipe da Medicina fetal nos casos com indicação absoluta para realizar este exame.

3. Procedimentos rotineiros durante o seguimento de 12 meses incluem coletas de sangue de metodologia já descrita acima, no período ao nascer (entre $3^{\circ}$ e $7^{\circ}$ dia), no $2^{\circ}, 6^{\circ}$ e $12^{\circ}$ mês de vida, e de urina, de metodologia já descrita acima, no período ao nascer (entre $3^{\circ}$ a $7^{\circ}$ dia), no $1^{\circ}, 2^{\circ}, 3^{\circ}, 6^{\circ}, 9^{\circ}$ e $12^{\circ}$ mês de vida. O objetivo destes exames é controle de rotina do paciente, com fins diagnósticos. Também, de rotina com objetivo de confirmação do diagnóstico da doença renal e de seu controle serão realizados exames radiológicos: ultrasom do aparelho urinário no pré-natal (como exame a ser realizado rotineiramente nesses casos), ultrasom do aparelho urinário com color doppler de artérias e veias renais 
até primeiros 10 dias de vida, com 6 e 12 meses de vida, e cintilografia renal estática com DMSA (ácido dimercaptosuccinico) aos 6 meses de vida, que consiste em injeção dessa substância pela veia do braço que em algumas horas acumula nos rins, sendo paciente posicionado debaixo de uma câmera especial que produz imagens dos rins. Exame normalmente não necessita preparos especiais nem sedação e é importante para confirmar a presença e determinar a extenção da lesão renal.

4. Em relação aos desconfortos e riscos esperados nos procedimentos dos itens 2 e 3 , é esperado dor a punção de veia, que pode ser minimizada pela coleta por equipe altamente treinada e experiente como no caso dos coletores do ICr-HCFMUSP. Quanto a coleta de urina, ela não deverá apresentar nenhum desconforto maior, porém as vezes o tempo de espera para micção do paciente pode ser prolongado (até algumas horas), levando a estafa. Desconfortos relacionados aos exames de imagem referem se principalmente a cintilografia com DMSA onde é necessário realizar a punção da veia para administração da substância a ser radiografada e o tempo de espera necessário para conclusão do exame, de algumas horas. Não são conhecidos maiores desconfortos quanto USG de rins e vias urinárias com Doppler de artérias e veias renais.

5. Mencionando os benefícios aos pacientes participantes, a pesquisa e os resultados da pesquisa somente vão estar disponíveis ao final do período de analise dos dados, não podendo interferir nas condutas tomadas durante o seguimento do paciente, um dos benefícios será o monitoramento detalhado do paciente pela equipe médica envolvida. Os resultados finais da pesquisa, poderão comprovar que a dosagem das substâncias mencionadas na urina e sangue dos pacientes, será útil para a detecção precoce de doença renal e neste caso no futuro poderá servir como padrão em diagnóstico precoce de doença renal para os pacientes que ainda vão nascer.

6. Neste estudo não serão realizados procedimentos alternativos, apenas os que foram mencionados acima.

7. Garantia de acesso: em qualquer etapa do estudo, você terá acesso aos profissionais responsáveis pela pesquisa para esclarecimento de eventuais dúvidas. O principal investigador é a Dra. Vera H. Koch que pode ser encontrada no endereço Av. Dr. Enéas Carvalho de Aguiar, 647, São Paulo - SP (CEP 05403.000), Telefone: 2661-8533. Se você tiver alguma consideração ou dúvida sobre a ética da pesquisa, entre em contato com a Comissão de Ética para Análise de Projetos de Pesquisa do HCFMUSP - CAPPesq no telefone (11) 2661-6442 ramais 16, 17 ou 18 ou no endereço: Rua. Dr. Ovídio Pires de Campos, 225 - São Paulo - SP CEP: 05403-905 durante o horário de atendimento, que é das 07h às 16h ou pelo e-mail: marcia.carvalho@hc.fm.usp.br; ou a CONEP- Conselho Nacional de Saúde (Coordenador da CONEP: Jorge Venâncio)- SEPN 510 Norte, Bloco A 1 subsolo, Edifício ExINAN- Unidade II- Ministério da Saúde- CEP: 70750-251- Brasília- DF, Tel (61) 3315-5878, FAX: (61)3315-5879. É garantida a liberdade da retirada de consentimento a qualquer momento e deixar de participar do estudo, sem qualquer prejuízo à continuidade de seu tratamento na Instituição; 
8. Direito de confidencialidade - As informações obtidas serão analisadas em conjunto com outros pacientes, não sendo divulgado a identificação de nenhum paciente;

9. Direito de ser mantido atualizado sobre os resultados parciais da pesquisa, que sejam do conhecimento dos pesquisadores;

10. Despesas e compensações: não há despesas pessoais para o participante em qualquer fase do estudo, incluindo exames e consultas. Também não há compensação financeira relacionada à sua participação. Se existir qualquer despesa adicional, ela será absorvida pelo orçamento da pesquisa.

11. Pesquisador se responsabiliza de utilizar os dados e o material coletado somente para esta pesquisa.

Acredito ter sido suficientemente informado a respeito das informações que li ou que foram lidas para mim, descrevendo o estudo "Biomarcadores para Diagnóstico Precoce de Injúria Renal em Uropatias Obstrutivas Congênitas"

Eu discuti com a Dra. Vera H. Koch sobre a minha decisão em participar nesse estudo. Ficaram claros para mim quais são os propósitos do estudo, os procedimentos a serem realizados, seus desconfortos e riscos, as garantias de confidencialidade e de esclarecimentos permanentes. Ficou claro também que minha participação é isenta de despesas e que tenho garantia do acesso a tratamento hospitalar quando necessário.

Concordo voluntariamente em participar deste estudo e poderei retirar o meu consentimento a qualquer momento, antes ou durante o mesmo, sem penalidades ou prejuízo ou perda de qualquer benefício que eu possa ter adquirido, ou no meu atendimento neste Serviço.

Assinatura do paciente/representante legal

Data

Assinatura da testemunha

Data

para casos de pacientes menores de 18 anos, analfabetos, semi-analfabetos ou portadores de deficiência auditiva ou visual.

(Somente para o responsável do projeto)

Declaro que obtive de forma apropriada e voluntária o Consentimento Livre e Esclarecido deste paciente ou representante legal para a participação neste estudo.

Assinatura do responsável pelo estudo Data

TCLE- versão2 - 10 de junho de 2014. Hospital das Clinicas da Faculdade de Medicina
da USP - Instituto da Criança. tel: (11) 2661-8833

Página 4 de 4 


\section{Anexo B - Termo de consentimento livre e esclarecido do grupo- controle}

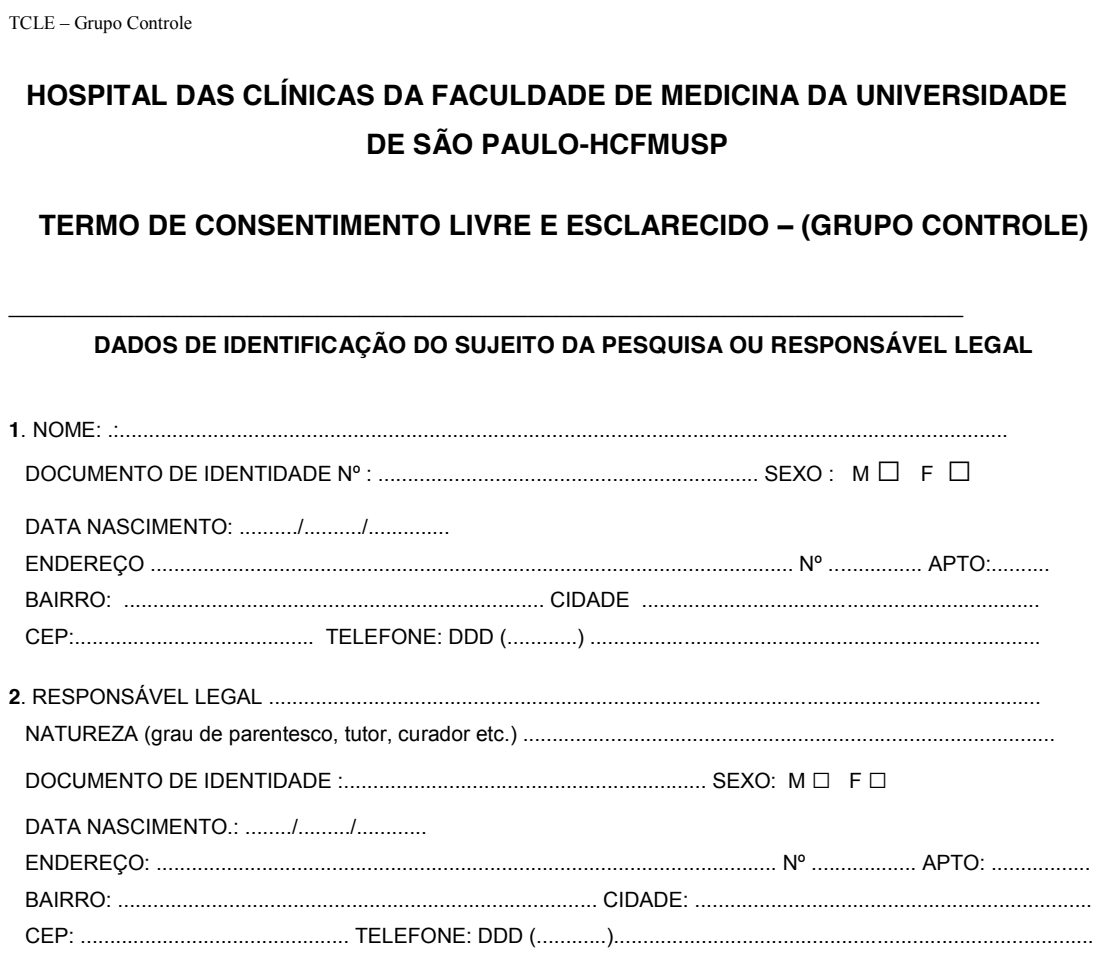

1. TÍTULO DO PROTOCOLO DE PESQUISA : "Biomarcadores para diagnóstico precoce de injúria renal em uropatias obstrutivas congênitas".

2. PESQUISADOR : Dra. Vera H. Koch CARGO/FUNÇÃO: Médica Assistente INSCRIÇÃO CONSELHO REGIONAL N 41627 UNIDADE DO HCFMUSP: Nefrologia Pediátrica - Instituto da Criança

3. AVALIAÇÃO DO RISCO DA PESQUISA:

\begin{tabular}{|c|c|c|}
\hline RISCO MÍNIMO & $\mathrm{X}$ & RISCO MÉDIC \\
\hline RISCO BAIXO & $\square$ & RISCO M \\
\hline
\end{tabular}

4. DURAÇÃO DA PESQUISA : ...12 meses. 
TCLE - Grupo Controle

\section{INFORMAÇÕES GERAIS DO PROJETO E CONSENTIMENTO INFORMADO PARA GRUPO CONTROLE}

Título: "Biomarcadores para diagnóstico precoce de injúria renal em uropatias obstrutivas congênitas".

1. Você está sendo convidado a autorizar a inclusão do seu filho recém nascido no estudo que visa avaliar a sua função renal através da coleta de amostras de urina e sangue para detecção e mensuração de certas substâncias cujo nível, quando aumentado, pode revelar a presença da doença renal mais cedo do que com os metodos convencionais. Sabendo da existência da doença do rim com antecedência, teriamos chance de prevenir ou minimizar as consequências que a doença renal leva quando despercebida ou encontrada com atraso.

2. Apos o seu consentimento os procedimentos realizados serão coleta de urina e de sangue da criança. Urina será colhida através de uso de saco coletor, sem nenhum rísco ao paciente, nas consultas marcadas com objetivo de dosar substâncias que em pesquisas prévias estão relacionadas a lesao renal. Sangue será coletado por punção da veia (da mão ou do antebraço) em quantidade mínima necessária (até no máximo de 1,0 ml) em condições estéreis, nas consultas de puericultura, aproveitando a coleta de rotina realizada para a avaliação ambulatorial durante o seguimento do paciente, com objetivo de dosar substâncias que em pesquisas prévias estão relacionadas a lesao renal. No caso da coleta de sangue a punção será realizada por profissional altamente treinado e experiente do laboratório do $\mathrm{ICr}$ HCFMUSP. Também, com objetivo de controle da normalidade do aparelho urinário será realizado exame radiológico: ultrasom do aparelho urinário no pré-natal, aos 10 dias de vida e aos 12 meses de vida.

3. Procedimentos rotineiros durante o seguimento de 12 meses incluem coletas de sangue e urina de metodologia já descrita acima. Sangue será coletado no período entre $3^{\circ}$ a $7^{\circ}$ dia de vida, no $6^{\circ}$ e $12^{\circ}$ mês de vida. Urina será coletada no período entre $3^{\circ}$ a $7^{\circ}$ dia, $1^{\circ}, 2^{\circ}, 3^{\circ}, 6^{\circ}, 9^{\circ}$ e $12^{\circ}$ mês de vida. $\mathrm{O}$ objetivo destes exames é controle de rotina do paciente, com fins diagnósticos. Também, de rotina com o objetivo de confirmação do diagnósticos da doença renal e de seu controle será realizado ultrassom de rins e vias urinárias e Color Doppler de artérias e veias renais até $10^{\circ}$ dia de vida e no $12^{\circ}$ mês de vida.

4. Em relação aos desconfortos e ríscos esperados nos procedimentos dos itens 2 e 3, é esperado dor a punção de veia, que pode ser minimizada pela coleta por equipe altamente treinada e experiente como no caso dos coletores do ICr-HCFMUSP. Quanto a coleta de urina, ela não deverá apresentar nenhum desconforto maior, porém as vezes o tempo de espera para micção do paciente pode ser prolongado (até algumas horas), levando a estafa. Não são conhecidos maiores desconfortos quanto USG de rins e vias urinárias com Doppler de artérias e veias renais. 
TCLE - Grupo Controle

5. Mencionando os benefícios aos pacientes do grupo controle - não existem benefícios diretos da pesquisa, mas existem benfícios indiretos relacionados a realização de seguimento de puericultura no ambulatório do Berçário Anexo a Maternidade (BAM) do ICr-HCFMUSP.

6. Neste estudo não serão realizados procedimentos alternativos, apenas os que foram mencionados acima.

7. Garantia de acesso: em qualquer etapa do estudo, você terá acesso aos profissionais responsáveis pela pesquisa para esclarecimento de eventuais dúvidas. O principal investigador é a Dra. Vera $\mathrm{H}$. Koch que pode ser encontrada no endereço Av. Dr. Enéas Carvalho de Aguiar, 647, São Paulo - SP CEP - 05403.900, Telefone: 2661-8833. Se você tiver alguma consideração ou dúvida sobre a ética da pesquisa, entre em contato com a Comissão de Ética para Análise de Projetos de Pesquisa do HCFMUSP - CAPPesq no telefone (11) 2661-6442 ramais 16, 17 ou 18 ou no endereço: Rua. Dr. Ovídio Pires de Campos, 225 - São Paulo - SP CEP: 05403-905 durante o horário de atendimento, que é das $07 \mathrm{~h}$ às $16 \mathrm{~h}$ ou pelo e-mail: marcia.carvalho@hc.fm.usp.br; ou a CONEP- Conselho Nacional de Saúde (Coordenador da CONEP: Jorge Venâncio)- SEPN 510 Norte, Bloco A 1 subsolo, Edifício Ex-INAN- Unidade II- Ministério da Saúde- CEP: 70750-251- Brasília- DF, Tel (61) 3315-5878, FAX: (61)3315-5879.

8. É garantida a liberdade da retirada de consentimento a qualquer momento e deixar de participar do estudo, sem qualquer prejuízo à continuidade de seu tratamento na Instituição;

9. Direito de confidencialidade - As informações obtidas serão analisadas em conjunto com outros pacientes, não sendo divulgado a identificação de nenhum paciente;

10. Direito de ser mantido atualizado sobre os resultados parciais da pesquisa, que sejam do conhecimento dos pesquisadores;

11. Despesas e compensações: não há despesas pessoais para o participante em qualquer fase do estudo, incluindo exames e consultas. Também não há compensação financeira relacionada à sua participação. Se existir qualquer despesa adicional, ela será absorvida pelo orçamento da pesquisa.

12. Pesquisador se responsabiliza de utilizar os dados e o material coletado somente para esta pesquisa.

Acredito ter sido suficientemente informado a respeito das informações que li ou que foram lidas para mim, descrevendo o estudo "Biomarcadores para Diagnóstico Precoce de Injúria Renal em Uropatias Obstrutivas Congênitas"

Eu discuti com a Dra. Vera H. Koch sobre a minha decisão em participar nesse estudo. Ficaram claros para mim quais são os propósitos do estudo, os procedimentos a serem realizados, seus desconfortos e riscos, as garantias de confidencialidade e de esclarecimentos permanentes. TCLE - versão2 - 10 de junho de 2014. Hospital das Clinicas da Faculdade de 
TCLE - Grupo Controle

Ficou claro também que minha participação é isenta de despesas e que tenho garantia do acesso a tratamento hospitalar quando necessário.

Concordo voluntariamente em participar deste estudo e poderei retirar o meu consentimento a qualquer momento, antes ou durante o mesmo, sem penalidades ou prejuízo ou perda de qualquer benefício que eu possa ter adquirido, ou no meu atendimento neste Serviço.

Assinatura do paciente/representante legal Data

Data

Assinatura da testemunha

para casos de pacientes menores de 18 anos, analfabetos, semi-analfabetos ou portadores de deficiência auditiva ou visual.

(Somente para o responsável do projeto)

Declaro que obtive de forma apropriada e voluntária o Consentimento Livre e Esclarecido deste paciente ou representante legal para a participação neste estudo.

Assinatura do responsável pelo estudo

Data 
Anexo C - Características demográficas e clínicas dos pacientes com UOC em relação a indicação cirúrgica

Tabela 7 - Características demográficas e clínicas dos pacientes operados, não operados e do grupo-controle em relação a indicação cirúrgica nos portadores de UOC. 
Tabela 7 - Características demográficas e clínicas dos pacientes operados, não operados e do grupo-controle em relação a indicação cirúrgica nos portadores de UOC

\begin{tabular}{|c|c|c|c|c|c|c|c|c|}
\hline \multirow[t]{2}{*}{ Características da Coorte } & \multirow{2}{*}{$\begin{array}{l}\text { Pacientes } \\
\boldsymbol{n}=\mathbf{3 7}\end{array}$} & \multicolumn{4}{|c|}{$\begin{array}{c}\mathrm{GOP}^{1}+\mathrm{GOI}^{2}(<12 \text { meses }) \\
n=17 / 37(46 \%) \\
\end{array}$} & \multirow{2}{*}{$\begin{array}{c}\text { GOT }^{3} \\
n=7 / 37 \\
(18,9 \%)\end{array}$} & \multirow{2}{*}{$\begin{array}{c}\mathrm{GNO}^{4} \\
n=13 / 37 \\
(35,1 \%)\end{array}$} & \multirow{2}{*}{$\begin{array}{c}\text { Controles } \\
\boldsymbol{n}=\mathbf{2 4}\end{array}$} \\
\hline & & Todos (17) & HU (5) & HB (4) & OTUB (8) & & & \\
\hline Idade materna (anos) & $28,1 \pm 4,4$ & $27,5 \pm 7,2$ & $26,2 \pm 3,7$ & $27,3 \pm 10,8$ & $28,5 \pm 6,4$ & $28,9 \pm 6,1$ & $28,4 \pm 4,4$ & $30,5 \pm 4,7$ \\
\hline \multicolumn{9}{|l|}{ Sexo } \\
\hline Masculino (\%) & $\begin{array}{c}29 \\
(78,4 \%)\end{array}$ & $\begin{array}{c}15 \\
(88,2 \%)\end{array}$ & $\begin{array}{c}4 \\
(80 \%)\end{array}$ & $\begin{array}{c}3 \\
(75 \%)\end{array}$ & $\begin{array}{c}8 \\
(100 \%)\end{array}$ & $\begin{array}{c}7 \\
(87,5 \%)\end{array}$ & $\begin{array}{c}8 \\
(61,5 \%)\end{array}$ & $\begin{array}{c}14 \\
(58,3 \%)\end{array}$ \\
\hline Feminino $(\%)$ & $\begin{array}{c}8 \\
(21,6 \%)\end{array}$ & $\begin{array}{c}2 \\
(11,8 \%)\end{array}$ & $\begin{array}{c}1 \\
(20 \%)\end{array}$ & $\begin{array}{c}1 \\
(25 \%)\end{array}$ & - & $\begin{array}{c}1 \\
(12,5 \%)\end{array}$ & $\begin{array}{c}5 \\
(38,5 \%)\end{array}$ & $\begin{array}{c}10 \\
(41,7 \%)\end{array}$ \\
\hline \multicolumn{9}{|l|}{ Etnia } \\
\hline Pardo e negro (\%) & $\begin{array}{c}19 \\
(51,3 \%)\end{array}$ & $\begin{array}{c}7 \\
(41,2 \%)\end{array}$ & $\begin{array}{c}2 \\
(40 \%)\end{array}$ & $\begin{array}{c}1 \\
(25 \%)\end{array}$ & $\begin{array}{c}4 \\
(50 \%)\end{array}$ & $\begin{array}{c}5 \\
(71,4 \%)\end{array}$ & $\begin{array}{c}7 \\
(53,8 \%)\end{array}$ & $\begin{array}{c}12 \\
(50 \%)\end{array}$ \\
\hline Branco (\%) & $\begin{array}{c}18 \\
(48,6 \%)\end{array}$ & $\begin{array}{c}10 \\
(58,8 \%)\end{array}$ & $\begin{array}{c}3 \\
(60 \%)\end{array}$ & $\begin{array}{c}3 \\
(75 \%)\end{array}$ & $\begin{array}{c}4 \\
(50 \%)\end{array}$ & $\begin{array}{c}2 \\
(28,6 \%)\end{array}$ & $\begin{array}{c}6 \\
(46,2 \%)\end{array}$ & $\begin{array}{c}12 \\
(50 \%)\end{array}$ \\
\hline Idade gestacional (sem.) & $38,1 \pm 2,4$ & $37,1 \pm 2,9^{*}$ & $39,1 \pm 0,7$ & $37,5 \pm 1,1$ & $35,7 \pm 3,6$ & $39,6 \pm 1,0^{*}$ & $38,9 \pm 1$ & $38,9 \pm 1,4$ \\
\hline Peso ao nascer (kg) & $3,25 \pm 0,6$ & $3,10 \pm 0,7$ & $3,41 \pm 0,3$ & $3,56 \pm 0,2$ & $2,69 \pm 0,8^{*}$ & $3,63 \pm 0,5$ & $3,26 \pm 0,4$ & $3,05 \pm 0,4$ \\
\hline Peso aos 12 meses (kg) & $9,80 \pm 1,2$ & $9,8 \pm 1,4$ & $10,1 \pm 1,6$ & $10,3 \pm 1,3$ & $9,1 \pm 0,9$ & $9,9 \pm 0,8$ & $9,9 \pm 1,1$ & $9,59 \pm 1,1$ \\
\hline $\begin{array}{l}\text { Comprimento } \\
\text { aos } 12 \text { meses }(\mathrm{cm})\end{array}$ & $75,0 \pm 2,3$ & $75,1 \pm 2,8$ & $75,5 \pm 2,6$ & $75,9 \pm 3,2$ & $74,4 \pm 2,4$ & $75,1 \pm 1,9$ & $75,0 \pm 1,6$ & $75,1 \pm 2,3$ \\
\hline
\end{tabular}

Dados apresentados como média \pm desvio padrão ou como porcentagem (\%). A significância estatística em p $<0,05$ verificada através dos testes Qui-quadrado de Pearson, exato de Fisher e *t-Student com variâncias iguais em comparação ao grupo controle.

HU: hidro(uretero)nefrose unilateral; HB: hidro(uretero)nefrose bilateral; OTUB: obstrução do trato urinário baixo; ${ }^{1} \mathrm{GOP}$ : grupo operado precoce ( $<2$ meses), incluiu 3 HB e 6 OTUB pacientes; ${ }^{2} \mathrm{GOI}$ : grupo operado intermediário (2-12 meses), inclui $5 \mathrm{HU}, 1 \mathrm{HB}$ e 2 OTUB pacientes; ${ }^{3} \mathrm{GOT}$ : grupo operado tardio (>12 meses), inclui 3 HU, 3 HB e 1 OTUB paciente(s); ${ }^{4} \mathrm{GNO}$ : grupo não operado, inclui 6 HU, 6 HB e 1 OTUB paciente(s); UOC: uropatias obstrutivas congênitas; sem.: semanas. 
Anexo D - Características clínicas e cirúrgicas da UOC em grupos e subgrupos dos pacientes

Tabela 8 - Características clínicas e cirúrgicas da UOC em grupos e subgrupos dos pacientes. 
Tabela 8 - Características clínicas e cirúrgicas da UOC em grupos e subgrupos dos pacientes

\begin{tabular}{|c|c|c|c|c|c|c|c|c|c|c|}
\hline \multirow[t]{3}{*}{ Parâmetros } & \multirow{3}{*}{$\begin{array}{r}\text { Pacientes } \\
\boldsymbol{n}=\mathbf{3 7} \\
\mathbf{1 0 0 \%}\end{array}$} & \multicolumn{4}{|c|}{$\mathrm{GOP}+\mathrm{GOI}(<12$ meses $)$} & \multirow{3}{*}{$\begin{array}{c}\text { GOT } \\
n=7 \\
\mathbf{1 8 , 9 \%}\end{array}$} & \multicolumn{4}{|c|}{ GNO } \\
\hline & & Todos (17) & HU (5) & HB (4) & OTUB (8) & & Todos (13) & HU (6) & HB (6) & B (1) \\
\hline & & $46 \%$ & $29,4 \%$ & $23,5 \%$ & $47,1 \%$ & & $35,1 \%$ & $46,2 \%$ & $46,2 \%$ & $7,6 \%$ \\
\hline Idade na cirurgia & $5(0-19)$ & $1,5(0-11)$ & $7(3,5-9)$ & $1.5(0-4,5)$ & $1(0-11)$ & $17(13,5-19)$ & & & & \\
\hline \multicolumn{11}{|l|}{ DAP (mm) } \\
\hline pré-natal & $20(15-95)$ & $24(15-95)$ & $26(21-35)$ & $48(16-30)$ & $17,5(15-80)$ & $26(15-38)$ & $15(15-30)$ & $16(15-30)$ & $15(15-16)$ & 15 \\
\hline pré-operatório & $19(0-95)$ & $33(5-95)$ & $37(24-82)$ & $53(20-95)$ & $19(5-58)$ & $19(6-36)$ & $9(0-35)^{\dagger}$ & $13(7-35)^{\dagger}$ & $11,5(7-16)^{\dagger}$ & 0 \\
\hline pós-operatório & $14(0-117)$ & $10(0-117)^{* 1,2}$ & $17(10-117)$ & $10(9-15)$ & $14(0-85)$ & $20(8-43)$ & - & - & - & - \\
\hline Lateralidade (D/E) & $17 / 19$ & $10 / 7$ & $2 / 3$ & $4 / 4$ & $4 / 0$ & $3 / 4$ & $4 / 8$ & $2 / 4$ & $2 / 4$ & - \\
\hline \multicolumn{11}{|l|}{ FRD (\%) } \\
\hline pré-operatório & & $43(5-73)$ & $41(5-45)$ & $62(38-73)$ & $42(11-50)$ & $54(0-97)$ & $53(0-59)^{\dagger}$ & $51,5(5-59)^{\dagger}$ & $54(49-56)^{\dagger}$ & - \\
\hline pós-operatório & & $45(0-64)$ & $48(0-51)$ & $47(0-64)$ & $39(9-50)$ & $52(0-93)$ & - & - & - & - \\
\hline \multicolumn{11}{|l|}{ Complicações } \\
\hline DRC & $8(21,6 \%)$ & $7(41,2 \%)$ & - & - & $7(87,5 \%)$ & $1(14,3 \%)$ & $1(7,7 \%)$ & $1(16,7 \%)$ & - & - \\
\hline Hipercalemia & $10(27 \%)$ & $8(80 \%)$ & - & $2(20 \%)$ & $6(60 \%)$ & - & $2(20 \%)$ & - & $2(20 \%)$ & - \\
\hline ATR & $13(35,1 \%)$ & $7(53,8 \%)$ & $1(7,7 \%)$ & - & $6(46,2 \%)$ & $2(15,4 \%)$ & $2(15,4 \%)$ & $1(7,7 \%)$ & $1(7,7 \%)$ & - \\
\hline \multicolumn{11}{|l|}{ Procedimentos } \\
\hline Nefrectomia ${ }^{\S}$ & $2(5,4 \%)$ & $1(50 \%)$ & $1(50 \%)$ & - & - & $1(50 \%)$ & & & & \\
\hline Pieloplastia & $16(43,2 \%)$ & $11(68,8 \%)$ & $4(25 \%)$ & $4(25 \%)$ & $3(18,8 \%)$ & $5(31,3 \%)$ & & & & \\
\hline Fulguração & $7(18,9 \%)$ & - & - & - & $6(75 \%)$ & $1(14,3 \%)$ & & & & \\
\hline Ureterostomia & $4(10,8 \%)$ & $4(100 \%)$ & - & $2(50 \%)$ & $2(50 \%)$ & - & - & - & - & - \\
\hline \multicolumn{11}{|c|}{ Coleta de amostras (dias) } \\
\hline pré-operatório & & $7(3-59)$ & $15(3-59)$ & $4(3-38)$ & $5(3-59)$ & - & & & & \\
\hline pós-operatório & & $32(11-84)$ & $48(11-84)$ & $33(17-53)$ & $21,5(14-42)$ & - & & & & \\
\hline
\end{tabular}

${ }^{\S}$ realizadas após 12 meses de vida. ${ }^{\dagger}$ observado aos 12 meses de vida. Dados apresentados como mediana e (5: 95) percentis ou como porcentagem (\%). A *significância estatística em $\mathrm{p}<0,05$ verificada através dos testes ${ }^{1} \mathrm{t}$-Student $\mathrm{e}^{2}$ Wilcoxon para dados pareados. UOC: uropatias obstrutivas congênitas; HU: hidro(uretero)nefrose unilateral; OTUB: obstrução do trato urinário baixo; HB: hidro(uretero)nefrose bilateral; GOP: grupo operado precoce; GOI: grupo operado intermediário; GOT: grupo operado tardio; GNO: grupo não operado; DAP: diâmetro anteroposterior da pelve renal; D: rim direito; E: rim esquerdo; FRD: função renal diferencial; ATR: acidose tubular renal; DRC: doença renal crônica. 
Anexo E - Potencial benefício dos biomarcadores na tomada das decisões sobre a indicação cirúrgica a tempo, comparado com os métodos diagnósticos tradicionais

Tabela 11 - Características dos biomarcadores de acordo com o seu desempenho em relação à tomada convencional das decisões cirúrgicas 
Tabela 11 - Características dos biomarcadores de acordo com o seu desempenho em relação à tomada das decisões cirúrgicas convencional

\begin{tabular}{|c|c|c|c|c|}
\hline Subgrupos dos pacientes $\left(\mathrm{n}^{\circ}\right.$ dos casos / \%) & $\begin{array}{l}\mathrm{HU} \\
(14)\end{array}$ & $\begin{array}{l}\mathrm{HB} \\
(13)\end{array}$ & $\begin{array}{l}\text { OTUB } \\
(10) \\
\end{array}$ & $\begin{array}{c}\text { Todos } \\
\text { pacientes } \\
(37 / 100 \%)\end{array}$ \\
\hline Pacientes operados entre 0 e 2 meses (GOP) & 0 & 3 & 6 & $9 / 24,3 \%$ \\
\hline Pacientes operados entre 3 e 12 meses (GOI) & 5 & 1 & 2 & $8 / 21,6 \%$ \\
\hline Pacientes operados no $2^{\circ}$ ano de vida (GOT) & 3 & 3 & 1 & $7 / 18,9 \%$ \\
\hline Pacientes não operados (GNO) nos primeiros 2 anos de vida & 6 & 6 & 1 & $13 / 35,1 \%$ \\
\hline Total dos pacientes operados nos primeiros 2 anos de vida & 8 & 7 & 9 & $24 / 64,9 \%$ \\
\hline \multicolumn{5}{|l|}{ Decisão cirúrgica convencional em relação aos valores dos BMs ( $\mathrm{n}^{\circ}$ dos casos) } \\
\hline Cirurgia realizada a tempo - em concordância com BMs (valores acima do corte) & 0 & 2 & 3 & $5 / 13,5 \%$ \\
\hline Cirurgia realizada com "atraso" - em discordância com BMs (valores acima do corte) & 8 & 4 & 3 & $15 / 40,5 \%$ \\
\hline Cirurgia não necessária e não realizada - em concordância com BMs (valores baixos) & 3 & 3 & 0 & $6 / 16,2 \%$ \\
\hline Cirurgia não realizada até 2 anos - em discordância com BMs (valores acima do corte) & 3 & 3 & 1 & $7 / 18,9 \%$ \\
\hline Cirurgia realizada e necessária - em discordância com BMs (valores baixos) & 0 & 1 & 3 & $4 / 10,8 \%$ \\
\hline Biomarcadores benéficos para antecipação / decisão cirúrgica* & 13 & 9 & 7 & $29 / 78,37 \%$ \\
\hline O tempo estimado de antecipação da cirurgia quando aplicados BMs (em meses, mediana): & 3 & 4,5 & 8,5 & $\geq 3$ \\
\hline
\end{tabular}

${ }^{*}$ para indicar e/ou antecipar a cirurgia 4 ou mais BMs (pelo menos 4 urinários ou 3 urinários e pelo menos 1 sérico) apresentaram valores acima do corte, simultaneamente, no mesmo momento da coleta.

UOC: uropatias obstrutivas congênitas; BMs: biomarcadores; HU: hidro(uretero)nefrose unilateral; OTUB: obstrução do trato urinário baixo; HB: hidro(uretero)nefrose bilateral; GOP: grupo operado precoce; GOI: grupo operado intermediário; GOT: grupo operado tardio; GNO: grupo não operado; 


\section{Anexo F - Potencial benefício dos biomarcadores na tomada das decisões sobre a indicação cirúrgica a tempo, comparado com os métodos diagnósticos tradicionais e analisado para cada biomarcador, individualmente}

Tabela 12 - Características dos biomarcadores séricos e urinários, de acordo com o seu desempenho em relação à tomada das decisões cirúrgicas convencional, analisados individualmente: concordância e discordância entre os métodos. 
Tabela 12 - Concordância e discordância entre o método tradicional e de acordo com o desempenho dos biomarcadores renais séricos e urinários em relação à tomada das decisões sobre a indicação cirúrgica a tempo

\begin{tabular}{|c|c|c|c|c|c|c|c|c|c|c|c|c|c|c|c|c|}
\hline \multirow[b]{3}{*}{ Biomarcador } & \multirow{2}{*}{\multicolumn{2}{|c|}{$\begin{array}{c}\text { GOP } \\
\text { HB+OTUB }\end{array}$}} & \multicolumn{4}{|c|}{ GOI } & \multicolumn{4}{|c|}{ GOT } & \multicolumn{4}{|c|}{ GNO } & \multirow{2}{*}{\multicolumn{2}{|c|}{$\begin{array}{c}\text { Todos } \\
\text { pacientes }\end{array}$}} \\
\hline & & & \multicolumn{2}{|c|}{$\mathrm{HU}$} & \multicolumn{2}{|c|}{$\mathrm{HB}+\mathrm{OTUB}$} & \multicolumn{2}{|c|}{$\mathrm{HU}$} & \multicolumn{2}{|c|}{ HB+OTUB } & \multicolumn{2}{|c|}{$\mathrm{HU}$} & \multicolumn{2}{|c|}{$\mathrm{HB}+\mathrm{OTUB}$} & & \\
\hline & $\mathrm{C}$ & $\mathrm{DC}$ & $\mathrm{C}$ & $\mathrm{DC}$ & $\mathrm{C}$ & $\mathrm{DC}$ & $\mathrm{C}$ & $\mathrm{DC}$ & $\mathrm{C}$ & $\mathrm{DC}$ & $\mathrm{C}$ & $\mathrm{DC}$ & $\mathrm{C}$ & $\mathrm{DC}$ & $\mathbf{C}$ & DC \\
\hline $\mathrm{CrS}$ & $7^{\S}$ & 0 & 0 & $5^{\pi}$ & 2 & 3 & 1 & $2^{\pi}$ & 2 & 2 & 0 & 6 & 3 & 4 & 15 & 22 \\
\hline $\mathrm{CyCs}$ & $4^{\S}$ & $3^{\pi}$ & $5^{*}$ & 0 & 0 & $3^{*}$ & $3^{*}$ & 0 & 2 & 1 & $3^{*}$ & 3 & 0 & 6 & 16 & 15 \\
\hline $\begin{array}{l}\text { BMs séricos } \\
\text { (todos) }\end{array}$ & $11^{\S}$ & $3^{\pi}$ & $5^{*}$ & $5^{\top}$ & 2 & 6 & 4 & $2^{\pi}$ & 4 & 3 & $3^{*}$ & 9 & 3 & 10 & 31 & 37 \\
\hline RBP & $5^{\S}$ & $2^{\pi}$ & $4^{*}$ & 1 & 4 & 1 & 2 & 1 & 3 & 1 & $3^{*}$ & 3 & 6 & 1 & 27 & 10 \\
\hline NGAL & $5^{\S}$ & $2^{\pi}$ & 3 & 2 & 5 & 0 & 3 & 0 & 3 & 1 & $3^{*}$ & 3 & 3 & 4 & 25 & 12 \\
\hline $\mathrm{CyCu}$ & $6^{\S}$ & $1^{\text {ब }}$ & $4^{*}$ & 1 & 5 & 0 & 2 & 1 & 3 & 1 & 4 & 2 & 3 & 4 & 27 & 10 \\
\hline TGF-ß1 & $4^{\S}$ & $3^{\pi}$ & 4 & 1 & $4^{*}$ & 1 & $3^{*}$ & 0 & 3 & 1 & 4 & 2 & 5 & 2 & 27 & 10 \\
\hline KIM-1 & $2^{\S}$ & $5^{\pi}$ & $5^{*}$ & 0 & $4^{*}$ & 1 & 2 & 1 & 2 & 2 & 2 & 4 & 4 & 3 & 21 & 16 \\
\hline$\mu \mathrm{ALB}$ & $3^{\S}$ & $4^{\pi}$ & $4^{*}$ & 1 & 5 & 0 & 3 & 0 & 4 & 0 & 1 & 5 & $2^{*}$ & 5 & 22 & 15 \\
\hline $\begin{array}{l}\text { BMs urinários } \\
\text { (todos) }\end{array}$ & 25 & 17 & 24 & 6 & 27 & 3 & 15 & 3 & 18 & 6 & 17 & 19 & 23 & 19 & 149 & 73 \\
\hline BMs - Todos & 36 & 20 & 29 & 11 & 29 & 9 & 19 & 5 & 22 & 9 & 20 & 28 & 26 & 29 & 180 & 110 \\
\hline
\end{tabular}

${ }^{*}$ os valores acima do corte em 4 ou mais dosagens dos biomarcadores diferentes simultaneamente (mesma coleta/amostra) e pelo menos durante 3 meses consecutivos.

$\S$ os valores acima do corte em 4 ou mais dosagens dos biomarcadores diferentes simultaneamente (mesma coleta/amostra).

" os valores abaixo do corte para determinado biomarcador.

UOC: uropatias obstrutivas congênitas; BMs: biomarcadores; HU: hidro(uretero)nefrose unilateral; OTUB: obstrução do trato urinário baixo; HB: hidro(uretero)nefrose bilateral; GOP: grupo operado precoce; GOI: grupo operado intermediário; GOT: grupo operado tardio; GNO: grupo não operado; C: concordância com decisão cirúrgica tradicional; DC: discordância da decisão cirúrgica tradicional; CrS: creatinina sérica; CyCs: cistatina C sérica; RBP: proteína ligadora de retinol; NGAL: lipocalina associada à gelatinase neutrofílica; $\mu \mathrm{ALB}$ : microalbuminúria; $\mathrm{CyCu}$ : cistatina $\mathrm{C}$ na urina; KIM-1: molécula de injúria renal 1; TGF-ß1: fator transformador de crescimento-beta 1. 
REFERÊNCIAS 


\section{REFERÊNCIAS}

1. Bullock KN, Whitaker RH. Does Good Upper Tract Compliance Preserve Renal Function. J Urol. 1984; 131(5): p. 914-916.

2. Peters CA. Urinary tract obstruction in children. J Urol. 1995 Nov; 154(5): p. 18741883.

3. Lee RS, Cendron M, Kinnamon DD, Nguyen HT. Antenatal Hydronephrosis as a Predictor of Postnatal Outcome: A Meta-analysis. Pediatrics. 2006 Aug; 118(2): p. 586-93.

4. Morris RK, Kilby MD. Congenital urinary tract obstruction. Best Pract Res Clin Obstet Gynaecol. 2008 Feb; 22(1): p. 97-122.

5. Anumba DO, Scott JE, Plant ND, Robson SC. Diagnosis and outcome of fetal lower urinary tract obstruction in the northern region of England. Prenat Diagn. 2005 Jan; 25(1): p. 7-13.

6. Chevalier RL, Thornhill BA, Forbes MS, Kiley SC. Mechanisms of renal injury and progression of renal disease in congenital obstructive nephropathy. Pediatr Nephrol. 2010; 25(4): p. 687-697.

7. Tripp BM, Homsy YL. Neonatal hydronephrosis- the controversy and the management. Pediatr Nephrol. 1995; 9(4): p. 503-509.

8. Nguyen HT, Benson CB, Bromley B, Campbell JB, Chow J, Coleman B, et al. Multidisciplinary consensus on the classification of prenatal and postnatal urinary tract dilation (UTD classification system). J Pediatr Urol. 2014 Dec; 10(6): p. 982998. 
9. Ismaili K, Hall M, Donner C, Thomas D, Vermeylen D, Avni FE. Results of systematic screening for minor degrees of fetal renal pelvis dilatation in an unselected population. Am J Obstet Gynecol. 2003 Jan; 188(1): p. 242-6.

10. Wuhl E, van Stralen K, Verrina E, Bjerre A, Wanner C, Heaf JG, et al. Timing and Outcome of Renal Replacement Therapy in Patients with Congenital Malformations of the Kidney and Urinary Tract. Clin J Am Soc Nephrol. 2013 Jan; 8(1): p. $67-74$.

11. Murer L, Benetti E, Centi S, Della Vella M, Artifoni L, Capizzi A, et al. Clinical and molecular markers of chronic interstitial nephropathy in congenital unilateral ureteropelvic junction obstruction. J Urol. 2006; 176(6 Pt 1): p. 2668-2673.

12. Truong LD, Gaber L, Eknoyan G. Obstructive uropathy. Contrib Nephrol. 2011; 169: p. 311-326.

13. Klein J, Gonzalez J, Miravete M, Caubet C, Chaaya R, Decramer S, et al. Congenital ureteropelvic junction obstruction: human disease and animal models. Int. J. Exp. Path. 2011; 92: p. 168-192.

14. Huang W, Peters C, Zurakowski D, Borer J, Diamond D, Bauer S, et al. Renal biopsy in congenital ureteropelvic junction obstruction: Evidence for parenchymal maldevelopment. Kidney Int. 2006 Jan; 69(1): p. 137-143.

15. Morris RK, Malin GL, Quinlan-Jones E, Middleton LJ, Hemming K, Burke D, et al. Percutaneous vesicoamniotic shunting versus conservative management for fetal lower urinary tract obstruction (PLUTO): a randomised trial. Lancet. 2013 Nov 2; 382(9903): p. 1496-1506. 
16. Chevalier RL, Peters CA. Congenital urinary tract obstruction: Proceedings of the State-Of-The-Art Strategic Planning Workshop-National Institutes of Health, Bethesda, Maryland, USA, 11-12 March 2002. Pediatr Nephrol. 2003; 18(6): p. 576-606.

17. Chevalier RL. Chronic partial ureteral obstruction and the developing kidney. Pediatr Radiol. 2008; 38(Suppl 1): p. S35-40.

18. Chevalier RL. Pathogenesis of renal injury in obstructive uropathy. Curr Opin Pediatr. 2006 Apr; 18(2): p. 153-60.

19. Misseri R, Rink RC, Meldrum DR, Meldrum KK. Inflammatory mediators and growth factors in obstructive renal injury. J Surg Res. 2004 Jun 15; 119(2): p. 149159.

20. Madsen MG. Urinary biomarkers in hydronephrosis. Dan Med J. 2013; 60(2): p. B4582.

21. Decramer S, Zürbig $\mathrm{P}$, Wittke $\mathrm{S}$, Mischak H, Bascands JL, Schanstra JP. Identification of Urinary Biomarkers by Proteomics in Newborns: Use in Obstructive Nephropathy. Contrib Nephrol. 2008; 160: p. 127-41.

22. Madsen MG, Nørregaard R, Frøkiær J, Jørgensen TM. Urinary biomarkers in prenatally diagnosed unilateral hydronephrosis. J Pediatr Urol. 2011; 7(2): p. 10512.

23. Chevalier RL. Biomarkers of congenital obstructive nephropathy: past, present and future. J Urol. 2004; 172(3): p. 852-7. 
24. Freedman AL, Bukowski TP, Smith CA, Evans MI, Berry SM, Gonzalez R, et al. Use of urinary beta-2-microglobulin to predict severe renal damage in fetal obstructive uropathy. Fetal Diagn Ther. 1997; 12(1): p. 1-6.

25. Decramer S, Wittke S, Mischak H, Zurbig P, Walden M, Bouissou P, et al. Predicting the clinical outcome of congenital unilateral ureteropelvic junction obstruction in newborn by urinary proteome analysis. Nat Med. 2006; 12(4): p. 398400.

26. Lee RS. Biomarkers for pediatric urological disease. Curr Opin Urol. 2009 Jul; 19(4): p. 397-401.

27. Gerber C, Harel M, Lynch ML, Herbst KW, Ferrer FA, Shapiro LH. Proximal tubule proteins are significantly elevated in bladder urine of patients with ureteropelvic junction obstruction and may represent novel biomarkers: A pilot study. J Pediatr Urol. 2016; 12(2): p. e1-7.

28. Karakus S, Oktar T, Kucukgergin C, Kalelioglu I, Seckin S, Atar A, et al. Urinary IP-10, MCP-1, NGAL, Cystatin-C, and KIM-1 Levels in Prenatally Diagnosed Unilateral Hydronephrosis: The Search for an Ideal Biomarker. Urology. 2016; 87: p. $185-192$.

29. Noyan A, Parmaksiz G, Dursun H, Ezer S, Anarat R, Cengiz N. Urinary NGAL, KIM-1 and L-FABP concentrations in antenatal hydronephrosis. J Pediatr Urol. 2015; 11(5): p. 249.e1-6.

30. Trnka P, Hiatt MJ, Tarantal AF, Matsell DG. Congenital urinary tract obstruction: de ning markers of developmental kidney injury. Pediatr Res. 2012; 72(5): p. 44654. 
31. Saeidi B, Koralkar R, Griffin RL, Halloran B, Ambalavanan N, Askenazi DJ. Impact of gestational age, sex, and postnatal age on urine biomarkers in premature neonates. Pediatr Nephrol. 2015; 30: p. 2037-2044.

32. DeFreitas MJ, Seeherunvong W, Katsoufis CP, RamachandraRao S, Duara S, Yasin $\mathrm{S}$, et al. Longitudinal patterns of urine biomarkers in infants across gestational ages. Pediatr Nephrol. 2016; 31: p. 1179-1188.

33. Bennett MR, Nehus E, Haffner C, Ma Q, Devarajan P. Pediatric reference ranges for acute kidney injury biomarkers. Pediatr Nephrol. 2015 April; 30(4): p. 677-685.

34. Pasala S, Carmody JB. How to use. serum creatinine, cystatin C and GFR. Arch Dis Child Educ Pract Ed. 2016; 0: p. 1-7.

35. Abitbol CL, DeFreitas MJ, Strauss J. Assessment of kidney function in preterm infants: lifelong implications. Pediatr Nephrol. 2016; 31: p. 2213-2222.

36. LaBaer J. So, you want to look for biomarkers (introduction to the special biomarker issue). J. Proteome Res. 2005; 4: p. 1053-1059.

37. Lisowska-Myjak B. Serum and Urinary Biomarkers of Acute Kidney Injury. Blood Purif. 2010; 29: p. 357-365.

38. Nguyen MT, Devarajan P. Biomarkers for the early detection of acute kidney injury. Pediatr Nephrol. 2008; 23(1): p. 2151-2157.

39. Ricci Z, Ronco C. Today's approach to the critically ill patient with acute kidney injury. Blood Purif. 2009; 27(1): p. 127-134. 
40. Wheeler DS, Devarajan P, Ma Q, Harmon K, Monaco M, Cvijanovich N, et al. Serum neutrophil gelatinase-associated lipocalin (NGAL) as a marker of acute kidney injury in critically ill children with septic shock. Crit Care Med. 2008; 36(4): p. $1297-1303$.

41. Mishra J, Ma Q, Prada A, Mitsnefes M, Zahedi K, Yang J, et al. Identification of neutrophil gelatinase-associated lipocalin as a novel urinary biomarker for ischemic injury. J Am Soc Nephrol. 2003; 14(10): p. 2534-2543.

42. Mishra J, Mori K, Ma Q, Kelly C, Yang J, Mitsnefes M, et al. Amelioration of ischemic acute renal injury by neutrophil gelatinase-associated lipocalin. J Am Soc Nephrol. 2004; 15(12): p. 3073-3082.

43. Bolignano D, Coppolino G, Campo S, Aloisi C, Nicocia G, Frisina N, et al. Urinary neutrophil gelatinase-associated lipocalin (NGAL) is associated with severity of renal disease in proteinuric patients. Nephrol Dial Transplant. 2008; 23(1): p. 4146.

44. Devarajan P. Emerging urinary biomarkers in the diagnosis of acute kidney injury. Expert Opin Med Diagn. 2008; 2(4): p. 387-398.

45. Haase M, Bellomo R, Devarajan P, Schlattmann P, Haase-Fielitz A, NGAL Metaanalysis Investigator Group. Accuracy of neutrophil gelatinase-associated lipocalin (NGAL) in diagnosis and prognosis in acute kidney injury: a systematic review and meta-analysis. Am J Kidney Dis. 2009; 54(6): p. 1012-24.

46. Bharadwaj S, Ginoya S, Tandon P, Gohel TD, Guirguis J, Vallabh H, et al. Malnutrition: laboratory markers vs nutritional assessment. Gastroenterol Rep. 2016; 4(4): p. 272-280. 
47. Kim I, Lee HJ, Kang J, Song J. Relationship of serum retinol-binding protein 4 with weight status and lipid profile among Korean children and adults. Eur J Clin Nutr. 2011; 65(2): p. 226-33.

48. Yamamoto K, Kitagawa N, Takamasu T. Standard values of rapid turnover proteins and zinc in Japanese children. Asia Pac J Clin Nutr. 2015; 24(3): p. 504-508.

49. Hua MJ, Kun HY, Jie CS, Yun NZ, De WQ, Yang Z. Urinary microalbumin and retinol-binding protein assay for verifying children's nephron development and maturation. Clin Chim Acta. 1997; 264(1): p. 127-132.

50. Smith GC, Winterborn MH, Taylor CM, Lawson N, Guy M. Assessment of retinolbinding protein excretion in normal children. 1993; 8(8): p. 148-150.

51. Bangstad HJ, Kierulf P, Kjaersgaard P, Mevold K, Dahl-Jorgensen K. Urinary excretion of retinol-binding protein in healthy children and adolescents. Pediatr Nephrol. 1995; 9(9): p. 299-302.

52. Lehrnbecher T, Greissinger S, Navid F, Pfuller H, Jeschke R. Albumin, IgG, retinol-binding protein, and a1-microglobulin excretion in childhood. Pediatr Nephrol. 1998; 12(1): p. 290-292.

53. Han WK, Bailly V, Abichandani R, Thadhani R, Bonventre JV. Kidney Injury Molecule-1 (KIM-1): A novel biomarker for human renal proximal tubule injury. Kidney Int. 2002; 62(1): p. 237-44.

54. Ichimura T, Brooks CR, Bonventre JV. Kim-1/Tim-1 and Immune cells: Shifting Sands. Kidney Int. 2012; 81(9): p. 809-811.

55. Vaidya VS, Ozer JS, Dieterle F, Collings B, Ramirez V, Troth S, et al. Kidney injury molecule-1 outperforms traditional biomarkers of kidney injury in preclinical biomarker qualification studies. Nat Biotechnol. 2010; 28(5): p. 478-85. 
56. Dharnidharka VR, Kwon C, Stevens G. Serum cystatin C is superior to serum creatinine as a marker of kidney function: a meta-analysis. Am J Kidney Dis. 2002; 40(2): p. 221-6.

57. Koyner JL, Bennett MR, Worcester EM, Ma Q, Raman J, Jeevanandam V, et al. Urinary cystatin $\mathrm{C}$ as an early biomarker of acute kidney injury following adult cardiothoracic surgery. Kidney Int. 2008; 74(8): p. 1059-1069.

58. Armangil D, Yurdakök M, Canpolat FE, Korkmaz A, Yiğit S, Tekinalp G. Determination of reference values for plasma cystatin $\mathrm{C}$ and comparison with creatinine in premature infants. Pediatr Nephrol. 2008; 23: p. 2081-2083.

59. Basile DP. The transforming growth factor beta system in kidney disease and repair: recent progress and future directions. Curr Opin Nephrol Hypertens. 1999; 8(1): p. 21-30.

60. Cotton SA, Gbadegesin RA, Williams S, Brenchley PEC, Webb NJA. Role of TGFbeta1 in renal parenchymal scarring following childhood urinary tract infection. Kidney Int. 2002; 61(1): p. 61-67.

61. Tsakas S, Goumenos DS. Accurate Measurement and Clinical Significance of Urinary Transforming Growth Factor-Beta1. Am J Nephrol. 2006; 26(1): p. 186193.

62. De Muro P, Faedda R, Fresu P, Masala A, Cigni A, Concas G, et al. Urinary transforming growth factor- 1 in various types of nephropathy. Pharmacol Res. 2004; 49(3): p. 293-8.

63. Wasilewska A, Zoch-Zwierz W, Taranta-Janusz K. Urinary transforming growth factor beta1 in children and adolescents with congenital solitary kidney. Pediatr Nephrol. 2009; 24(1): p. 753-759. 
64. Trnka P, Ivanova L, Hiatt MJ, Matsell DG. Urinary Biomarkers in Obstructive Nephropathy. Clin J Am Soc Nephrol. 2012; 7(10): p. 1567-75.

65. Taha MA, Shokeir AA, Osman HG, Abd El-Aziz Ael-A, Farahat SE. Pelvi-ureteric junction obstruction in children: the role of urinary transforming growth factor-beta and epidermal growth factor. BJU Int. 2007; 99(4): p. 899-903.

66. Lobato GR, Lobato MR, Thomé FS, Veronese FV. Performance of urinary kidney injury molecule-1, neutrophil gelatinase-associated lipocalin, and N-acetyl-b-Dglucosaminidase to predict chronic kidney disease progression and adverse outcomes. Braz J Med Biol Res. 2017; 50(5): p. e6106.

67. Rademacher ER, Sinaiko AR. Albuminuria in children. Curr Opin Nephrol Hypertens. 2009; 18(1): p. 246-251.

68. Ralib AM, Pickering JW, Shaw GM, Devarajan P, Edelstein CL, Bonventre JV, et al. Test Characteristics of Urinary Biomarkers Depend on Quantitation Method in Acute Kidney Injury. J Am Soc Nephrol. 2012; 23(2): p. 322-333.

69. Che M, Xie B, Xue S, Dai H, Qian J, Ni Z, et al. Clinical usefulness of novel biomarkers for the detection of acute kidney injury following elective cardiac surgery. Nephron Clin Pract. 2010; 115(1): p. c66-72.

70. Grignon A, Filion R, Filiatrault D, Robitaille P, Homsy Y, Boutin H, et al. Urinary tract dilatation in utero: classification and clinical applications. Radiology. 1986; 160(3): p. 645-647.

71. Nguyen HT, Herndon CDA, Cooper C, Gatti J, Kirsch A, Kokorowski P, et al. The Society for Fetal Urology consensus statement on the evaluation and management of antenatal hydronephrosis. J Pediatr Urol. 2010; 6(3): p. 212-231. 
72. American Academy of Pediatrics Subcommittee on Hyperbilirubinemia. Management of hyperbilirubinemia in the newborn infant 35 or more weeks of gestation. Pediatrics. 2004; 114(1): p. 297-316.

73. Okarska-Napierała M, Wasilewska A, Kuchar E. Urinary tract infection in children: Diagnosis, treatment, imaging - Comparison of current guidelines. J Pediatr Urol. 2017 Dec; 13(6):567-573.

74. CDC. Vital signs: awareness and treatment of uncontrolled hypertension among adults-United States, 2003-2010. MMWR Morb Mortal Wkly Rep. 2012 Sep 7; 61:703-9.

75. Jetton JG, Askenazi D. Update on acute kidney injury in the neonate. Curr Opin Pediatr. 2012 Apr; 24(2): p. 191-196.

76. Schwartz GJ, Work DF. Measurement and Estimation of GFR in Children and Adolescents. Clin J Am Soc Nephrol. 2009; 4(1555-9041/411-1832): p. 18321843.

77. Finney H, Newman DJ, Thakkar H, Fell JME, Price CP. Reference ranges for plasma cystatin $\mathrm{C}$ and creatinine measurements in premature infants, neonates, and older children. Arch Dis Child. 2000; 82(82): p. 71-75.

78. Hossain MA, Emara M, Moselhi HE, Shoker A. Comparing Measures of Cystatin C in Human Sera by Three Methods. Am J Nephrol. 2009; 29: p. 381-391.

79. Quantikine R\&D Systems. Human Cystatin C Immunoassay (Cat. N ${ }^{o}$ DSCTC0). [Online].; 2010 [cited 2018 Março. Available from: goo.gl/fbmMuA.

80. Quantikine R\&D Systems. Human Lipocalin-2/NGAL Immunoassay. [Online].; 2013 [cited 2018 março 12. Available from: goo.gl/FDA6Td. 
81. Quantikine R\&D Systems. KIM-1 Sandwich ELISA. Cat. N DY1750. [Online].; 2013 [cited 2018 março. Available from: https://goo.gl/4nbnBQ.

82. Quantikine R\&D Systems. Human TGF-ß1 Immunoassay. [Online].; 2013 [cited 2018 março. Available from: https://goo.gl/QkLDu1.

83. Quantikine R\&D Systems. Human RBP4 Sandwich ELISA Cat. N ${ }^{\circ}$ DRB400. [Online].; 2013 [cited 2018 março. Available from: https://goo.gl/f3R1U7.

84. Villar J, Cheikh Ismail L, Victora CG, Ohuma EO, Bertino E, Altman DG, et al. International standards for newborn weight, length, and head circumference by gestational age and sex: the Newborn Cross-Sectional Study of the INTERGROWTH-21st Project. Lancet. 2014; 384(9946): p. 857-868.

85. Waikar SS, Betensky RA, Emerson SC, Bonventre JV. Imperfect Gold Standards for Kidney Injury Biomarker Evaluation. J Am Soc Nephrol. 2012; 23: p. 13-21.

86. Allegaert K, Mekahli D, van den Anker J. Cystatin C in newborns: a promising renal biomarker in search for standardization and validation. J Matern Fetal Neonatal Med. 2015; 28(15): p. 1833-1838.

87. Zappitelli M, Parvex P, Joseph L, Paradis G, Grey V, Lau S, et al. Derivation and validation of cystatin C-based prediction equations for GFR in children. Am J Kidney Dis. 2006; 48(48): p. 221-230.

88. Deng F, Finer G, Haymond S, Brooks E, Langman CB. Applicability of estimating glomerular filtration rate equations in pediatric patients: comparison with a measured glomerular filtration rate by iohexol clearance. Transl Res. 2015; 165(3): p. 437-45. 
89. Allegaert K, Vermeersch P, Smits A, Mekahli D, Levtchenko E, Pauwels S. Paired measurement of urinary creatinine in neonates based on a Jaffe and an enzymatic IDMS-traceable assay. BMC Nephrol. 2014; 15: p. 62.

90. Boer DP, de Rijke YB, Hop WC, Cransberg K, Dorresteijn EM. Reference values for serum creatinine in children younger than 1 year of age. Pediatr Nephrol. 2010; 25(1): p. 2107-2113.

91. McCaffrey J, Dhakal AK, Milford DV, Webb NJA, Lennon R. Recent developments in the detection and management of acute kidney injury. Arch Dis Child. 2017; 102: p. 91-96.

92. Nakhjavan-Shahraki B, Yousefifard M, Ataei N, Baikpour M, Ataei F, Bazargani $\mathrm{B}$, et al. Accuracy of cystatin $\mathrm{C}$ in prediction of acute kidney injury in children; serum or urine levels: which one works better? A systematic review and metaanalysis. BMC Nephrol. 2017; 18: p. 120.

93. Sweetman DU. Neonatal acute kidney injury - Severity and recovery prediction and the role of serum and urinary biomarkers. Early Hum Dev. 2017; 105(1): p. 5761.

94. Zwiers AJM, de Wildt SN, de Rijke YB, Willemsen SP, Abdullahi NS, Tibboel D, et al. Reference intervals for renal injury biomarkers neutrophil gelatinaseassociated lipocalin and kidney injury molecule-1 in young infants. Clin Chem Lab Med. 2015; 53(8): p. 1279-1289.

95. McWilliam SJ, Antoine DJ, Sabbisetti V, Pearce RE, Jorgensen AL, Lin Y, et al. Reference intervals for urinary renal injury biomarkers KIM-1 and NGAL in healthy children. Biomark Med. 2014; 8(10): p. 1189-1197.

96. Zappitelli M, Washburn KK, Arikan AA, Loftis L, Ma Q, Devarajan P, et al. Urine neutrophil gelatinase-associated lipocalin is an early marker of acute kidney injury in critically ill children: a prospective cohort study. Crit Care. 2007; 11(4): p. R84. 
97. Rybi-Szuminska A, Wasilewska A, Litwin M, Kułaga Z, Szuminski M. Paediatric normative data for urine NGAL/creatinine ratio. Acta Paediatr. 2013; 102(6): p. e269-72.

98. Goldstein SL. Urinary kidney injury biomarkers and urine creatinine normalization: a false premise or not? Kidney Int. 2010; 78(1): p. 433-435.

99. Helmersson-Karlqvist J, Ärnlöv J, Carlsson AC, Lind L, Larsson A. Urinary KIM1 , but not urinary cystatin $\mathrm{C}$, should be corrected for urinary creatinine. Clin Biochem. 2016; 49(15): p. 1164-1166.

100. Mandelia A, Bajpai M, Agarwala S, Gupta AK, Kumar R, Ali A. The role of urinary TGF- $\beta 1$, TNF- $\alpha$, IL-6 and microalbuminuria for monitoring therapy in posterior urethral valves. Pediatr Nephrol. 2013; 28: p. 1991-2001.

101. Palmer LS, Maizels M, Kaplan WE, Firlit CF, Cheng EY. Urine levels of transforming growth factor-beta 1 in children with ureteropelvic junction obstruction. Urology. 1997; 50(5): p. 769-73.

102. MacRae Dell K, Hoffman BB, Leonard MB, Ziyadeh FN, Schulman SL. Increased urinary transforming growth factor-beta(1) excretion in children with posterior urethral valves. Urology. 2000; 56(2): p. 311-314.

103. van den Belt SM, Gracchi V, de Zeeuw D, Heerspink H. Comparison of urine collection methods for albuminuria assessment in young children. Clin Chim Acta. 2016; 458: p. 120-123.

104. Miklovicova D, Cervenova O, Cernianska A, Jancovicova Z, Dedik L, Vasilenkova A. Long-term follow-up of renal function in patients after surgery for obstructive uropathy. Pediatr Nephrol. 2008; 23(6): p. 937-945. 
105. Tomlinson PA, Smellie JM, Prescod N, Dalton RN, Chantler C. Differential excretion of urinary proteins in children with vesieoureterie reflux and reflux nephropathy. Pediatr Nephrol. 1994; 8: p. 21-25.

106. Madsen MG, Nørregaard R, Palmfeldt J, Olsen LH, Frøkiær J, Jørgensen TM. Urinary NGAL, cystatin C, $\beta 2$-microglobulin, and osteopontin significance in hydronephrotic children. Pediatr Nephrol. 2012; 27(11): p. 2099-2106.

107. Wasilewska A, Taranta-Janusz K, Dębek W, Zoch-Zwierz W, KuroczyckaSaniutycz E. KIM-1 and NGAL: new markers of obstructive nephropathy. Pediatr Nephrol. 2011; 26(4): p. 579-586.

108. Dell KM, Hoffman BB, Leonard MB, Ziyadeh FN, Schulman SL. Increased urinary transforming growth factor-beta(1) excretion in children with posterior urethral valves. Urology. 2000; 56(2): p. 311-4.

109. El-Sherbiny M, Mousa O, Shokeir A, Ghoneim M. Role of urinary transforming growth factor-betal concentration in the diagnosis of upper urinary tract obstruction in children. J Urol. 2002; 168(4 Pt 2): p. 1798-1800.

110. Furness PD, Maizels M, Han SW, Cohn RA, Cheng EY. Elevated bladder urine concentration of transforming growth factor-betal correlates with upper urinary tract obstruction in children. J Urol. 1999; 162((3 Pt 2)): p. 1033-1036.

111. Liatsikos EN, Dinlenc Z, Bernardo O, Kapoor R, Jabbour ME, Smith AD, et al. Endopyelotomy failure is associated with reduced urinary transforming growth factor-beta 1 levels in patients with upper urinary tract obstruction. J Endourol. 2001; 15(6): p. 567-70. 